\title{
Glial TGF $\beta$ activity promotes axon survival in peripheral nerves
}

\author{
Alexandria P. Lassetter ${ }^{1}$, Megan M. Corty ${ }^{1}$, Romina Barria ${ }^{1}$, Amy E. Sheehan ${ }^{1}$, Jo Hill ${ }^{2}$, \\ Sue A. Aicher ${ }^{2}$, A. Nicole Fox ${ }^{3}$ and Marc R. Freeman ${ }^{1,4}$ * \\ ${ }^{1}$ Vollum Institute, Oregon Health \& Science University, Portland, OR, 97239, USA \\ ${ }^{2}$ Department of Chemical Physiology \& Biochemistry, Oregon Health \& Science University, Portland, OR, \\ 97239, USA \\ ${ }^{3}$ University of Massachusetts Medical School, Worcester, MA, 01655, USA \\ ${ }^{4}$ Lead Contact \\ *Author for correspondence: freemmar@ohsu.edu
}

\begin{abstract}
:
Axons can represent the majority of the volume of a neuron and are energetically very demanding. Specialized glia ensheathe axons and are believed to support axon function and maintenance throughout life, but molecular details of glia-neuron support mechanisms remain poorly defined. Here we identify a collection of secreted and transmembrane genes that are required in glia for long-term axon survival in vivo. We show that key components of the TGF $\beta$ superfamily are required cell-autonomously in glia for peripheral nerve maintenance, although their loss does not disrupt glial morphology. We observe age-dependent neurodegeneration in the absence of glial TGF $\beta$ signaling that can be rescued by genetic blockade of Wallerian degeneration. Our data argue that glial TGF $\beta$ signaling normally acts to promote axon survival and suppress neurodegeneration.
\end{abstract}

Keywords: Axon, glia, peripheral nervous system, nerves, TGF $\beta$, degeneration

\section{Significance Statement:}

Axon maintenance is critical to preserving the functional integrity of the nervous system across animal lifespan. Glia contribute to axon maintenance, but their precise roles remain to be fully characterized. We identify glial genes that regulate axon support and provide new molecular insight into the means by which glia promote axon survival, which may help explain why neurodegeneration occurs when glia are lost in disease. We show that TGF $\beta$ signaling in mature glia is essential for long-term maintenance of axons, and that loss of TGF $\beta$ signaling activates an axon death signaling pathway. 
Lassetter et al. 2021

\section{Introduction:}

Axons connect distant structures in the nervous system and maintaining axon integrity is crucial to preserve neural circuit function. Axons can traverse great distances across the body and have complex morphologies, such that the majority of a neuron's volume is contained within the axon. Axons in the human sciatic nerve can be a meter long (Jessen \& Mirsky, 2005), and axons of single dopaminergic neurons in the substantia nigra pars compacta branch so profusely that their estimated cumulative linear length can be up to nearly $800 \mathrm{~mm}$ (Matsuda et al., 2009). Sustaining axons presents a significant challenge for the neuron both in terms of their size, and the substantial metabolic demand required for signal transduction (Harris et al., 2012).

Glial cells that ensheathe axons are believed to serve as a local, external sources of support to axons, particularly at great distances from the cell body. Evidence from human diseases such as multiple sclerosis (MS) or Charcot-Marie-Tooth (CMT), where loss of glia or glial molecules causes neurodegeneration, further implicate glia in the support of axon maintenance (Brennan et al., 2015; Kornek et al., 2000; Kuhlmann et al., 2002; Trapp et al., 1998). Disrupting a single glial gene causes neurodegeneration in the absence of glial cell loss (Griffiths et al., 1998;

Lappe-Siefke et al., 2003). A growing body of work has established that glia provide significant metabolic support to axons (Fünfschilling et al., 2012; Volkenhoff et al., 2015) and more recently, defense against iron-mediated toxicity (Mukherjee et al., 2020). However, a comprehensive mechanistic understanding of glial support of axons in vivo remains elusive.

To identify mechanisms by which glia support axon maintenance in vivo, we conducted a screen in Drosophila to identify glial molecules required to sustain long-term axon survival. We identified over 200 genes that-when depleted from glia-lead to axon degeneration or animal lethality. Interestingly, we found that glial loss of the majority of TGF $\beta$ superfamily molecules, a multi-functional family of molecules that regulate diverse aspects of metazoan growth, differentiation and homeostasis (Upadhyay et al., 2017), resulted in age-dependent axon loss and cell body death in sensory neurons in the peripheral nervous system. We provide evidence that glial TGF $\beta$ signaling is required to support axons directly (versus supporting the cell body), since all neurodegeneration after glial TGF $\beta$ depletion can be suppressed by supplying the axon survival factor Wallerian degeneration Slow $\left(\mathrm{Wld}^{\mathrm{S}}\right)$ to neurons. These data identify the TGF $\beta$ superfamily as a key regulator of in vivo glial functions in supporting long-term maintenance of axons. 
Lassetter et al. 2021

\section{Results:}

\section{Ablation of wrapping glia leads to axon degeneration}

We aimed to explore the mechanisms by which glia support axon function and survival. We used the adult L1 wing nerve of Drosophila melanogaster as a model, where it is possible to independently manipulate neurons and glia and examine their morphology with single cell/axon resolution in vivo (Fig. 1A-B). This sensory nerve contains roughly 280 sensory neurons (Fig. 1C). Their cell bodies are positioned along the anterior wing margin, and they project their axons into the thorax (Fig. 1A; (Palka et al., 1983). These are among the longest axons in Drosophila (Fig. 1A; (Palka et al., 1983) and each is individually ensheathed by glia along their length (Fig. 1B \& C): wrapping glia (WG) cover the entire nerve and interdigitate into the axon bundle separating axons from one another (Fig. 1C; (Neukomm et al., 2014). Given their length, and their relatively unusually extensive ensheathment by Drosophila glia, we speculated that the glia surrounding these neurons would be a good model to explore how glia provide essential support for neuronal function and maintenance.

To assess whether glia were required for maintenance of axons in this model, we selectively ablated WG and measured neuronal integrity as the animals aged. We used the Gal4/UAS binary expression system (Brand \& Dormand, 1995) to overexpress the cell death molecules Dronc \& Dark, or Reaper (Dorstyn et al., 1999; White et al., 1994; Zhou et al., 1999) - and tdTomato in a subset of the WG by using a split Gal4 construct (Luan et al., 2006). This split Gal4 was exclusively expressed in WG and is henceforth referred to as WG split-Gal4. WG split-Gal4 labeled $87 \%$ of WG in the wing as determined by nuclear reporter expression as compared to nrv2-Gal4, which is expressed in all the WG in the wing but is also widely expressed in the central nervous system (Figure S1; (Neukomm et al., 2014). We combined the WG split-Gal4 with the independent binary expression system QF2/QUAS (Potter et al., 2010; Riabinina et al., 2015) to fluorescently label a subset of VGlut neurons in the wing ( 40) in order to evaluate the effect of ablating WG on neurons in this nerve (Fig. 1D-F). Interestingly, ablating WG in these animals caused increased age-dependent degeneration of axons within this peripheral sensory nerve in the wing (Fig. D-G). A larger proportion of nerves from aged, ablated animals exhibited mild or severe degeneration compared with the control group (control: $2 / 18$ animals or $11 \%$, Dronc::GFP, Dark: $11 / 18$ or $61 \%$, Reaper: $10 / 18$ or $56 \%$; Fig. $1 \mathrm{G} \&$ Figure S2A).

In addition to the effect that ablating WG had on axons, to our surprise, ablating WG also caused cell death of sensory neurons (Fig. 1H \& Figure S2B). At baseline (4 days post eclosion) there were no significant differences in the average number of intact $\mathrm{GFP}^{+}$neuron cell bodies per wing between genotypes (control: $38.0 \pm 2.1 \mathrm{n}=21$, Dronc::GFP, Dark: $36.9 \pm 2.7 \mathrm{n}=20$, Reaper: $37.2 \pm 2.4 \mathrm{n}=20$; Fig. $1 \mathrm{H}$ ). However, at 28 days of age, cell death had increased significantly in WG-ablated animals compared to controls (control: $36.7 \pm 3.1 \mathrm{n}=18$, Dronc::GFP, Dark: $31.7 \pm 8.3 n=18$, Reaper: $29.0 \pm 8.1 \mathrm{n}=18$; Fig. $1 \mathrm{H}$ ). Together, these data indicate that WG are required for axon and neuronal maintenance in the sensory nerve of the wing.

\section{Identification of glial genes required for axon maintenance}

Our results demonstrated that WG are required for axon maintenance in the L1 nerve, and we sought to use this system to identify glial genes required for supporting axon survival. We accomplished this by severing the axon from its soma thereby creating a situation where all that remains are the axons and the glia that ensheathe them (Fig. 2A). However, when wild type 
Lassetter et al. 2021

axons are severed, the portion of the axon distal to the injury site undergoes Wallerian degeneration (WD) (MacDonald et al., 2006). This can be genetically blocked by overexpressing WId ${ }^{S}$ in neurons, which suppresses WD and allows severed axons to remain intact for weeks

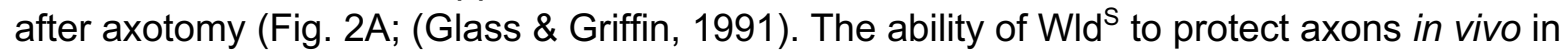
intact nerves far exceeds its ability to do so in purified neurons in vitro (Adalbert et al., 2005; Buckmaster et al., 1995; Conforti et al., 2006; Lunn et al., 1989; Wang et al., 2005). We hypothesized that this greater protection was due to glial support of axon survival in vivo in intact nerves. Consistent with this notion, we found that when we ablated WG, WId ${ }^{\mathrm{s}}$-expressing axons exhibited increased axon degeneration compared to controls (degeneration phenotype: control=7/24 (29\%), WG-ablated=18/21 (86\%); Fig. 2C).

To identify glial genes that promote long term axon survival, we designed a genetic screen where we could sever Wld ${ }^{\mathrm{S}+}$ axons, which allowed axons to survive for weeks after axotomy (and without a cell body), then systematically knock down genes selectively in glia and assay for axon loss compared to controls. Using VGlut-QF2 (Diao et al., 2015), we expressed a membrane-tethered GFP and $\mathrm{Wld}^{\mathrm{S}}$ in glutamatergic neurons in the $\mathrm{L} 1$ nerve of the wing to both visualize axons and block Wallerian degeneration (WD), respectively (Fig. 2B). In these animals, we removed the cell bodies from most of the neurons by cutting off the distal portion of the wing, leaving behind the WD-resistant axons and glia that surround them (Fig. 2A). We used GAL4/UAS to express RNA interference (RNAi) (Perrimon et al., 2010) constructs in all glia with the pan-glial driver repo-Gal4 (Sepp et al., 2001). We then screened $>2,000$ publicly available UAS-RNAi lines targeting a panel of genes enriched for those encoding proteins containing predicted transmembrane domains or signal peptides (Fig. 2B).

In control animals, Wld ${ }^{s}$ prevented WD and axons remained intact at 10 days post axotomy (dpa) (Fig. 2C). In our screen, we sought to identify genes that, when knocked down in glia, resulted in axon degeneration (Fig. 2B). When we knocked down single genes in glia using this assay, we identified 70 candidate genes whose loss in glia resulted in axon degeneration or defects in axon morphology. For instance, depletion of a TGF $\beta$ receptor (wit), a fibroblast growth factor (FGF) (bnl), or a mitofusin ( $f z O)$ led to robust axon loss (Fig. 2D). Glial loss of the sodiumchloride co-transporter Ncc69, led to an axon blebbing phenotype similar to the neuronal activity-dependent axon disruption observed in zebrafish slc12a2b (NKCC1b) mutants (Marshall-Phelps et al., 2020). In addition, and consistent with previous work (Mukherjee et al., 2020), we also identified 141 genes that caused lethality-defined by absence of viable adult progeny-when selectively knocked down in glia (Fig. 2D).

\section{Knocking down glial TGF $\beta$ superfamily genes results in degeneration of severed Wld ${ }^{\mathrm{s}}$ - expressing axons}

The TGF $\beta$ receptor wit was one of several members of the TGF $\beta$ superfamily identified in our screen. The TGF $\beta$ superfamily is made up of two major branches (TGF $\beta$ and BMP)(Upadhyay et al., 2017). Our initial screening panel did not include RNAis targeting all members of the TGF $\beta$ superfamily. We therefore obtained and tested additional RNAi lines to test all genes in this pathway using our sensitized screening approach (Fig. 3B). We found that most RNAi constructs targeting components of this superfamily caused axon degeneration or lethality when expressed in glia (Fig. 3B \& C), suggesting a role for TGF $\beta$ signaling in glial support of axons. Surprisingly, knocking down of both ligands and their receptors-selectively in glia-caused axon defects, suggesting a potential glial autocrine signaling mechanism. 
Lassetter et al. 2021

\section{TGF $\beta$ receptor babo is expressed in adult WG in the wing}

To examine whether TGF $\beta$ proteins were expressed in nerve glia, we utilized a transgenic fly line where the Gal4 sequence was inserted into the babo gene (Lee et al., 2018). We examined co-localization of a nuclear reporter (UAS-lamin::GFP) driven by babo-Gal4 expression with an antibody that specifically labels WG nuclei within the larval peripheral nerves (Oaz) as well as the pan-glial protein Repo (Figure S3). All Oaz ${ }^{+}$nuclei within larval nerves were $\mathrm{GFP}^{+} / \mathrm{Repo}^{+}$ $\left(n=18 \mathrm{Oaz}^{+}\right.$nuclei from $\mathrm{n}=3$ larvae, Figure S3) indicating that babo was expressed in WG in peripheral nerves during development. Additionally, all Repo ${ }^{+} \mathrm{Oaz}-$ nuclei were also $\mathrm{GFP}^{+}$, indicating that babo was also expressed in other nerve glia as well as WG ( $n=123 \mathrm{Repo}^{+} / \mathrm{Oaz}^{-}$ nuclei form $\mathrm{n}=3$ larvae, Figure S3). To test whether babo was also expressed in adults, we crossed the babo-Gal4 animals to a nuclear reporter (UAS-mCherry.NLS) in a genetic background where WG were labeled independently with GFP (a nrv2-GFP protein trap which labels all WG membranes (Stork et al., 2008)). As expected, our positive control (nrv2-Gal4) had nuclear reporter expression in WG nuclei within the GFP ${ }^{+}$WG membrane at all timepoints tested ( $n=57$ wings, Fig. 4). The experimental babo-Gal4 wings also labeled nuclei within the WG membrane at 4 ( $n=20 / 20$ wings, Fig. 4A), 14 ( $n=15 / 15$ wings, Fig. 4B), and $28(n=17 / 17$ wings, Fig. 4C) days of age (and Figure S4). Importantly, the only nuclei present within the nerve in this region are glial nuclei (Neukomm et al., 2014), indicating that babo is expressed in mature WG within the peripheral sensory nerve in the wing. The babo-Gal4 also appeared to label a subset of neurons within the wing at all timepoints tested (Figure S5). The expression of babo in adult WG suggests that the Babo receptor is present in adult glia and therefore could contribute to axon maintenance.

\section{Loss of TGF $\beta$ does not alter ensheathment of axons}

TGF $\beta$ molecules play crucial roles in tissue development and morphogenesis, so we next examined whether loss of this pathway would affect glial development and morphology. We evaluated the overall coverage of the $L 1$ nerve by labeling the glia using a genetically encoded fluorescent reporter (tdTomato) and imaged the nerve at 4 and 28 days. When we examined nerves where TGF $\beta$ genes were knocked down in all glia, there were no obvious defects in glial morphology or coverage of the nerve in knockdown animals compared to controls at either timepoint (4 days: control: $n=24$ animals, babo: $n=23$, Smox: $n=21 ; 28$ days: control: $n=21$, babo: $n=22$, Smox: $n=16$ ) (Fig. 5A \& Figure S6A). Even in nerves that had axonal debris present, glial ensheathment appeared normal (Fig. 5A). Since WG directly ensheathe axons in this nerve, we also assessed WG morphology specifically, by examining reporter expression in WG-specific knockdown conditions compared to controls. Again, we found no changes in morphology or coverage of the nerve by WG despite the presence of neurodegeneration (4 days: control: $n=23$ animals, babo: $n=23$, Smox: $n=23$; 28 days: control: $n=22$, babo: $n=24$, Smox: $n=23$ ) (Fig. 5B \& Figure S6B).

While these results suggested that gross morphology of WG were unaltered upon knockdown of TGF $\beta$ signaling, to examine whether axonal ensheathment was truly unperturbed required us to assess the ultrastructure of this nerve using transmission electron microscopy. We examined nerves from control, babo, and Smox pan-glial knockdown animals and found no evidence of defects in glial ensheathment at 28 days (control: $n=3$ animals, babo: $n=5$, Smox: $n=4$; Fig. 5C-E \& Figure S6 C-E). To quantify this form of multi-axonal ensheathment, we measured the wrapping index for each nerve (Matzat et al., 2015). When we calculated the wrapping index for each condition, there was no significant difference between the conditions, although one nerve 
Lassetter et al. 2021

from the Smox knockdown condition did appear to have reduced ensheathment (control: $0.88 \pm 0.020 \mathrm{n}=4$, babo: $0.84 \pm 0.083 \mathrm{n}=5$, Smox: $0.81 \pm 0.21 \mathrm{n}=4$; Fig 5F). Together, our data indicate that inhibiting TGF $\beta$ in glia does not cause defects in glial morphology and therefore disrupted glial ensheathment would not explain the degeneration observed in TGF $\beta$ knockdown animals.

Although WG ensheathment was not disrupted, it remained possible that the number of WG could be impacted by inhibiting TGF $\beta$. We quantified the number of WG present in the nerve in control and knockdown animals by using a genetically encoded nuclear reporter (UASlamin::GFP) (Figure S7). Knock down of babo or Smox in WG caused a slight increase in the number of WG in the nerve at 4 days (nrv2>: $24.9 \pm 3.52, n r v 2>l a c Z: 26.9 \pm 3.37, n r v 2>b a b o^{\text {RNAi: }}$ :

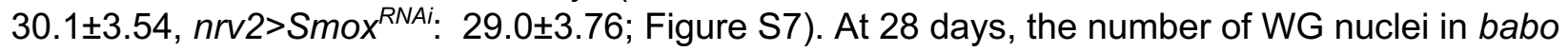
knockdown animals remained elevated compared to controls, but the number of WG nuclei in Smox knockdown animals was not significantly different from controls ( $n r v 2>: 24.5 \pm 3.40$, nrv2>lacZ: 26.2 \pm 3.39 , nrv2>babo ${ }^{R N A i}: 29.5 \pm 3.38, n r v 2>S m o x^{R N A i}: 25.4 \pm 6.76$; Figure S7).

In summary, while we find a slight increase in the total number of WG in the adult nerve when TGF $\beta$ signaling is inhibited, overall glial morphology and axonal ensheathment appeared normal.

\section{TGF $\beta$ superfamily is required in WG for long-term neuron maintenance}

Our finding that ablating WG caused spontaneous, age-dependent degeneration supports a role for WG in suppressing neurodegeneration as animals age. The TGF $\beta$ signaling receptor Babo appears to be expressed for at least 28 days into adulthood, but is glial TGF $\beta$ signaling involved in this glia $\rightarrow$ neuron pro-survival mechanism? To explore this possibility, we targeted each of the TGF $\beta$ superfamily genes using RNAi and evaluated axon integrity and neuron survival during normal aging at three timepoints: 4, 14, and 28 days. Interestingly, we found robust agedependent neurodegeneration in several TGF $\beta$ knockdown conditions compared to controls, with the strongest phenotype elicited by knock down of the TGF $\beta$ receptor babo (Fig. $6 \mathrm{~A}-\mathrm{C}$ \& Figure S8). Additionally, we used an RNAi-independent method to inhibit TGF $\beta$ signaling by overexpressing a dominant negative form of the receptor $\left(b a b o^{D N}\right)$ in glia that lacked the kinase domain (Brummel et al., 1999). Glial expression of $b a b o^{D N}$ phenocopied the RNAi-mediated knockdown (Fig. 6D), indicating that disruption of Babo in glia is sufficient to induce neurodegeneration. We confirmed the specificity of the RNAi targeting babo and its downstream target Smox with additional non-overlapping RNAi constructs (Fig. 6E). From these data, we conclude that the TGF $\beta$ pathway is required in glia for long-term neuron survival.

It is possible that the effects we observe on neuronal survival could be due to developmental defects or represent a role for TGF $\beta$ signaling in adults. To determine whether there is a requirement for TGF $\beta$ signaling in adults, we combined glial-specific knockdown with a temperature-sensitive Gal80 construct to temporally control RNAi expression (McGuire et al., 2003). Using this tool, we inhibited RNAi expression during development by rearing animals at $18^{\circ} \mathrm{C}$ until they eclosed as adults. We then transferred adult animals to $31^{\circ} \mathrm{C}$ to allow gliaspecific RNAi expression to knock down babo or Smox. At 4 days post temperature shift, there was no significant difference in the number of neuron cell bodies between control and TGF $\beta$

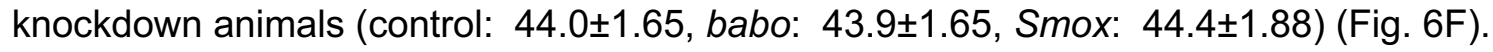
However, after 14 days of RNAi-mediated knockdown, both babo and Smox knockdown animals had fewer intact neuron cell bodies (control: 44.0 \pm 1.71 , babo: $41.8 \pm 1.94$, Smox: $40.9 \pm 3.31$ ) 
Lassetter et al. 2021

(Fig. 6F). These data indicate that babo and Smox are required in glia in the mature nerve to promote neuron survival and suppress neurodegeneration.

\section{Neuronal WId ${ }^{\mathrm{S}}$ expression rescues age-dependent neurodegeneration induced by glial babo knockdown}

In aging animals both the axons and cell body of the neurons were affected by babo knockdown in glia. This could result from a lack of glial support of neuronal cell bodies or axons. The neuroprotective effects of WId ${ }^{S}$ are known to specifically mediate injury-induced axon degeneration while it fails to block apoptosis in several contexts (Beirowski et al., 2008; Deckwerth \& Johnson, 1994; Hoopfer et al., 2006). We tested whether promoting axon survival with Wld ${ }^{S}$ could save axons, and if so, we could use this to test whether the cell body loss observed in babo glial-knockdown animals was dependent on axon loss. We overexpressed WId ${ }^{S}$, in the glutamatergic neurons to prevent WD in aged control and babo knockdown animals and measured its effect on both axon and cell body integrity. Blocking WD rescued the axon degeneration observed in babo knockdown animals at 28 days (control - Wld $^{S} n=17$, control $+\mathrm{Wld}^{\mathrm{S}} \mathrm{n}=19$, babo $^{R N A i}-\mathrm{Wld}^{\mathrm{S}} \mathrm{n}=27$, babo $^{R N A i}+\mathrm{Wld}^{\mathrm{S}} \mathrm{n}=20$ ) (Fig. 7A \& B) indicating that loss of babo in glia leads to activation of a $\mathrm{Wld}^{\mathrm{S}}$-sensitive axon degeneration pathway in axons.

Moreover, we found that suppressing axon degeneration with $\mathrm{Wld}^{\mathrm{S}}$ also completely rescued neuron cell death (Fig. 7A \& C). These data are consistent with a similar finding that suppressing axon degeneration with $\mathrm{Wld}^{S}$ in a model of motoneuron disease reduced subsequent cell death of neurons (Ferri et al., 2003). Our findings suggest that glial loss of Babo leads to activation of an axon degeneration pathway in neurons that can ultimately result in neuronal cell death. 
Lassetter et al. 2021

\section{Discussion:}

In this study, we sought to identify genetic pathways that modulate glial support of axons in vivo. We focused on the L1 wing nerve of adult Drosophila, as these are among the longest axons in the fly, and the wrapping glia that ensheathe them separate axons at the single axon level. Through a genetic screen to identify genes with roles in promoting axon survival, we assayed a library consisting of most of the secreted and transmembrane proteins encoded in the Drosophila genome. We identified an array of molecules that, when depleted selectively from glia, lead to axon degeneration. Components of the TGF $\beta$ superfamily were over-represented in our candidates from this screen, and here we have shown that loss of glial TGF $\beta$ signalingligands, receptors, or downstream signaling molecules-leads to age-dependent axon degeneration and neuronal loss. Surprisingly, we found that providing $\mathrm{Wld}^{S}$ to neurons was sufficient to overcome neurodegeneration caused by reduced TGF $\beta$ signaling in glia. We propose that TGF $\beta$ signaling in glia normally promotes axon maintenance, and this support is required to sustain neuronal survival over the animal's lifespan.

The intense ensheathment of axons by wrapping glia in the adult L1 wing nerve suggests that isolating individual axons in this tissue is critical for neuronal function, maintenance, or both. It is also worth noting that this ensheathment creates a physical barrier that likely prevents axons from directly accessing metabolites outside the nerve needed to support their activity. This anatomical arrangement suggests that glia act as the go-between and provide support to the axons they enwrap. Using a new, highly specific split Gal4 line, we showed that ablating most of the wrapping glia in the adult peripheral nerve in the wing caused robust age-dependent neurodegeneration. These results are remarkably similar to what has been seen in vertebrate models of CMT where loss of myelinating glia results in neurodegeneration in peripheral nerves (Adlkofer et al., 1995; Verhamme et al., 2011). Whether the loss of wrapping glia in the fly leads to axon degeneration because of a loss of metabolic support, as is observed in mammals (Fünfschilling et al., 2012; Y. Lee et al., 2012), or is a direct result of a lack of survival cues through TGF $\beta$ signaling remains unclear. Nevertheless, our study supports the notion that the L1 wing nerve of Drosophila should be an excellent model to explore how glia support axon maintenance and function.

One could imagine that disruptions in the physical association between axons and glia could indirectly disrupt signaling between them, for instance by impinging on the ability of glia to provide metabolites or survival cues to axons. Conversely, reduced ensheathment could presumably impair the ability of glia to maintain proper extracellular ion concentrations causing disruptions to axon integrity like is seen in our $N c c 69^{R N A i}$ condition (Figure 1; Leiserson et al., 2011) and the homologous NKCC1b mutant zebrafish (Marshall-Phelps et al., 2020). However, reduced glial ensheathment does not appear to explain the phenotypes reported here in babo and Smox knockdown animals. Our live imaging and ultrastructural analyses both indicate that glia remain tightly associated with axons in these knockdown animals. Additionally, knockdown of either babo or Smox did not cause a decrease in WG numbers, but rather an increase. This result is consistent with previous literature on the role of TGF $\beta$ in developmental apoptosis (D'Antonio et al., 2006; Parkinson et al., 2001). Indeed, inhibiting apoptosis in WG phenocopied the increase in WG numbers observed in $b a b o^{R N A i}$ indicating that this phenotype was likely caused by TGF $\beta$ 's role in developmental apoptosis. However, we do not believe that the increase in WG is responsible for the age-dependent neurodegeneration present in $b a b o^{R N A i}$ conditions since adult-specific knockdown was sufficient to induce neurodegeneration. We 
Lassetter et al. 2021

propose that our data point instead to a direct signaling role for glial TGF $\beta$ in promoting neuron maintenance.

The precise role of the TGF $\beta$ pathway in supporting axons remains unclear. Inhibiting members of both branches of the TGF $\beta$ superfamily (TGF $\beta$ and BMP) in glia caused neurodegeneration in aged animals. The TGF $\beta$ receptor Babo phosphorylates and activates the Smad transcription factor Smox, allowing it to enter the nucleus (Upadhyay et al., 2017). Smox has the potential to modify many genetic pathways simultaneously, and given that loss of Smox phenocopies Babo depletion, our data argue that at least part of the ability of TGF $\beta$ signaling to support axon maintenance involves gene regulation. Identifying the key transcriptional targets for Smox that promote this pro-survival function in axons will be an exciting next step in understanding the full array of molecules involved in glial support of axon maintenance.

Is TGF $\beta$ signaling required during development or in the adult to support axon survival? Using a genetically encoded reporter, we found that babo (encoding the TGF $\beta$ receptor) is expressed in glia in the adult wing, supporting a role for this receptor in mature glia. We further showed that mature glia utilize the TGF $\beta$ pathway to promote axon maintenance, as conditional knockdown of babo or Smox specifically in mature glia was sufficient to induce neurodegeneration. The adult-specific knockdown was modest compared to the constitutive knockdown conditions, and this could indicate that TGF $\beta$ signaling is required both during development and in the mature nerve. However, there were crucial differences between these experimental approaches that make direct comparison challenging. Nevertheless, together our data support a role for the TGF $\beta$ pathway in mature tissues to promote axon survival.

The role of the axon in survival of the cell body appears complex, and context dependent. For instance, during development, a lack of trophic support in growing axons leads to death of dorsal root ganglion (DRG) cell bodies (Deckwerth \& Johnson, 1994). This allows sensory ganglia to scale DRG numbers according to segment specific changes in the size of the sensory field. Once mature, however, the majority of sensory and peripheral motor axons exhibit robust regenerative capacity when axotomized in vivo (Cajal et al., 1991) indicating the requirement for trophic molecules from distal axons in promoting cell body survival is transient. In the context of most neurodegenerative diseases, it remains unclear which part of the cell becomes sick first. Does the axon degenerate, fail to support the neuronal soma, and results in cell death? Alternatively, does the cell body die and axon degeneration follows as a result? One can explore this through examining the timing of these events. Dying back neuropathies, where axons are lost first, suggest that axon loss may drive neuronal death (Fischer et al., 2004; Monte et al., 1988; Schaumburg et al., 1974; Sima et al., 1983). However, neuronal drop out in many neurodegenerative diseases is often sparse and occurs over a protracted phase and highresolution imaging is not possible in human patients. Unless one can assay both parts of the very same neuron, it is impossible to know which came first. Our system in the L1 wing nerve allows us to assay these events with single cell precision in many cases. That said, we found that axon degeneration and neuronal cell loss was coordinately timed in both our glial-ablated and TGF $\beta$ knockdown animals. As such, we are unable to determine which compartment of the cell (i.e., axons versus cell body) began to degenerate first.

An alternative approach to determine where neurodegenerative mechanisms impinge on a healthy neuron (axon versus soma) is to block key genetic pathways that drive axonal degeneration versus cell death. Driving expression of the $\mathrm{Wld}^{\mathrm{S}}$ molecule in neurons is an effective way to suppress axon degeneration without altering apoptotic signaling pathways 
Lassetter et al. 2021

(Adalbert et al., 2006; Beirowski et al., 2008; Deckwerth \& Johnson, 1994) and can be used to probe whether neurodegeneration is driven by primarily the axon versus the cell body. In the case of the progressive motorneuronopathy $(\mathrm{pmn})$ mouse, which exhibits age dependent motor axon degeneration followed by motoneuron cell death, simply supplying Wld ${ }^{\mathrm{S}}$ was sufficient to block axon loss and suppress motoneuron death (Ferri et al., 2003). These data strongly suggested that axon loss was the primary driver of motoneuron loss in this model. Since this initial exciting discovery similar approaches have been used with $\mathrm{Wld}^{\mathrm{s}}$ and other components of the axon death signaling cascade like Sarm1 (Osterloh et al., 2012), to probe the molecular programs driving neurodegeneration in a number of disease models (reviewed in (Coleman \& Höke, 2020)). In some cases, blocking axon degeneration can profoundly block neurodegeneration (Ferri et al., 2003; Henninger et al., 2016; Samsam et al., 2003; Turkiew et al., 2017) while in others, it has surprisingly little effect (Adalbert et al., 2006; Beirowski et al., 2008; Fernandes et al., 2018; Fischer et al., 2005; Peters et al., 2018). The latter observation does not rule out a role for Wld ${ }^{S}$ or Sarm1 in these diseases, it only reveals that blockade of the axon death pathway alone is not sufficient to alleviate neurodegeneration in these models of human disease.

Our findings that preventing Wallerian degeneration of uninjured, normally aging axons in animals lacking glial TGF $\beta$ signaling rescues neurodegeneration argues that loss of glial TGF $\beta$ signaling activates a Wld ${ }^{\mathrm{s}}$-sensitive axon death signaling cascade to drive axon loss and ultimately cell body death. It is notable that $\mathrm{Wld}^{\mathrm{S}}$ was able to rescue age-dependent degeneration in TGF $\beta$ knockdown conditions, but not in our sensitized injury paradigm where TGF $\beta$ genes were knocked down in glia and axons were severed. One could imagine that an aged axon that still has a cell body is in a better position than an axon that has been severed and no longer has support from its own cell body. Therefore, the difference in these two sensitizing conditions likely explain the difference in the ability (or lack thereof) of Wld ${ }^{S}$ to rescue axon degeneration when TGF $\beta$ genes are also knocked down. Furthermore, the conditions where $\mathrm{Wld}^{S}$ was unable to rescue injury-induced degeneration when TGF $\beta$ genes were knocked down in glia, implicate this pathway in glial support of axon maintenance. We would speculate that loss of $d s a r m$ in axons would result in a similar phenotype (i.e., rescue of axons), but technical limitations precluded our doing this experiment. While it remains possible that Wld ${ }^{S}$ directly protects the neuron cell bodies, this would depart from the body of data supporting an axon-specific role for $\mathrm{WId}^{S}$ in suppressing neurodegeneration. Therefore, the simplest interpretation of our data is that TGF $\beta$ signaling activity is required in glia to support axon maintenance and its loss results in progressive axon degeneration culminating in neuron cell death.

A yet-to-be explained phenomenon in the study of axon degeneration is the observation that $\mathrm{WId}^{\mathrm{S}}$ is a much more potent suppressor of Wallerian degeneration in vivo as compared to in vitro. Severed Wld ${ }^{\text {S+ }}$ axons survive for many weeks in vivo (Adalbert et al., 2005; Lunn et al., 1989), yet in purified neuron cultures, protection persists for several days (Buckmaster et al., 1995; Wang et al., 2005). While there are many differences between these environments, one striking difference is the presence or absence of a glial sheath around axons. Our findings that Wld ${ }^{S}$ protection of injured axons in vivo is significantly impaired when glia are absent argues that when axons lack a neuronal cell body their survival is highly dependent upon glial support.

In summary, our work provides direct in vivo evidence that glia are crucial for supporting long axons. When these glia are eliminated, axons show increased age-dependent degeneration and 
Lassetter et al. 2021

even $\mathrm{Wld}^{\mathrm{S}}$ is unable to protect axons without glial support. We have identified several candidate glial genes required for this glial support of axon integrity and neuronal survival in vivo. Among these genes, our data show that the TGF $\beta$ signaling pathway plays a crucial role in suppressing axon degeneration, even in uninjured nerves, and its loss leads to activation of the axon death program that is sensitive to Wld $^{\mathrm{S}}$. 
Lassetter et al. 2021

\section{Materials and methods:}

\section{Fly husbandry:}

Flies were grown on standard molasses cornmeal agar with extra yeast and maintained at $25^{\circ} \mathrm{C}$. The following fly (Drosophila melanogaster) stocks used in this study were obtained from the following sources. Bloomington: OK371-QF2 (66473), 10xQUAS-6xGFP, UAS-mtdTomato3xHA (66479), Repo-GAL4 (7415), UAS-Reaper ${ }^{14}$ (5824), UAS-dronc::GFP (56759), UASlacZ.NZ ${ }^{312}$ (3956), UAS-lacZ.NZ ${ }^{20 b}$ (3955), VGlut-QF2 (60315), QUAS-mCD8::GFP (30002), UAS-lamin::GFP (BL7376), nrv2-GAL4 (6799), UAS-babo ${ }^{D N}$ (64423), babo ${ }^{\text {RNAi2 }}$ (40866), $S_{m o x}{ }^{R N A i 2}(41670), t^{R N A i}(40937)$, mav $^{\text {RNAi }}$ (34650), put ${ }^{\text {RNAi }}$ (39025), UAS-mCherry.NLS ${ }^{3}$ (38424), babo-Gal4 ${ }^{\text {CRIMIC00274 }}$ (83164), tubP-Gal80 ${ }^{\text {ts-20 }}$ (7019). Vienna Drosophila Resource Center RNAi lines are listed in the supplementary excel file (Supp File 1). Additional RNAi lines including $t k v^{R N A i}$, put ${ }^{R N A i}$, and $s a x^{R N A i}$ were generously provided by Dr. Michael O'Connor. UASdark was kindly provided by Dr. John M. Abrams (Akdemir et al., 2006). The protein trap nrv2GFP published in Stork et al., 2008. The WG split-Gal4 line was established using the nrv2-DNA binding domain construct previously reported in (Coutinho-Budd et al., 2017) combined with a VP16 activation domain converted from the IT.0117-Gal4 (BL62647) using methods described in (Gohl et al., 2011). Additional lines that we generated to complete this work were QUASWId ${ }^{s}(\mathrm{III})$.

\section{Sensitized RNAi screen:}

RNAi lines were crossed to the $w^{*}$; VGlut-QF2, QUAS-mCD8::GFP/CyO ; QUAS-WId ${ }^{\text {, }}$ RepoGal4/TM3 driver line. After 7 days, parents were discarded and progeny returned to $25^{\circ} \mathrm{C}$. Progeny were then anesthetized on $\mathrm{CO}_{2}$ fly pads, sorted for genotype using visible markers, aged 4 days at $25^{\circ} \mathrm{C}$, anesthetized on $\mathrm{CO}_{2}$ and one wing was cut between the two cross veins of the wing using spring scissors (F.S.T \#15002-08), while the other wing served as an uninjured control. Injured flies were transferred to fresh vials every 3-7 days and then imaged 10 or 14 -days post axotomy (see imaging). For each RNAi line at least 5 wings were evaluated, results are reported in the supplemental excel file (Supp File 1). RNAi lines were scored as lethal if no viable adult flies of the correct genotype emerged or if adults died before the imaging timepoint. Both female and male progeny were used except where genetics prohibited use of males.

\section{Aging assay:}

Animals of the appropriate genotypes were crossed, as described above, selected for markers at eclosion, and adults were aged for the indicated time windows at $25^{\circ} \mathrm{C}$. Aging flies were transferred into fresh vials every 3-7 days. The number of dead flies in each vial was recorded during each transfer and these tallies can be found in Supplementary Fig. 6. Subsets of wings from each cohort were imaged at 4,14 , and 28 days after progeny were originally collected. All wings were inspected at $63 x$ for injuries and were not evaluated if they had any visible tears or scars in the L1 wing vein containing the nerve.

\section{Adult-specific knockdown:}

Crosses were performed at $18^{\circ} \mathrm{C}$ and the progeny were allowed to develop at $18^{\circ} \mathrm{C}$. Adults of the correct genotype were collected into fresh cornmeal agar vials and transferred to $31^{\circ} \mathrm{C}$. Flies were maintained at $31^{\circ} \mathrm{C}$ and transferred to fresh vials every 3-5 days until imaging. 
Lassetter et al. 2021

\section{Imaging:}

Imaging of the wing nerve was done as previously described in (Neukomm et al., 2014). Briefly, flies were anesthetized using $\mathrm{CO}_{2}$ and their wings were removed using spring scissors, mounted on a slide in Halocarbon oil 27 (Sigma \#H8773), covered with \#1.5 cover glass, and imaged within 15 minutes of mounting. Z-stack images were taken of the nerve on a Zeiss Axio Examiner with a Yokogawa spinning disk and Hamamatsu camera using a 63x1.4NA oilimmersion objective. The same acquisition settings were used across samples for each of the experiments and control samples were imaged in the same imaging session as experimental samples. VGlut ${ }^{+}$neuron cell bodies in the L1 vein were counted under $63 x$ magnification. Cells were counted as intact if they had a clear nucleus and dendrite or were considered dead if they were shrunken and the dendrite or nucleus were not clearly visible (Supplemental Fig. 2B).

\section{Quantification of axon degeneration:}

Images were classified into phenotypic categories (intact, mild, or severe degeneration) with the conditions blinded to the scorer (Figure S2A). Images were given randomized numerical names and all genotypes and ages for a given experiment were scored together in one session and later decoded. For experiments in which the wrapping glia were ablated, the channel containing the axons was first extracted from the two-color images before blinding and scoring so that the scorer remained blind to the presence or absence of glia.

\section{Immunofluorescence:}

Wandering third instar larvae were dissected and pinned open as filets in cold PBS and fixed in 4\% paraformaldehyde in PBS for 15 minutes at room temperature. Larvae were then permeabilized in $0.3 \%$ PBST (PBS + TritonX-100) for 15 minutes at room temperature with agitation and remaining wash and antibody solutions were made in $0.3 \%$ PBST. Antibodies used were: $\left(1^{\circ}\right)$ anti-Repo (Mouse anti-Repo, DSHB \#8D12), Alexa Fluor® 647 anti-HRP (Goat anti-HRP, Jackson Labs \#123-605-021), anti-oaz (Rabbit anti-oaz, this paper), anti-GFP (Chicken anti-GFP abcam \#ab13970); (2 ) DyLight ${ }^{\text {TM }} 405$ Donkey anti-Mouse (Jackson Labs \#715-475-150), Alexa Fluor® 488 Donkey anti-Chicken (Jackson Labs \#703-545-155), Rhodamine Red ${ }^{\mathrm{TM}}$-X Donkey anti-Rabbit (Jackson Labs \#711-295-152). After staining, larva filets were mounted in Vectashield (Vector Labs \#H-1000) and covered with \#1.5 cover glass (Globe scientific \#1404-15) and stored at $4^{\circ} \mathrm{C}$.

\section{Electron microscopy:}

Aged flies were maintained as described above. For EM procedures we used a modified microwave protocol from (Cunningham \& Monk, 2018; Czopka \& Lyons, 2011). Flies were anesthetized with $\mathrm{CO}_{2}$ and their wings were removed with spring scissors and immediately put into freshly made fix solution ( $2 \%$ glutaraldehyde, $4 \%$ paraformaldehyde, $0.1 \mathrm{M}$ sodium cacodylate buffer). Forceps were used to gently submerge the tissue in a microcentrifuge tube and microwaved using the following settings: $2 x$ (100W for $1 \mathrm{~min}$, OFF for $1 \mathrm{~min}$ ), then immediately followed by $5 x\left(450 \mathrm{~W}\right.$ for $20 \mathrm{~s}$, OFF for $20 \mathrm{~s}$ ) before storing the tissue at $4^{\circ} \mathrm{C}$ overnight in fix solution. The following day samples were washed in $0.1 \mathrm{M}$ sodium cacodylate buffer followed by secondary fixation in $2 \%$ osmium tetroxide, $0.1 \mathrm{M}$ sodium cacodylate buffer and $0.1 \mathrm{M}$ imidazole $\mathrm{pH} 7.5$ and microwaved $2 \mathrm{x}$ (100W for $1 \mathrm{~min}$, OFF for $1 \mathrm{~min}$ ), 5x (450W for 20 s, OFF for 20s). Following osmium fixation, samples were rinsed in distilled water $3 \times 10-$ minute washes. Next, samples were stained in saturated uranyl acetate (UA) $8 \%$ in water and 
Lassetter et al. 2021

microwaved $2 x$ ( $450 \mathrm{~W}$ for $1 \mathrm{~min}$, OFF for $1 \mathrm{~min}$ ). This was followed by dehydration steps with an escalating ethanol series with each step microwaved at $250 \mathrm{~W}$ for $45 \mathrm{~s}$. The final $100 \% \mathrm{EtOH}$ step was repeated 3 times and each step was microwaved for 2x (250W for $1 \mathrm{~min}$, OFF for 1 $\mathrm{min})$. Following EtOH dehydration, samples were dehydrated in $100 \%$ acetone and microwaved 2x ( $250 \mathrm{~W}$ for $1 \mathrm{~min}$, OFF for $1 \mathrm{~min}$ ) and repeated 3 times. Next, samples were transferred to a 50:50 resin:acetone solution and agitated overnight at room temperature. Final resin infiltration was done in $100 \%$ resin and agitated at room temperature for at least 1 hour. Tissues were embedded in Embed 812 resin (EMS \#14120) and cured in a $60^{\circ} \mathrm{C}$ oven overnight. Ultrathin 70 $\mathrm{nm}$ sections were cut on a Leica ultramicrotome and transferred to 100mesh Formvar grids (EMS \#FCF100-Cu). Grids were counter stained for 20 minutes in 5\% uranyl acetate followed by 7 minutes in Reynold's lead citrate. Micrographs were acquired on a FEI Tecnai T12 interfaced to Advanced Microscopy Techniques (AMT) CCD camera.

\section{Statistical analysis:}

Statistical analyses were done in GraphPad Prism 8. When analyzing the effect of two variables (genotype and age) two-way ANOVA was used with Sidak's multiple comparisons test to analyze the effect of genotype at each age. When comparing multiple experimental groups to the same control group Welch's ANOVA was used with Dunnett's T3 multiple comparison test to compare experimental groups to the control. When comparing one experimental group to a control a one-tailed Welch's t test was used. Significance was determined using an $\alpha$ of 0.05 . In figures, $p$-values are represented as follows: ${ }^{*} p<0.05,{ }^{* *} p<0.01,{ }^{* * *} p<0.001,{ }^{* * * *} p<0.0001$. 
Lassetter et al. 2021

\section{Acknowledgements:}

We thank all the Freeman Lab members for their discussion and feedback. We would like to acknowledge the technical support and expertise of the staff in the electron microscopy core facility, particularly Dr. Robert Kayton as well as Dr. Deborah Hegarty from the Aicher Lab. We would also like to acknowledge Dr. Kelly Monk and members of the Monk Lab for sharing their expertise and equipment in regards to the electron microscopy experiments. We thank Dr. Kevin Wright and Dr. Ben Emery for their critical feedback throughout the development of this work. We also acknowledge Dr. Rachel Dresbeck critical reading of the manuscript. The study was supported by funding from NIH grant from NINDS P30 NS061800 (S.A.A.) and NIH RO1 grants NS059991 and NS112215 (M.R.F.) and OHSU.

\section{Author Contributions:}

Conceptualization, A.P.L and M.R.F.; Methodology A.P.L, M.M.C., J.H., A.N.F. and M.R.F.; Investigation, A.P.L., M.M.C., R.B., A.E.S., J.H., A.N.F.; Resources, S.A.A. and M.R.F., Writing - Original Draft, A.P.L. and M.R.F. Writing - Review \& Editing, A.P.L, M.M.C., S.A.A. and M.R.F.; Supervision, M.R.F.; Funding Acquisition, S.A.A and M.R.F. 
Lassetter et al. 2021

\section{References:}

Adalbert, R., Gillingwater, T. H., Haley, J. E., Bridge, K., Beirowski, B., Berek, L., Wagner, D., Grumme, D., Thomson, D., Celik, A., Addicks, K., Ribchester, R. R., \& Coleman, M. P. (2005). A rat model of slow Wallerian degeneration (WldS) with improved preservation of neuromuscular synapses. European Journal of Neuroscience, 21(1), 271-277. https://doi.org/10.1111/J.1460-9568.2004.03833.X

Adalbert, R., Nógrádi, A., Szabó, A., \& Coleman, M. P. (2006). The slow Wallerian degeneration gene in vivo protects motor axons but not their cell bodies after avulsion and neonatal axotomy. European Journal of Neuroscience, 24(8), 2163-2168. https://doi.org/10.1111/J.1460-9568.2006.05103.X

Adlkofer, K., Martini, R., Aguzzi, A., Zielasek, J., Toyka, K. v., \& Suter, U. (1995). Hypermyelination and demyelinating peripheral neuropathy in Pmp22-deficient mice. Nature Genetics, 11(3), 274-280. https://doi.org/10.1038/ng1195-274

Akdemir, F., Farkaš, R., Chen, P., Juhasz, G., Medved'ova, L., Sass, M., Wang, L., Wang, X., Chittaranjan, S., Gorski, S. M., Rodriguez, A., \& Abrams, J. M. (2006). Autophagy occurs upstream or parallel to the apoptosome during histolytic cell death. Development, 133(8), 1457-1465. https://doi.org/10.1242/dev.02332

Beirowski, B., Babetto, E., Coleman, M. P., \& Martin, K. R. (2008). The WIdS gene delays axonal but not somatic degeneration in a rat glaucoma model. European Journal of Neuroscience, 28(6), 1166-1179. https://doi.org/10.1111/J.1460-9568.2008.06426.X

Brand, A. H., \& Dormand, E. L. (1995). The GAL4 system as a tool for unravelling the mysteries of the Drosophila nervous system. Current Opinion in Neurobiology, 5(5), 572-578. https://doi.org/10.1016/0959-4388(95)80061-1

Brennan, K. M., Bai, Y., \& Shy, M. E. (2015). Demyelinating CMT-what's known, what's new and what's in store? Neuroscience Letters, 596, 14-26. https://doi.org/10.1016/J.NEULET.2015.01.059

Brummel, T., Abdollah, S., Haerry, T. E., Shimell, M. J., Merriam, J., Raftery, L., Wrana, J. L., \& O'Connor, M. B. (1999). The Drosophila Activin receptor Baboon signals through dSmad2 and controls cell proliferation but not patterning during larval development. Genes \& Development, 13(1), 98-111. https://doi.org/10.1101/gad.13.1.98

Buckmaster, E. A., Perry, V. H., \& Brown, M. C. (1995). The Rate of Wallerian Degeneration in Cultured Neurons from Wild Type and C57BL/WIdS Mice Depends on Time in Culture and may be Extended in the Presence of Elevated K+ Levels. European Journal of Neuroscience, 7(7), 1596-1602. https://doi.org/10.1111/J.1460-9568.1995.TB01155.X

Cajal, S. R. y, May, R. M., DeFelipe, J., \& Jones, E. G. (1991). Cajal's Degeneration and Regeneration of the Nervous System (P. Corsi, E. G. Jones, \& G. M. Shepherd, Eds.). Oxford University Press. https://doi.org/10.1093/acprof:oso/9780195065169.001.0001

Coleman, M. P., \& Höke, A. (2020). Programmed axon degeneration: from mouse to mechanism to medicine. Nature Reviews Neuroscience 2020 21:4, 21(4), 183-196. https://doi.org/10.1038/S41583-020-0269-3 
Lassetter et al. 2021

Conforti, L., Fang, G., Beirowski, B., Wang, M. S., Sorci, L., Asress, S., Adalbert, R., Silva, A., Bridge, K., Huang, X. P., Magni, G., Glass, J. D., \& Coleman, M. P. (2006). NAD + and axon degeneration revisited: Nmnat1 cannot substitute for Wld $S$ to delay Wallerian degeneration. Cell Death \& Differentiation 2007 14:1, 14(1), 116-127. https://doi.org/10.1038/sj.cdd.4401944

Coutinho-Budd, J. C., Sheehan, A. E., \& Freeman, M. R. (2017). The secreted neurotrophin Spätzle 3 promotes glial morphogenesis and supports neuronal survival and function. Genes \& Development, 31(20), 2023-2038. https://doi.org/10.1101/gad.305888.117

Cunningham, R. L., \& Monk, K. R. (2018). Transmission Electron Microscopy for Zebrafish Larvae and Adult Lateral Line Nerve. Methods in Molecular Biology, 1739, 385-400. https://doi.org/10.1007/978-1-4939-7649-2_26

Czopka, T., \& Lyons, D. A. (2011). Dissecting Mechanisms of Myelinated Axon Formation Using Zebrafish. In Methods in Cell Biology (Vol. 105, pp. 25-62). Academic Press Inc. https://doi.org/10.1016/B978-0-12-381320-6.00002-3

D’Antonio, M., Droggiti, A., Feltri, M. L., Roes, J., Wrabetz, L., Mirsky, R., \& Jessen, K. R. (2006). TGF $\beta$ type II receptor signaling controls schwann cell death and proliferation in developing nerves. Journal of Neuroscience, 26(33), 8417-8427. https://doi.org/10.1523/JNEUROSCI.1578-06.2006

Deckwerth, T. L., \& Johnson, E. M. (1994). Neurites Can Remain Viable after Destruction of the Neuronal Soma by Programmed Cell Death (Apoptosis). Developmental Biology, 165(1), 63-72. https://doi.org/10.1006/DBIO.1994.1234

Diao, F., Ironfield, H., Luan, H., Diao, F., Shropshire, W. C., Ewer, J., Marr, E., Potter, C. J., Landgraf, M., \& H., W. B. (2015). Plug-and-Play Genetic Access to Drosophila Cell Types using Exchangeable Exon Cassettes. Cell Reports, 10(8), 1410-1421. https://doi.org/10.1016/J.CELREP.2015.01.059

Dorstyn, L., Colussi, P. A., Quinn, L. M., Richardson, H., \& Kumar, S. (1999). DRONC, an ecdysone-inducible Drosophila caspase. Proceedings of the National Academy of Sciences of the United States of America, 96(8), 4307-4312. https://doi.org/10.1073/pnas.96.8.4307

Fernandes, K. A., Mitchell, K. L., Patel, A., Marola, O. J., Shrager, P., Zack, D. J., Libby, R. T., \& Welsbie, D. S. (2018). Role of SARM1 and DR6 in retinal ganglion cell axonal and somal degeneration following axonal injury. Experimental Eye Research, 171, 54-61. https://doi.org/10.1016/J.EXER.2018.03.007

Ferri, A., Sanes, J. R., Coleman, M. P., Cunningham, J. M., \& Kato, A. C. (2003). Inhibiting Axon Degeneration and Synapse Loss Attenuates Apoptosis and Disease Progression in a Mouse Model of Motoneuron Disease. Current Biology, 13(8), 669-673. https://doi.org/10.1016/S0960-9822(03)00206-9

Fischer, L. R., Culver, D. G., Davis, A. A., Tennant, P., Wang, M., Coleman, M., Asress, S., Adalbert, R., Alexander, G. M., \& Glass, J. D. (2005). The WldS gene modestly prolongs survival in the SOD1G93A fALS mouse. Neurobiology of Disease, 19(1-2), 293-300. https://doi.org/10.1016/J.NBD.2005.01.008 
Lassetter et al. 2021

Fischer, L. R., Culver, D. G., Tennant, P., Davis, A. A., Wang, M., Castellano-Sanchez, A., Khan, J., Polak, M. A., \& Glass, J. D. (2004). Amyotrophic lateral sclerosis is a distal axonopathy: evidence in mice and man. Experimental Neurology, 185(2), 232-240. https://doi.org/10.1016/J.EXPNEUROL.2003.10.004

Fünfschilling, U., Supplie, L. M., Mahad, D., Boretius, S., Saab, A. S., Edgar, J., Brinkmann, B. G., Kassmann, C. M., Tzvetanova, I. D., Möbius, W., Diaz, F., Meijer, D., Suter, U., Hamprecht, B., Sereda, M. W., Moraes, C. T., Frahm, J., Goebbels, S., \& Nave, K. A. (2012). Glycolytic oligodendrocytes maintain myelin and long-term axonal integrity. Nature, 485(7399), 517-521. https://doi.org/10.1038/nature11007

Glass, J. D., \& Griffin, J. W. (1991). Neurofilament redistribution in transected nerves: Evidence for bidirectional transport of neurofilaments. Journal of Neuroscience, 11(10), 3146-3154. https://doi.org/10.1523/jneurosci.11-10-03146.1991

Gohl, D. M., Silies, M. A., Gao, X. J., Bhalerao, S., Luongo, F. J., Lin, C. C., Potter, C. J., \& Clandinin, T. R. (2011). A versatile in vivo system for directed dissection of gene expression patterns. Nature Methods, 8(3), 231-237. https://doi.org/10.1038/nmeth.1561

Griffiths, I., Klugmann, M., Anderson, T., Yool, D., Thomson, C., Schwab, M. H., Schneider, A., Zimmermann, F., McCulloch, M., Nadon, N., \& Nave, K. A. (1998). Axonal swellings and degeneration in mice lacking the major proteolipid of myelin. Science, 280(5369), 16101613. https://doi.org/10.1126/science.280.5369.1610

Harris, J. J., Jolivet, R., \& Attwell, D. (2012). Synaptic Energy Use and Supply. Neuron, 75(5), 762-777. https://doi.org/10.1016/J.NEURON.2012.08.019

Henninger, N., Bouley, J., Sikoglu, E. M., An, J., Moore, C. M., King, J. A., Bowser, R., Freeman, M. R., \& Brown, R. H. (2016). Attenuated traumatic axonal injury and improved functional outcome after traumatic brain injury in mice lacking Sarm1. Brain, 139(4), 10941105. https://doi.org/10.1093/BRAIN/AWW001

Hoopfer, E. D., McLaughlin, T., Watts, R. J., Schuldiner, O., O’Leary, D. D. M., \& Luo, L. (2006). Wids Protection Distinguishes Axon Degeneration following Injury from Naturally Occurring Developmental Pruning. Neuron, 50(6), 883-895. https://doi.org/10.1016/J.NEURON.2006.05.013

Jessen, K. R., \& Mirsky, R. (2005). The origin and development of glial cells in peripheral nerves. Nature Reviews Neuroscience, 6(9), 671-682. https://doi.org/10.1038/nrn1746

Kornek, B., Storch, M. K., Weissert, R., Wallstroem, E., Stefferl, A., Olsson, T., Linington, C., Schmidbauer, M., \& Lassmann, H. (2000). Multiple Sclerosis and Chronic Autoimmune Encephalomyelitis: A Comparative Quantitative Study of Axonal Injury in Active, Inactive, and Remyelinated Lesions. The American Journal of Pathology, 157(1), 267-276. https://doi.org/10.1016/S0002-9440(10)64537-3

Kuhlmann, T., Lingfeld, G., Bitsch, A., Schuchardt, J., \& Brück, W. (2002). Acute axonal damage in multiple sclerosis is most extensive in early disease stages and decreases over time. Brain, 125(10), 2202-2212. https://doi.org/10.1093/BRAIN/AWF235 
Lassetter et al. 2021

Lappe-Siefke, C., Goebbels, S., Gravel, M., Nicksch, E., Lee, J., Braun, P. E., Griffiths, I. R., \& Nave, K.-A. (2003). Disruption of Cnp1 uncouples oligodendroglial functions in axonal support and myelination. Nature Genetics, 33(3), 366-374. https://doi.org/10.1038/ng1095

Lee, P.-T., Zirin, J., Kanca, O., Lin, W.-W., Schulze, K. L., Li-Kroeger, D., Tao, R., Devereaux, C., Hu, Y., Chung, V., Fang, Y., He, Y., Pan, H., Ge, M., Zuo, Z., Housden, B. E., Mohr, S. E., Yamamoto, S., Levis, R. W., ... Bellen, H. J. (2018). A gene-specific T2A-GAL4 library for drosophila. ELife, 7. https://doi.org/10.7554/eLife.35574

Lee, Y., Morrison, B. M., Li, Y., Lengacher, S., Farah, M. H., Hoffman, P. N., Liu, Y., Tsingalia, A., Jin, L., Zhang, P. W., Pellerin, L., Magistretti, P. J., \& Rothstein, J. D. (2012). Oligodendroglia metabolically support axons and contribute to neurodegeneration. Nature, 487(7408), 443-448. https://doi.org/10.1038/nature11314

Leiserson, W. M., Forbush, B., \& Keshishian, H. (2011). Drosophila glia use a conserved cotransporter mechanism to regulate extracellular volume. Glia, 59(2), 320-332. https://doi.org/10.1002/glia.21103

Luan, H., Peabody, N. C., Vinson, C. R. R., \& White, B. H. (2006). Refined Spatial Manipulation of Neuronal Function by Combinatorial Restriction of Transgene Expression. Neuron, 52(3), 425-436. https://doi.org/10.1016/j.neuron.2006.08.028

Lunn, E., Perry, V., Brown, M., Rosen, H., \& Gordon, S. (1989). Absence of Wallerian Degeneration Does not Hinder Regeneration in Peripheral Nerve. European Journal of Neuroscience, 1(1), 27-33.

MacDonald, J. M., Beach, M. G., Porpiglia, E., Sheehan, A. E., Watts, R. J., \& Freeman, M. R. (2006). The Drosophila Cell Corpse Engulfment Receptor Draper Mediates Glial Clearance of Severed Axons. Neuron, 50(6), 869-881. https://doi.org/10.1016/j.neuron.2006.04.028

Marshall-Phelps, K. L. H., Kegel, L., Baraban, M., Ruhwedel, T., Almeida, R. G., Rubio-Brotons, M., Klingseisen, A., Benito-Kwiecinski, S. K., Early, J. J., Bin, J. M., Suminaite, D., Livesey, M. R., Möbius, W., Poole, R. J., \& Lyons, D. A. (2020). Neuronal activity disrupts myelinated axon integrity in the absence of NKCC1b. Journal of Cell Biology, 219(7). https://doi.org/10.1083/JCB.201909022

Matsuda, W., Furuta, T., Nakamura, K. C., Hioki, H., Fujiyama, F., Arai, R., \& Kaneko, T. (2009). Single Nigrostriatal Dopaminergic Neurons Form Widely Spread and Highly Dense Axonal Arborizations in the Neostriatum. Journal of Neuroscience, 29(2), 444-453. https://doi.org/10.1523/JNEUROSCI.4029-08.2009

Matzat, T., Sieglitz, F., Kottmeier, R., Babatz, F., Engelen, D., \& Klämbt, C. (2015). Axonal wrapping in the Drosophila PNS is controlled by glia-derived neuregulin homolog Vein. Development (Cambridge), 142(7), 1336-1345. https://doi.org/10.1242/dev.116616

McGuire, S. E., Le, P. T., Osborn, A. J., Matsumoto, K., \& Davis, R. L. (2003). Spatiotemporal Rescue of Memory Dysfunction in Drosophila. Science, 302(5651), 1765-1768. https://doi.org/10.1126/science.1089035

Monte, S. M. de la, Gabuzda, D. H., Ho, D. D., Brown, R. H., Hedley-Whyte, E. T., Schooley, R. T., Hirsch, M. S., \& Bhan, A. K. (1988). Peripheral neuropathy in the acquired 
Lassetter et al. 2021

immunodeficiency syndrome. Annals of Neurology, 23(5), 485-492.

https://doi.org/10.1002/ANA.410230510

Mukherjee, C., Kling, T., Russo, B., Miebach, K., Kess, E., Schifferer, M., Pedro, L. D., Weikert, U., Fard, M. K., Kannaiyan, N., Rossner, M., Aicher, M. L., Goebbels, S., Nave, K. A., Krämer-Albers, E. M., Schneider, A., \& Simons, M. (2020). Oligodendrocytes Provide Antioxidant Defense Function for Neurons by Secreting Ferritin Heavy Chain. Cell Metabolism, 32(2), 259-272.e10. https://doi.org/10.1016/j.cmet.2020.05.019

Neukomm, L. J., Burdett, T. C., Gonzalez, M. a, Züchner, S., \& Freeman, M. R. (2014). Rapid in vivo forward genetic approach for identifying axon death genes in Drosophila. Proceedings of the National Academy of Sciences of the United States of America, 111(27), 9965-9970. https://doi.org/10.1073/pnas.1406230111

Osterloh, J. M., Yang, J., Rooney, T. M., Fox, A. N., Adalbert, R., Powell, E. H., Sheehan, A. E., Avery, M. A., Hackett, R., Logan, M. A., MacDonald, J. M., Ziegenfuss, J. S., Milde, S., Hou, Y.-J., Nathan, C., Ding, A., Brown, R. H., Conforti, L., Coleman, M., ... Freeman, M. R. (2012). dSarm/Sarm1 Is Required for Activation of an Injury-Induced Axon Death Pathway. Science, 337(6093), 481-484. https://doi.org/10.1126/science.1223899

Palka, J., Schubiger, M., \& Ellison, R. L. (1983). The polarity of axon growth in the wings of Drosophila melanogaster. Developmental Biology, 98(2), 481-492. https://doi.org/10.1016/0012-1606(83)90377-9

Parkinson, D. B., Dong, Z., Bunting, H., Whitfield, J., Meier, C., Marie, H., Mirsky, R., \& Jessen, K. R. (2001). Transforming Growth Factor $\beta$ (TGF $\beta$ ) Mediates Schwann Cell Death In Vitro and In Vivo: Examination of c-Jun Activation, Interactions with Survival Signals, and the Relationship of TGF $\beta$-Mediated Death to Schwann Cell Differentiation. The Journal of Neuroscience, 21(21), 8572-8585. https://doi.org/10.1523/JNEUROSCI.21-21-08572.2001

Perrimon, N., Ni, J. Q., \& Perkins, L. (2010). In vivo RNAi: today and tomorrow. In Cold Spring Harbor perspectives in biology (Vol. 2, Issue 8, p. a003640). Cold Spring Harbor Laboratory Press. https://doi.org/10.1101/cshperspect.a003640

Peters, O. M., Lewis, E. A., Osterloh, J. M., Weiss, A., Salameh, J. S., Metterville, J., Brown, R. H., \& Freeman, M. R. (2018). Loss of Sarm1 does not suppress motor neuron degeneration in the SOD1G93A mouse model of amyotrophic lateral sclerosis. Human Molecular Genetics, 27(21), 3761-3771. https://doi.org/10.1093/HMG/DDY260

Potter, C. J., Tasic, B., Russler, E. v, Liang, L., \& Luo, L. (2010). The Q System: A Repressible Binary System for Transgene Expression, Lineage Tracing, and Mosaic Analysis. Cell, 141(3), 536-548. https://doi.org/10.1016/j.cell.2010.02.025

Riabinina, O., Luginbuhl, D., Marr, E., Liu, S., Wu, M. N., Luo, L., \& Potter, C. J. (2015). Improved and expanded Q-system reagents for genetic manipulations. Nature Methods, 12(3), 219-222. https://doi.org/10.1038/nmeth.3250

Samsam, M., Mi, W., Wessig, C., Zielasek, J., Toyka, K. v., Coleman, M. P., \& Martini, R. (2003). The WIds Mutation Delays Robust Loss of Motor and Sensory Axons in a Genetic Model for Myelin-Related Axonopathy. Journal of Neuroscience, 23(7), 2833-2839. https://doi.org/10.1523/JNEUROSCI.23-07-02833.2003 
Lassetter et al. 2021

Schaumburg, H. H., Wisniewski, H. M., \& Spencer, P. S. (1974). ULTRASTRUCTURAL STUDIES OF THE DYING-BACK PROCESS: 1. PERIPHERAL NERVE TERMINAL AND AXON DEGENERATION IS SYSTEMIC ACRYLAMIDE INTOXICATION. Journal of Neuropathology \& Experimental Neurology, 33(2), 260-284.

Sepp, K. J., Schulte, J., \& Auld, V. J. (2001). Peripheral glia direct axon guidance across the CNS/PNS transition zone. Developmental Biology, 238(1), 47-63. https://doi.org/10.1006/dbio.2001.0411

Sima, A. A. F., Bouchier, M., \& Christensen, H. (1983). Axonal atrophy in sensory nerves of the diabetic BB-Wistar rat: A possible early correlate of human diabetic neuropathy. Annals of Neurology, 13(3), 264-272. https://doi.org/10.1002/ANA.410130307

Stork, T., Engelen, D., Krudewig, A., Silies, M., Bainton, R. J., \& Klambt, C. (2008). Organization and Function of the Blood Brain Barrier in Drosophila. Journal of Neuroscience, 28(3), 587-597. https://doi.org/10.1523/JNEUROSCI.4367-07.2008

Trapp, B. D., Peterson, J., Ransohoff, R. M., Rudick, R., Mörk, S., \& Bö, L. (1998). Axonal Transection in the Lesions of Multiple Sclerosis. Http://Dx.Doi.Org/10.1056/NEJM199801293380502, 338(5), 278-285. https://doi.org/10.1056/NEJM199801293380502

Turkiew, E., Falconer, D., Reed, N., \& Höke, A. (2017). Deletion of Sarm1 gene is neuroprotective in two models of peripheral neuropathy. Journal of the Peripheral Nervous System, 22(3), 162-171. https://doi.org/10.1111/JNS.12219

Upadhyay, A., Moss-Taylor, L., Kim, M.-J., Ghosh, A. C., \& O’Connor, M. B. (2017). TGF- $\beta$ Family Signaling in Drosophila. Cold Spring Harbor Perspectives in Biology, 9(9). https://doi.org/10.1101/cshperspect.a022152

Verhamme, C., King, R. H. M., ten Asbroek, A. L. M. A., Muddle, J. R., Nourallah, M., Wolterman, R., Baas, F., \& van Schaik, I. N. (2011). Myelin and Axon Pathology in a LongTerm Study of PMP22 -Overexpressing Mice. Journal of Neuropathology \& Experimental Neurology, 70(5), 386-398. https://doi.org/10.1097/NEN.0b013e318217eba0

Volkenhoff, A., Weiler, A., Letzel, M., Stehling, M., Klämbt, C., \& Schirmeier, S. (2015). Glial glycolysis is essential for neuronal survival in drosophila. Cell Metabolism, 22(3), 437-447. https://doi.org/10.1016/j.cmet.2015.07.006

Wang, J., Zhai, Q., Chen, Y., Lin, E., Gu, W., McBurney, M. W., \& He, Z. (2005). A local mechanism mediates NAD-dependent protection of axon degeneration. Journal of Cell Biology, 170(3), 349-355. https://doi.org/10.1083/JCB.200504028

White, K., Grether, M. E., Abrams, J. M., Young, L., Farrell, K., \& Steller, H. (1994). Genetic control of programmed cell death in Drosophila. Science, 264(5159), 677-683. https://doi.org/10.1126/science.8171319

Zhou, L., Song, Z., Tittel, J., \& Steller, H. (1999). HAC-1, a Drosophila homolog of APAF-1 and CED-4, functions in developmental and radiation-induced apoptosis. Molecular Cell, 4(5), 745-755. https://doi.org/10.1016/S1097-2765(00)80385-8 
Lassetter et al. 2021

\section{Figure Legends:}

Fig. 1: Ablating wrapping glia results in neurodegeneration in the peripheral nerve of the wing with age. A) Diagram of the sensory nerve in the wing of Drosophila B) Images from the area depicted in the box in A. A subset of glutamatergic neurons are genetically labeled with GFP and glia are labelled with tdTomato. The orthogonal fluorescent image corresponds to the location at the asterisk. C) Electron micrograph of a cross section of the nerve in the wing from the same region as in A. Wrapping glial membrane is psuedocolored in cyan. Example glia $(G)$ and axons $(\mathrm{Ax})$ are labeled. D-F) Representative images of control and glial-ablated wings at 28 days of age with subset of wrapping glia labeled with tdTomato. D-F' \& D-F”) Higher magnification images from ROls in D-F. G) Classification of axon phenotype for each condition categorized into intact, mild, or severe. n=number of wings. H) Quantification of the number of intact neuron cell bodies at each time point. Images are maximum intensity projections derived from z-stack images. Data are represented as mean $\pm 95 \% \mathrm{Cl}$. Statistics: Two-way ANOVA with Dunnett's multiple comparisons test. Significance: ${ }^{*}=p<0.05,{ }^{* *}=p<0.01,{ }^{* * *}=p<0.001,{ }^{* * * *}=$ $p<0.0001$. (See also Figure S1 \& S2).

Fig. 2: A screen for glial genes required for axon maintenance. A) Diagram illustrating the peripheral sensory nerve in the wing (left) with neurons labeled in green and glia in magenta. Expression of $\mathrm{Wld}^{\mathrm{S}}$ prevents axon degeneration 10 days post axotomy (dpa) in the wing (right). Images are maximum intensity projections of z-stack images. B) Diagram of screen workflow. Flies expressing GFP and WId ${ }^{S}$ in neurons and GAL4 in glia were crossed to UAS-RNAi flies and resulting progeny were injured and assessed for axon integrity at 10-14 dpa. C) Axon integrity in injured Wld ${ }^{S}$ expressing neurons in control and WG-ablated animals at $10 \mathrm{dpa}$. D) Summary of screen results with examples of individual screen hits: wit, Ncc69, bnl and fzo. Images are of single slices from middle of the axon bundle of z-stack images. (See also REFSup. file)

Fig. 3: Glial-specific knockdown of TGF $\beta$ and BMP pathway components causes axon degeneration in the sensory nerve of the wing. A) Diagram of the TGF $\beta$ superfamily members in the Drosophila genome. B) Table summarizing the phenotypes for the corresponding RNAis targeting the TGF $\beta$ superfamily genes. VDRC - ' $\mathrm{V}$ ', Bloominton - 'BL\#'. C) Images of $\mathrm{Wld}^{\mathrm{S}+}$ axons in the sensory nerve of the wing 10 days post-axotomy from control and TGF $\beta$ knockdown animals uninjured wing (top) axotomized wing (bottom). Scale bar $5 \mu \mathrm{m}$. Pan-glial knockdown of the ligand myo or the receptor tkv were lethal (not shown).

Fig. 4: TGF $\beta$ receptor babo is expressed in adult WG. A) Nuclear mCherry reporter expression under nrv2 (') or babo (") transcriptional control in a background where membranetethered GFP is expressed in WG at 4 (A), 14 (B), and 28 (C) days. Scale bar $200 \mu \mathrm{m}$. Higher magnification image of regions of interest in A-C showing mCherry ${ }^{+}$nuclei within the GFP $^{+}$WG membrane (yellow arrows). Scale bar $5 \mu \mathrm{m}$. (See also Figure S3-S5)

Fig. 5: Glial morphology appears intact in TGF $\beta$ knockdown animals. A) Axons (green) and glia (magenta) in control and pan-glial TGF $\beta$ knockdown animals from 4 (top) and 28 (bottom) day old L1 nerves. B) Nerves from WG-specific TGF $\beta$ knockdown animals from 4 (top) and 28 (bottom) day old L1 nerves. C-E) Electron micrographs of a cross section of the L1 nerve at 28 days from control (C), babo (D), and Smox (E) knockdown animals. Wrapping glia are highlighted in cyan. F) Quantification of the wrapping index [(individually wrapped axons + bundles of axons) / total axons]. Data are represented as mean $\pm 95 \% \mathrm{Cl}$. Statistics: One-way 
Lassetter et al. 2021

ANOVA with Dunnett's multiple comparisons test. Significance: $n s=p>0.05$. (See also Figure S6)

Fig. 6: Glial-specific knockdown of TGF $\beta$ superfamily members results in age-dependent neurodegeneration in the sensory nerve in the adult wing. A) Images from control and babo-knockdown animals of the axon bundle in the wing at each time point (left) and the proportion of wings in each classification (right) for all conditions. B) Quantification of the number of intact neuron cell bodies per wing at each time point in control and babo-knockdown animals. C) Comparison of the number of intact neuron cell bodies per wing at 28 days for control and TGF $\beta$ superfamily knockdown conditions. Note: repeated data shown in B and C for control and babo-knockdown at 28 days. D) Quantification of the number of intact neuron cell bodies at each time point in control animals and animals with over-expression of a dominant negative form of the babo receptor $\left(b a b o^{D N}\right)$. E) Quantification of the number of intact neuron cell bodies in control, babo, and Smox knockdown animals using two non-overlapping RNAis each. F) Quantification of the number of intact neuron cell bodies in adult-specific knockdown animals. Data are represented as mean $\pm 95 \%$ Cl. Statistics: (B, D, E, F) Two-way ANOVA with Sidak's multiple comparisons test; (C) One-way ANOVA with Dunnett's T3 multiple comparisons test. Significance: $n s=p>0.05,{ }^{*}=p<0.05,{ }^{* *}=p<0.01,{ }^{* * *}=p<0.001,{ }^{* * * *}=p<0.0001$. (See also Figure S8)

Fig. 7: Wld $^{\mathrm{s}}$ overexpression in neurons rescued neurodegeneration in babo knockdown animals. A) Representative images of neuron cell bodies and axons within the wing in control and babo knockdown animals at 4 (top) and 28 (bottom) days of age with and without Wld ${ }^{\mathrm{s}}$ expressed in neurons. Scale bar $5 \mu \mathrm{m}$. B) Classification of axon integrity in control and babo knockdown animals at 4 and 28 days with and without Wld ${ }^{S}$. C) Quantification of the number of VGlut $^{+}$neuron cell bodies in the wing from control and babo knockdown animals with and without $\mathrm{WId}^{S}$. Data are represented as mean $\pm 95 \% \mathrm{Cl}$. Statistics: 2-Way ANOVA with Tukey's multiple comparisons test. Significance: ns $=$ not significant, ${ }^{* * *}=p<0.0001$. 
A

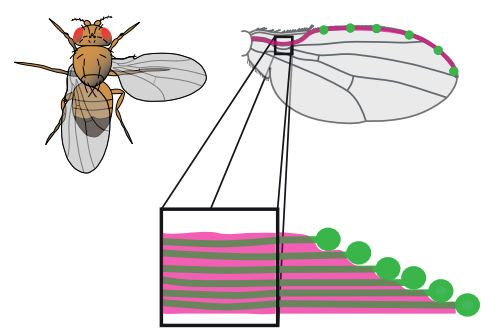

axons

glia
B
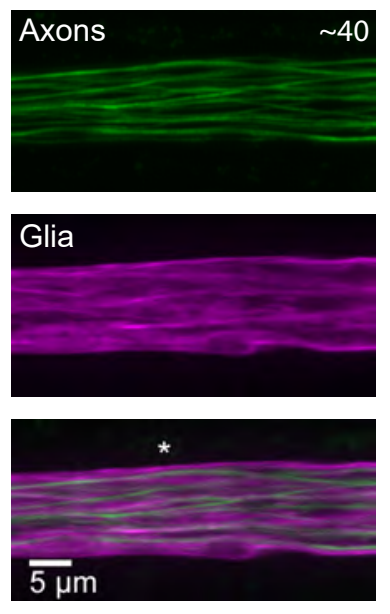

D

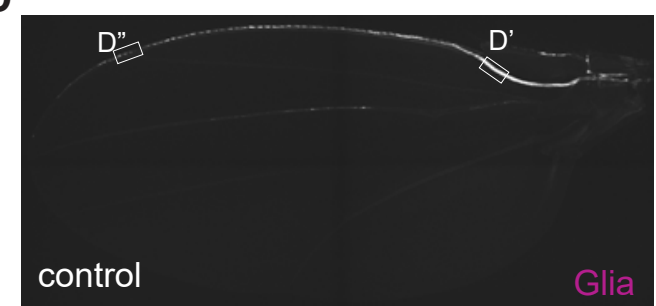

E

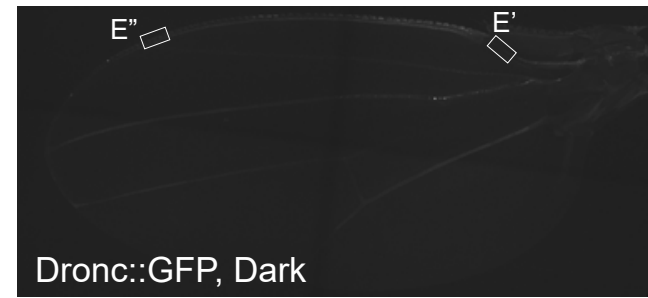

F

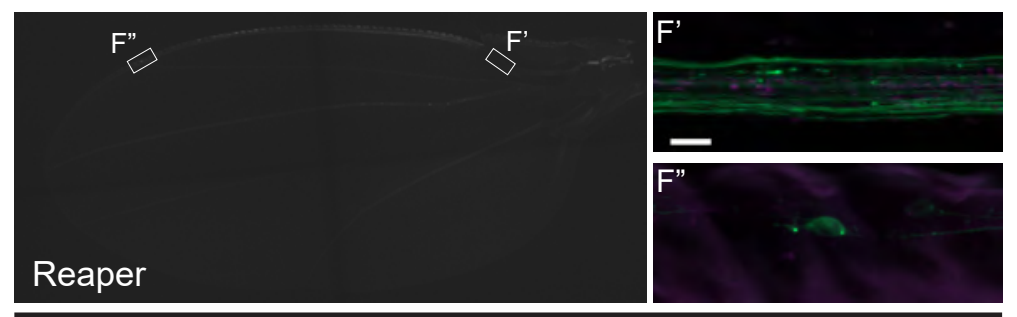

28 days
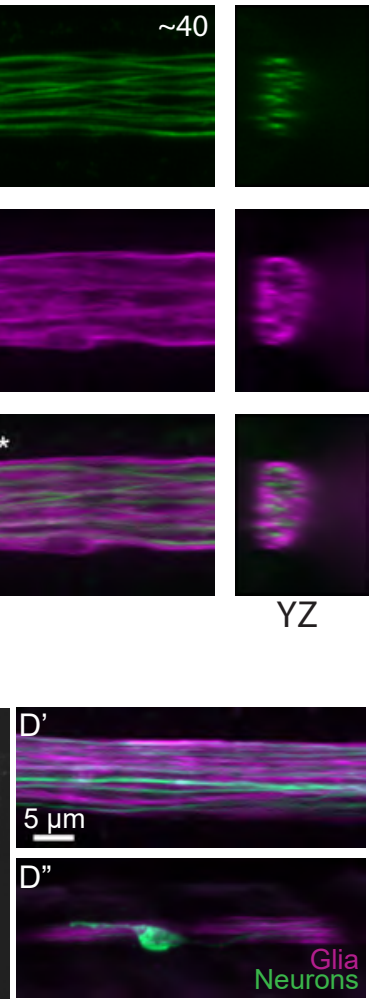

C

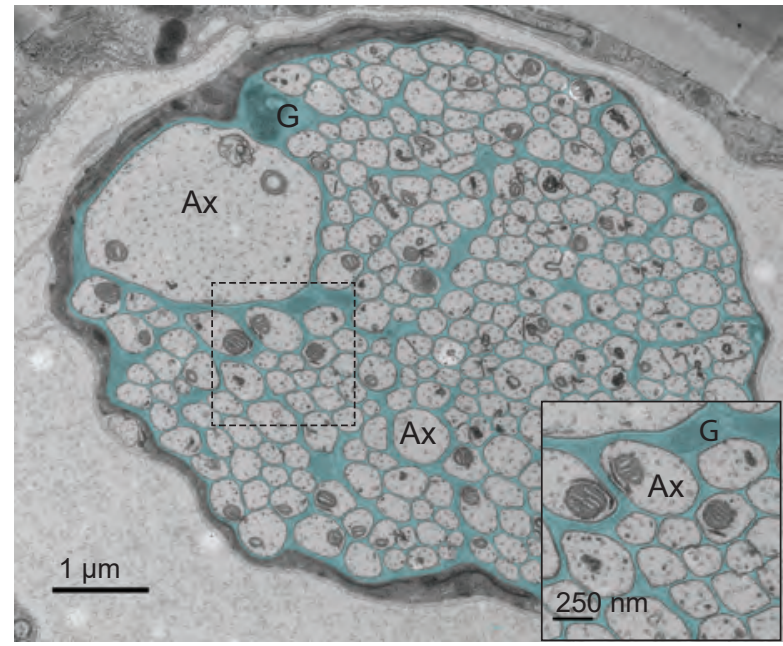

G

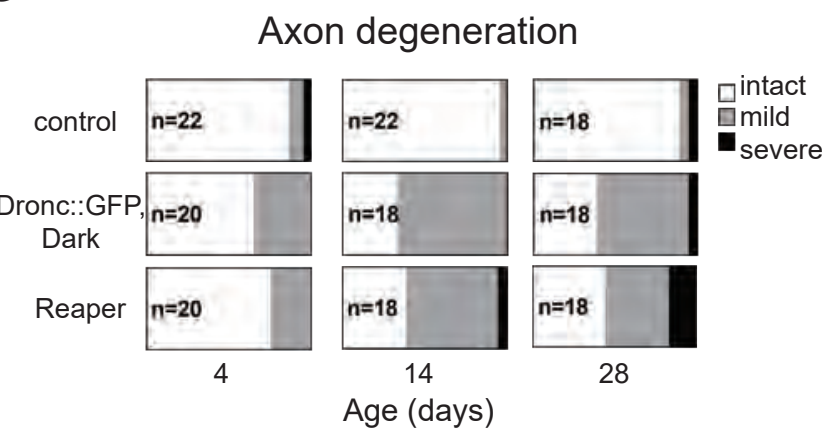

H
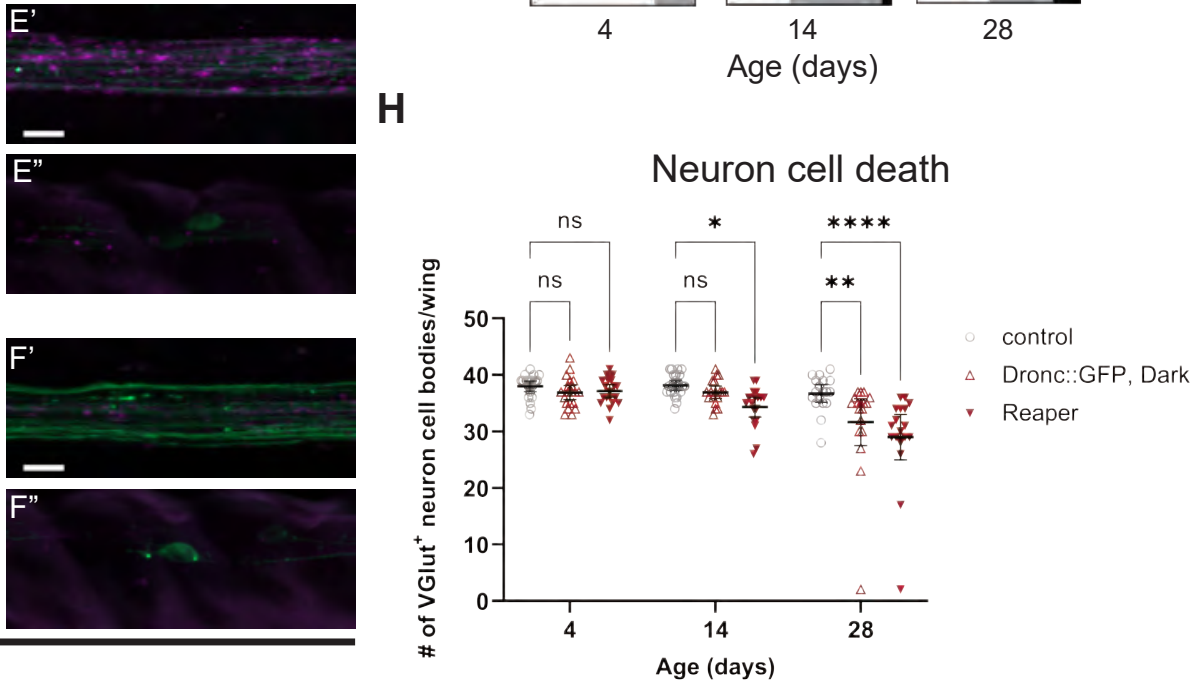
A

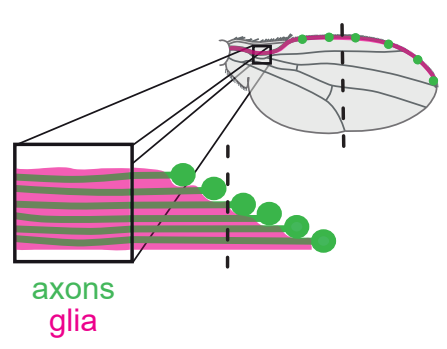

B

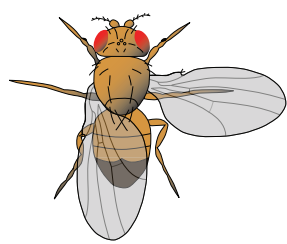

Genetics:

Neurons: GFP \& WIds Glia: RNAi

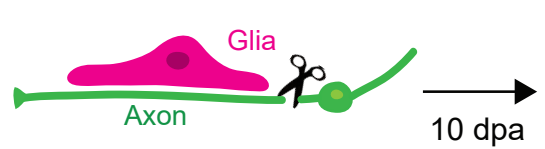

Uninjured:

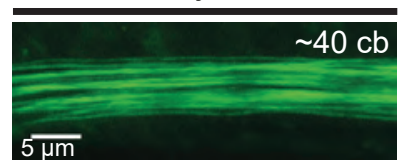

WD after axotomy:

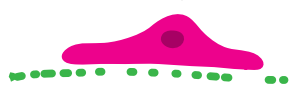

10 days post axotomy:

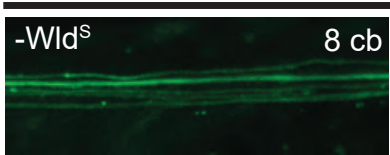

WIds blocks WD:

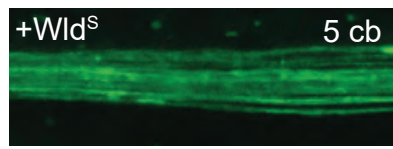

GFP $^{+}$Sensory Neurons Expressing Wld

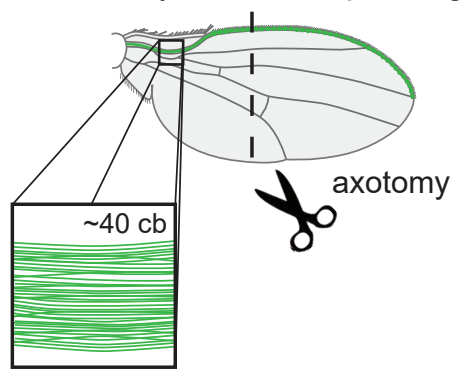

uninjured

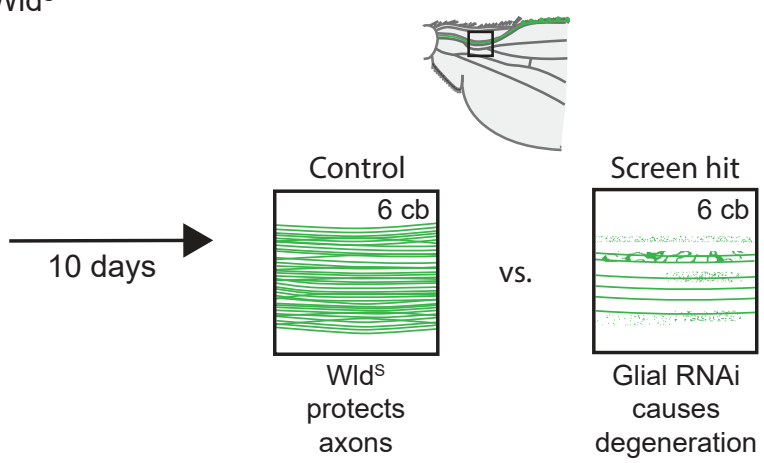

C

WId $^{\mathrm{S}+}$ axons 10 days post-axotomy
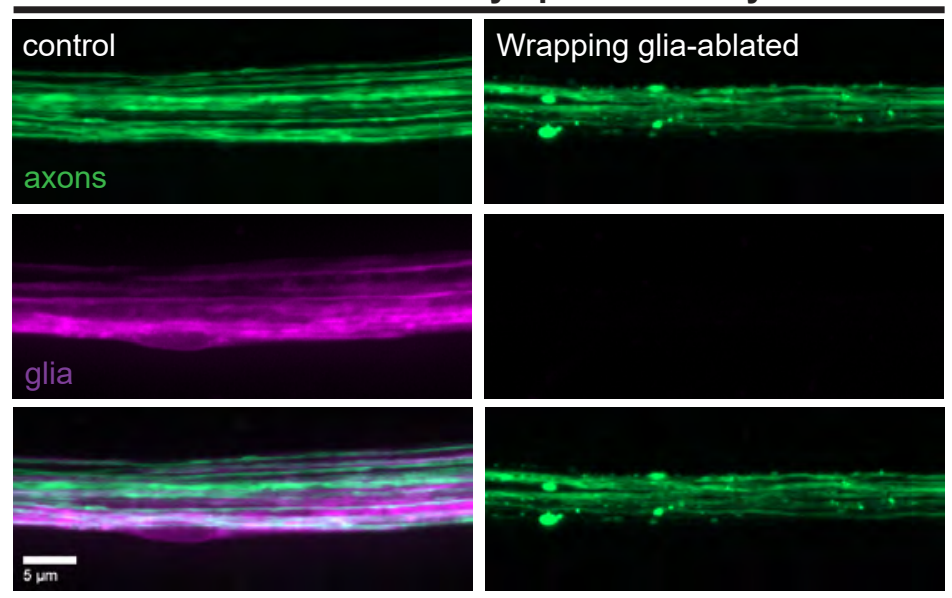

control
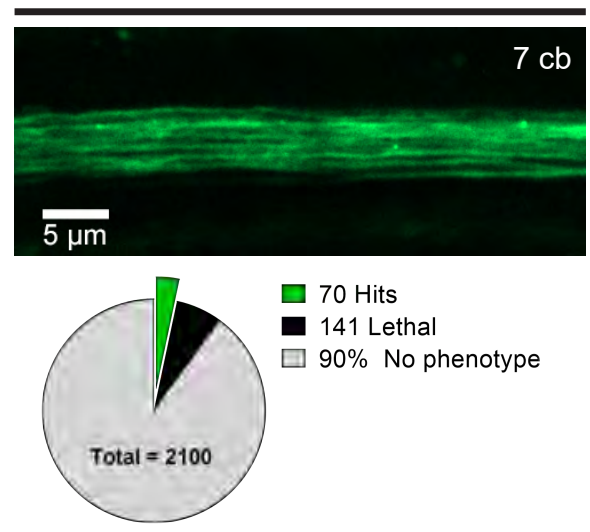

10 days post axotomy

\section{Axon degeneration}
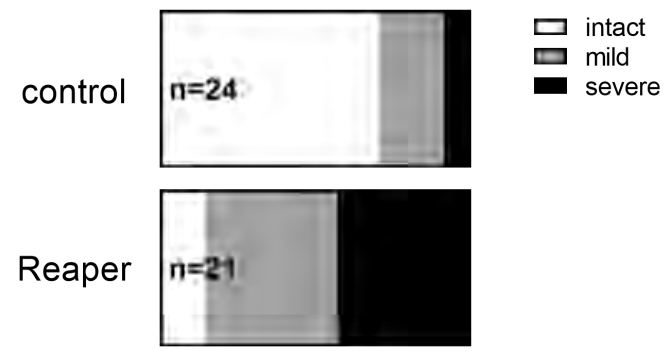

Screen hits
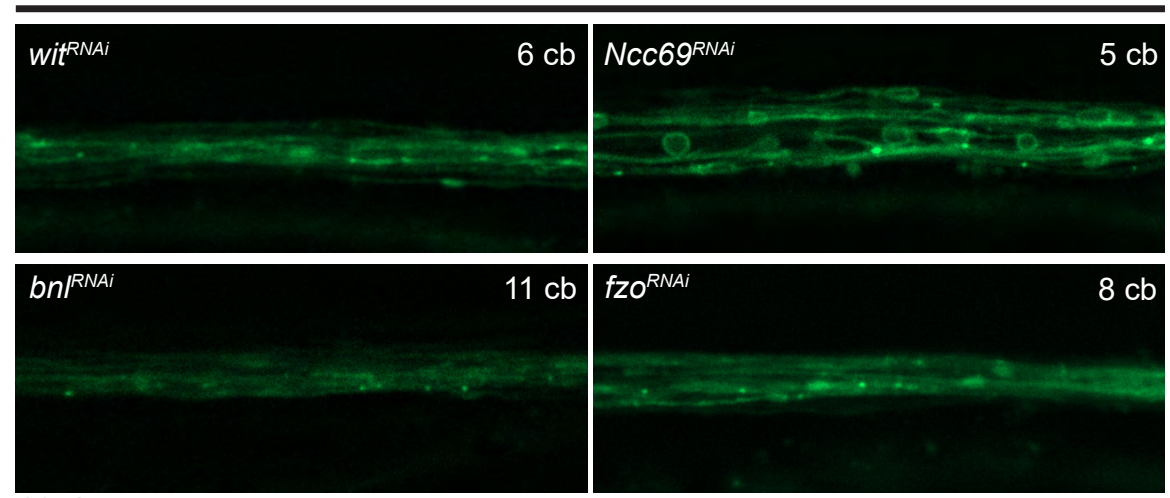
A

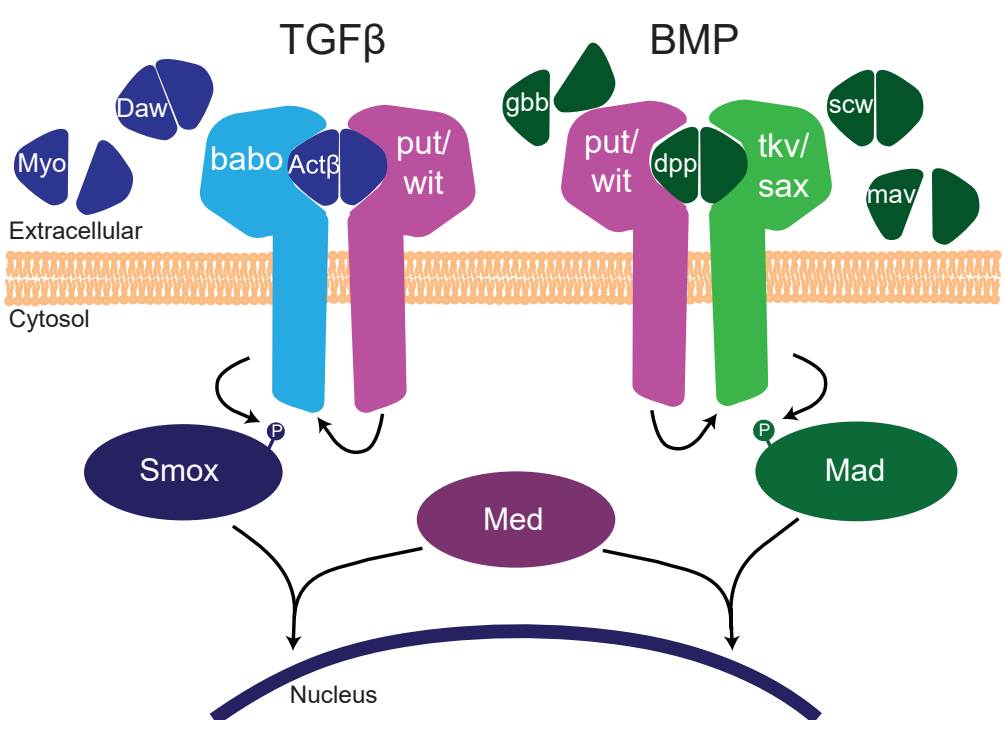

C

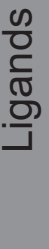

uninjured

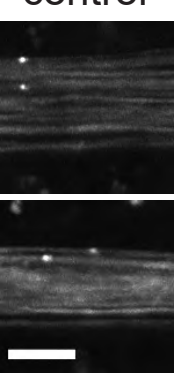

$$
\text { control }
$$

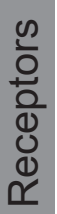

uninjured

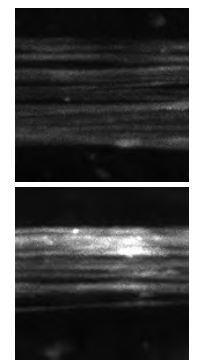

$$
\text { control }
$$

uninjured

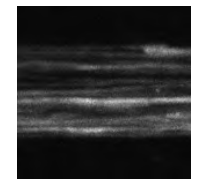

10 dpa

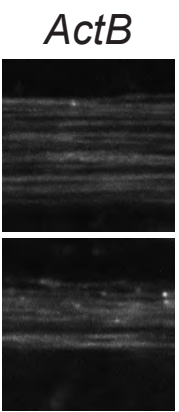

babo

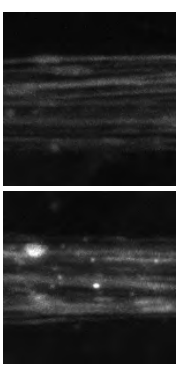

Smox
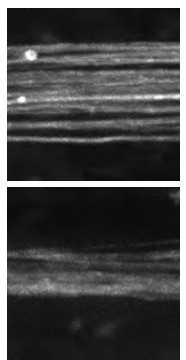

daw

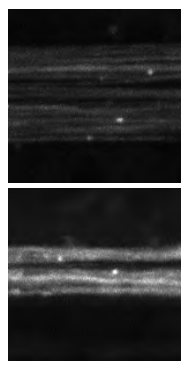

Med

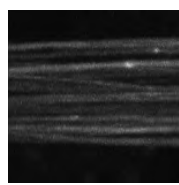

B

\begin{tabular}{|c|l|l|}
\hline Gene & RNAi \# & Phenotype \\
\hline myo & $\mathrm{v} 110195$ & lethal (no adults) \\
\hline Act $\beta$ & $\mathrm{v} 108663$ & debris \\
\hline daw & $\mathrm{v} 105309$ & axons intact \\
\hline babo & $\mathrm{v} 3825$ & axons intact \\
\hline Smox & $\mathrm{v} 105687$ & fewer axons \\
\hline mav & BL34650 & axons intact \\
\hline gbb & $\mathrm{v} 330684$ & debris \\
\hline dpp & $\mathrm{v} 330518$ & debris, fewer axons \\
\hline scw & $\mathrm{v} 105303$ & debris, fewer axons \\
\hline sax & $\mathrm{v} 9434$ & fewer axons \\
\hline tkv & $\mathrm{v} 105834$ & lethal (no adults) \\
\hline Mad & $\mathrm{v} 110517$ & fewer axons \\
\hline put & BL39025 & debris \\
\hline wit & $\mathrm{v} 103808$ & fewer axons \\
\hline Med & $\mathrm{v} 106767$ & debris \\
\hline
\end{tabular}
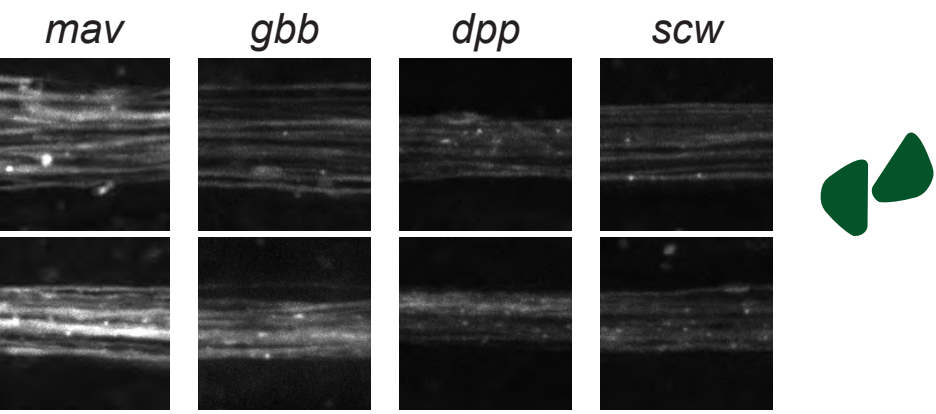

wit
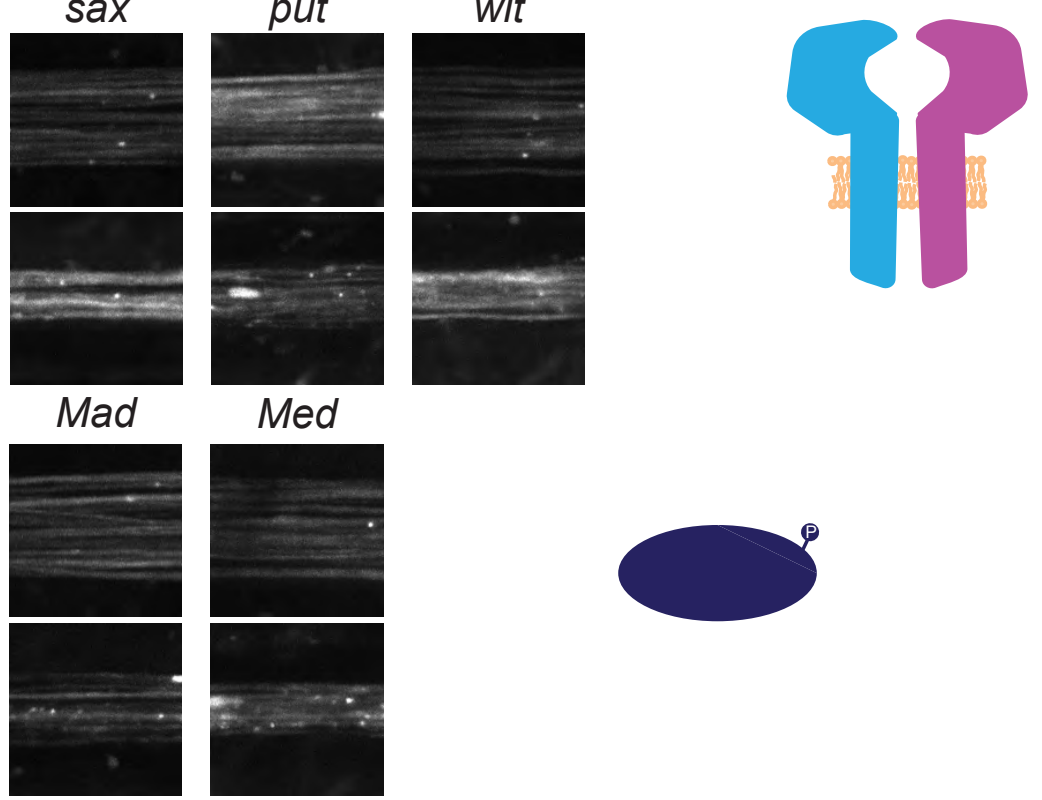
bioRxiv preprint doi: https://doi.org/10.1101/2021.09.02.458753; this version posted September 3, 2021. The copyright holder for this preprint (which was not certified by peer review) is the author/funder. All rights reserved. No reuse allowed without permission.

A
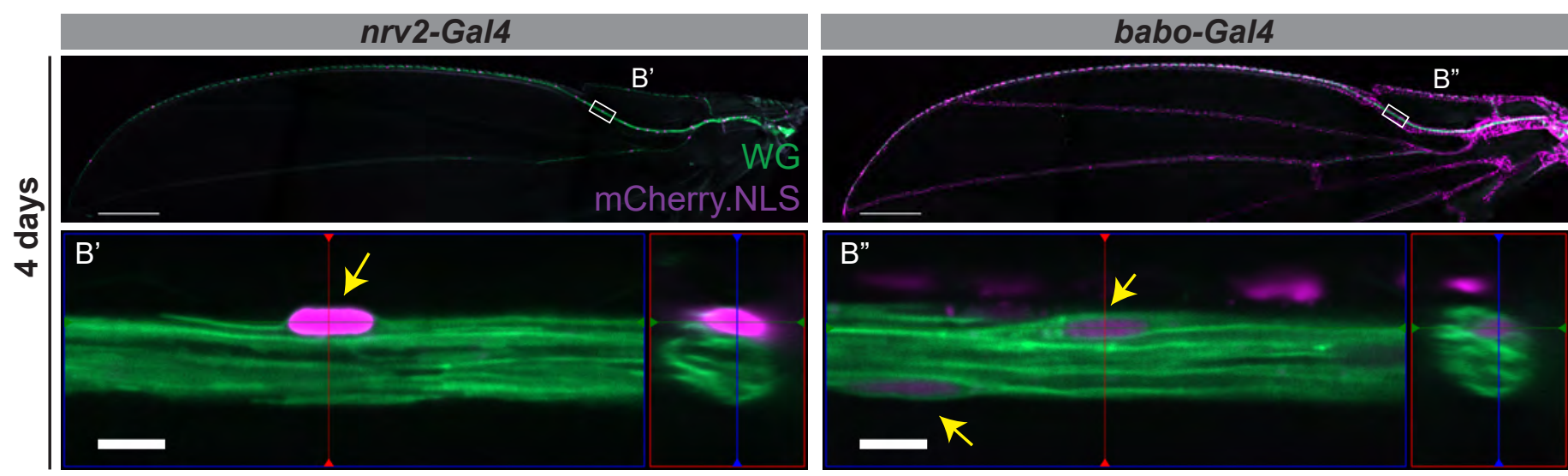

B
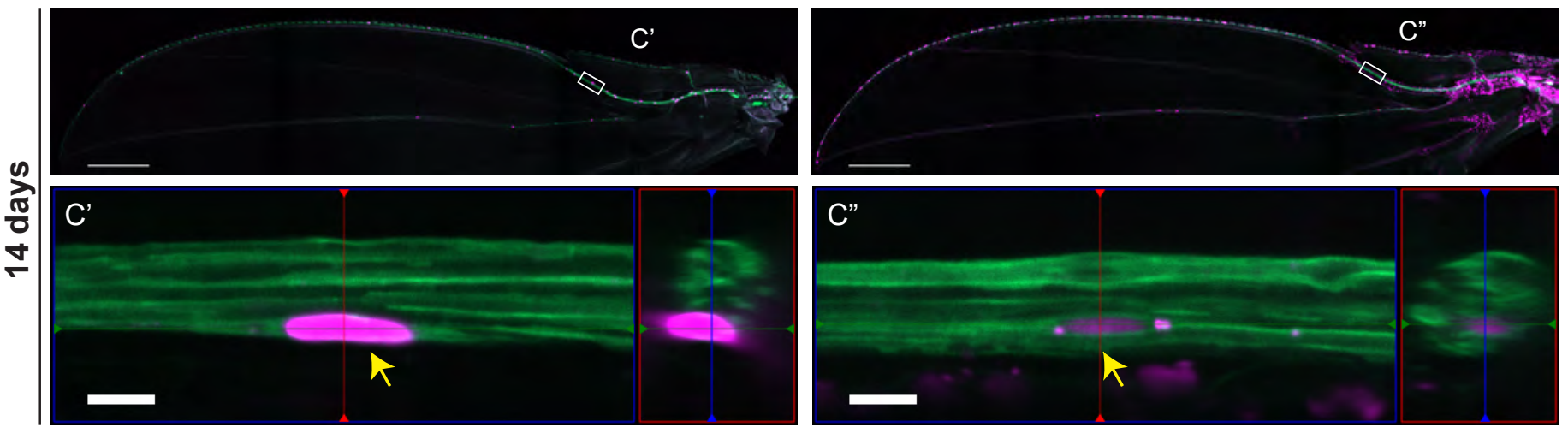

C
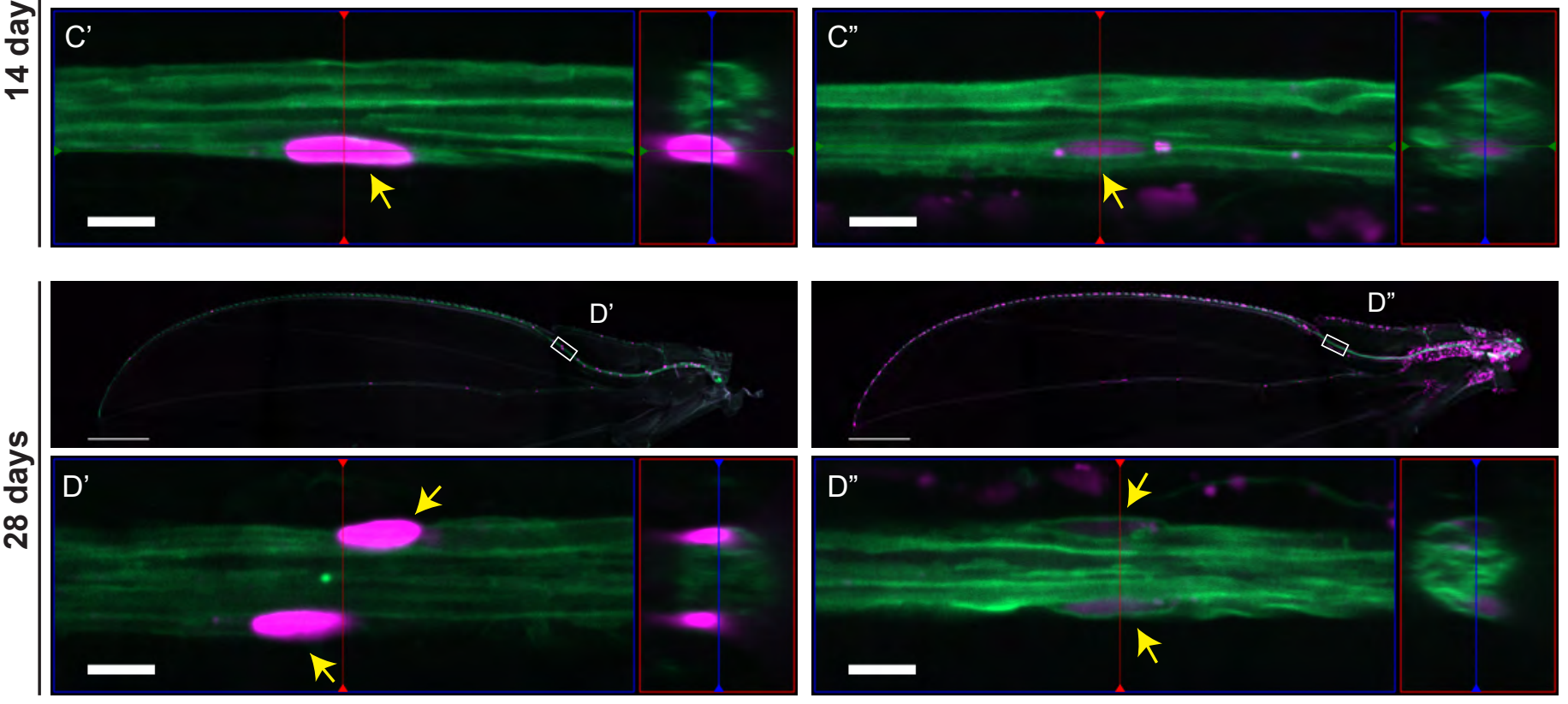
bioRxiv preprint doi: https://doi.org/10.1101/2021.09.02.458753; this version posted September 3, 2021. The copyright holder for this preprint (which was not certified by peer review) is the author/funder. All rights reserved. No reuse allowed without permission.

A

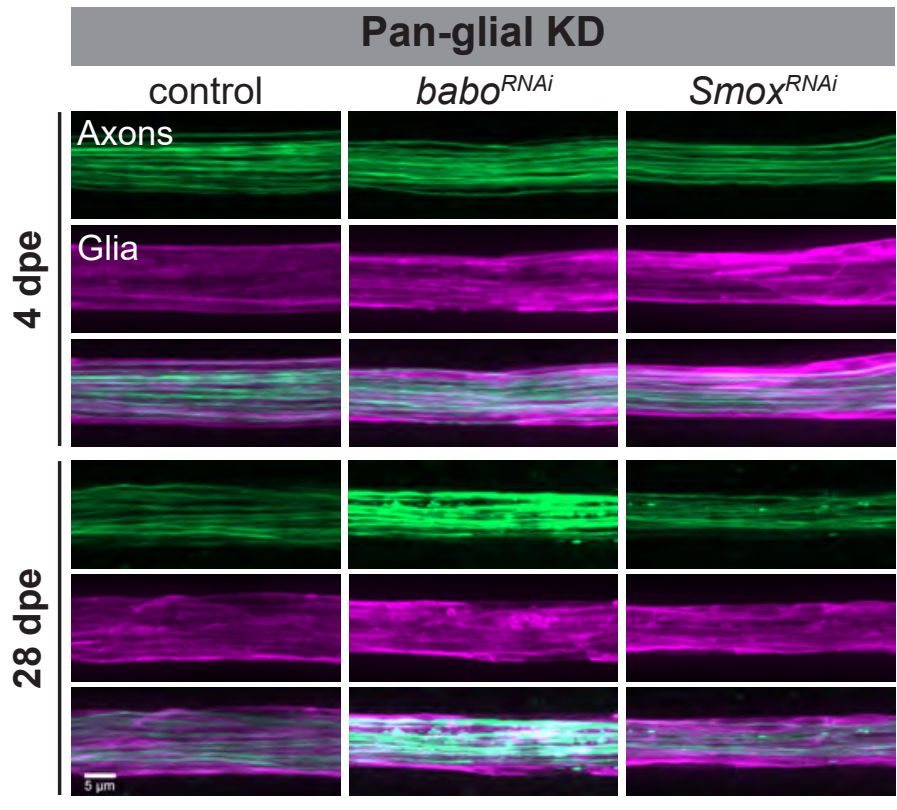

C

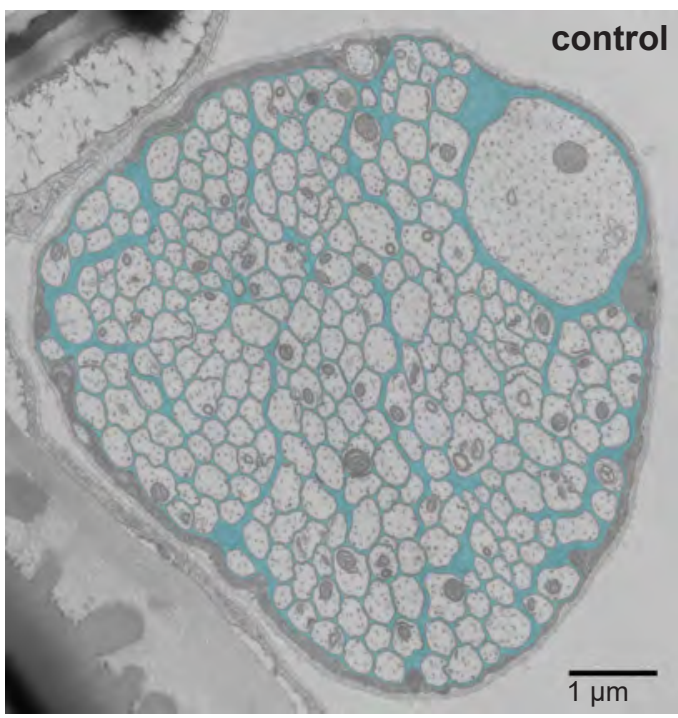

D

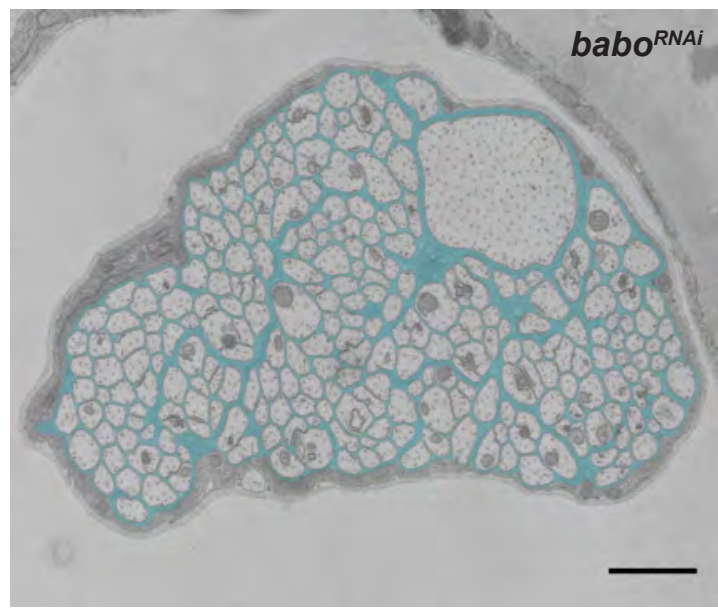

B

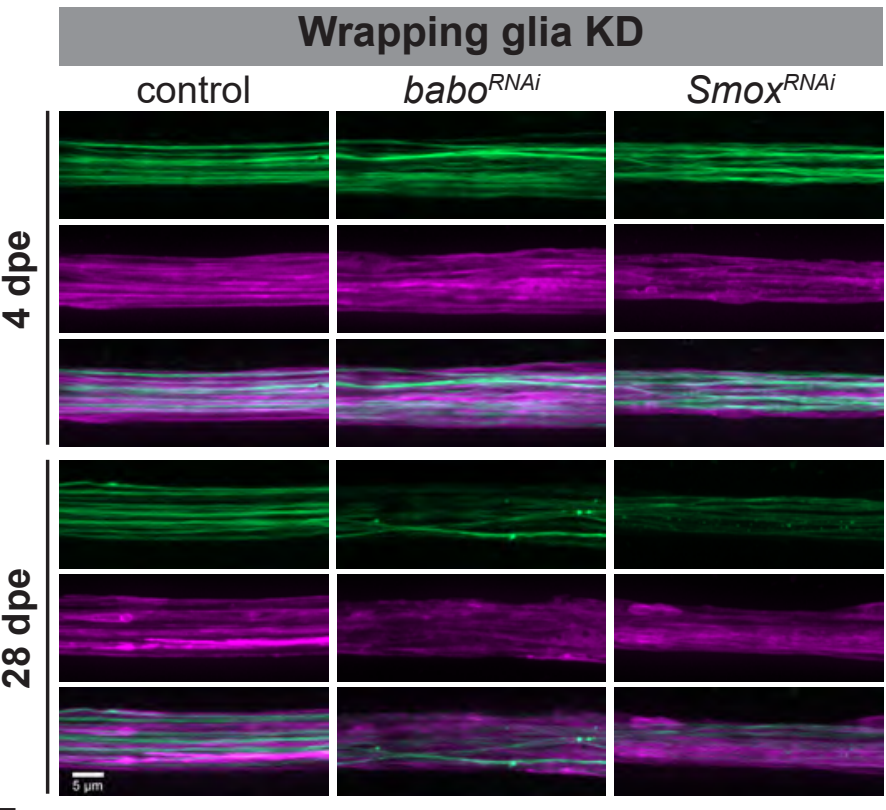

E

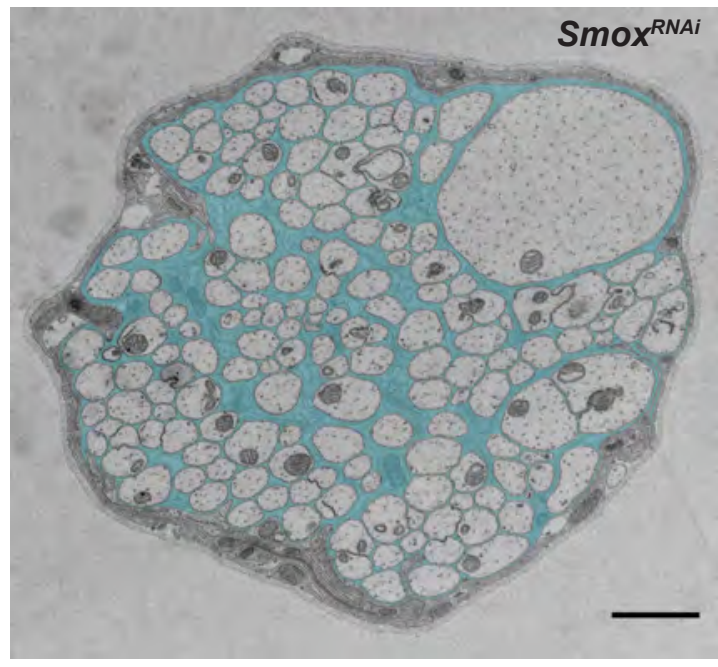

$\mathbf{F}$

Glial ensheathement (28 days)

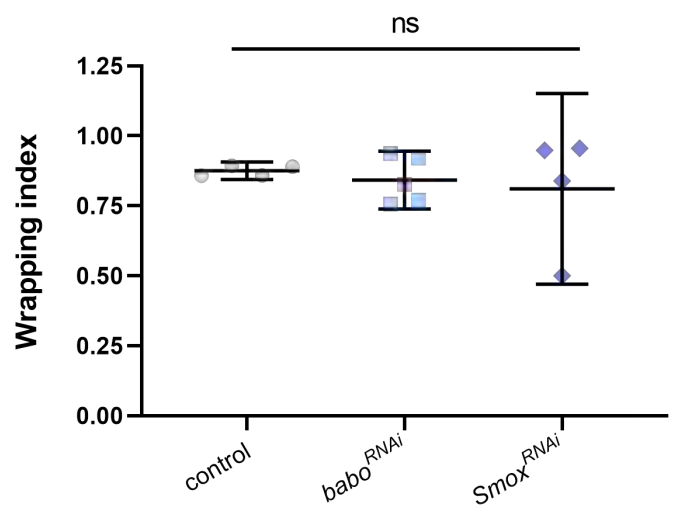


bioRxiv preprint doi: https://doi.org/10.1101/2021.09.02.458753; this version posted September 3, 2021. The copyright holder for this preprint (which was not certified by peer review) is the author/funder. All rights reserved. No reuse allowed without permission.

A

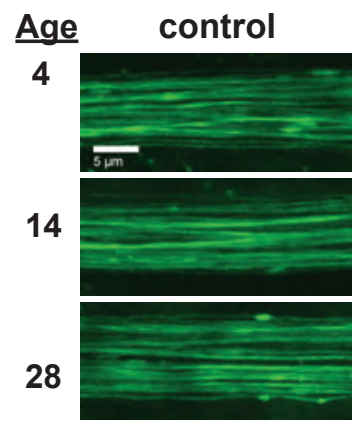

babo ${ }^{R N A i}$

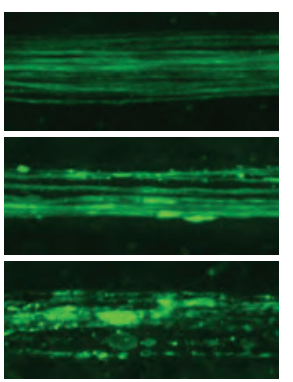

babo $^{R N A i}$
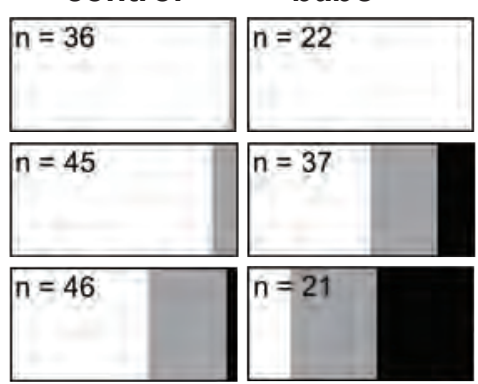

B
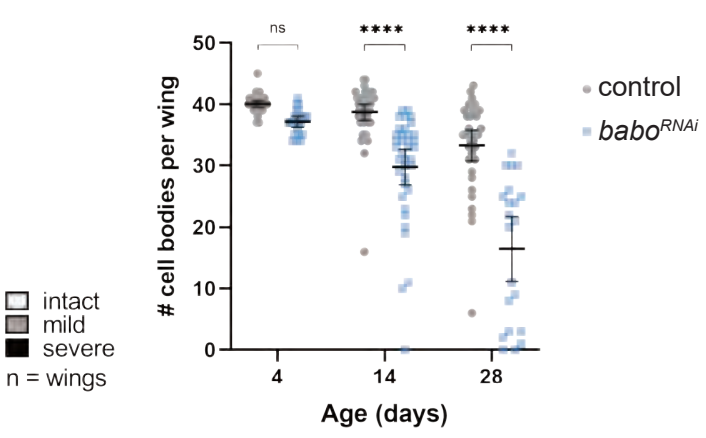

C

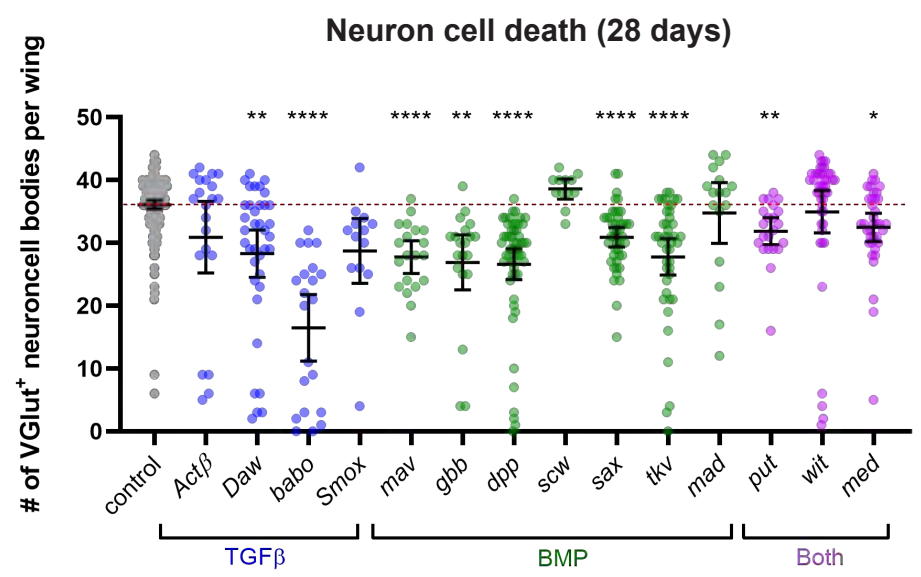

E

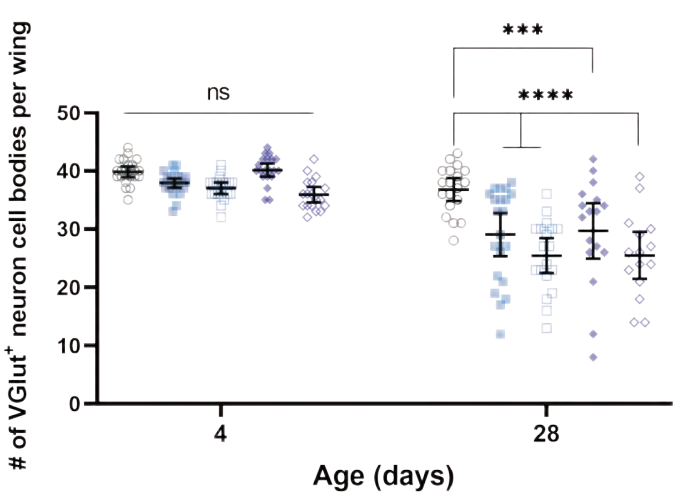

D

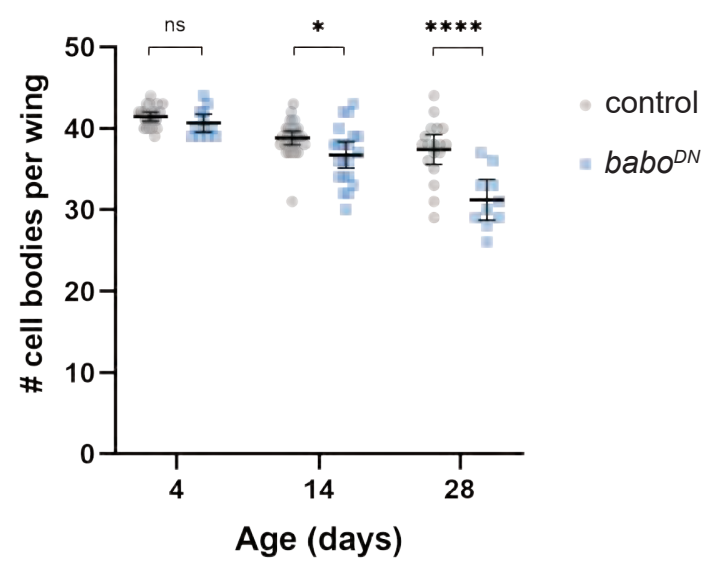

F

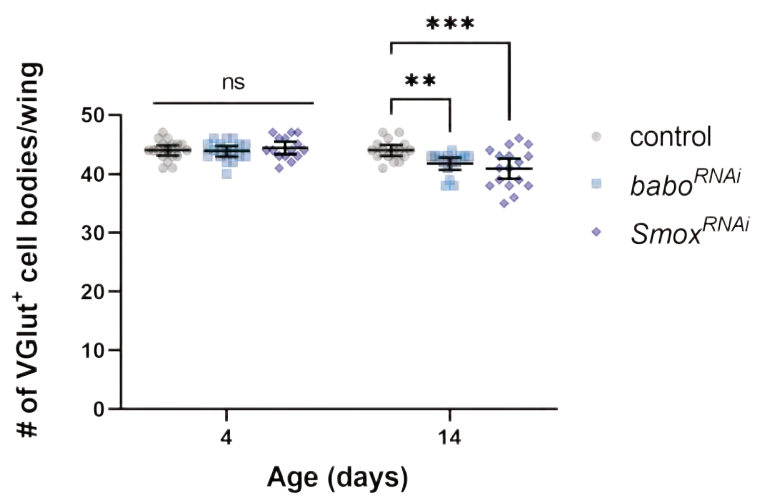


bioRxiv preprint doi: https://doi.org/10.1101/2021.09.02.458753; this version posted September 3, 2021. The copyright holder for this preprint (which was not certified by peer review) is the author/funder. All rights reserved. No reuse allowed without permission.

A
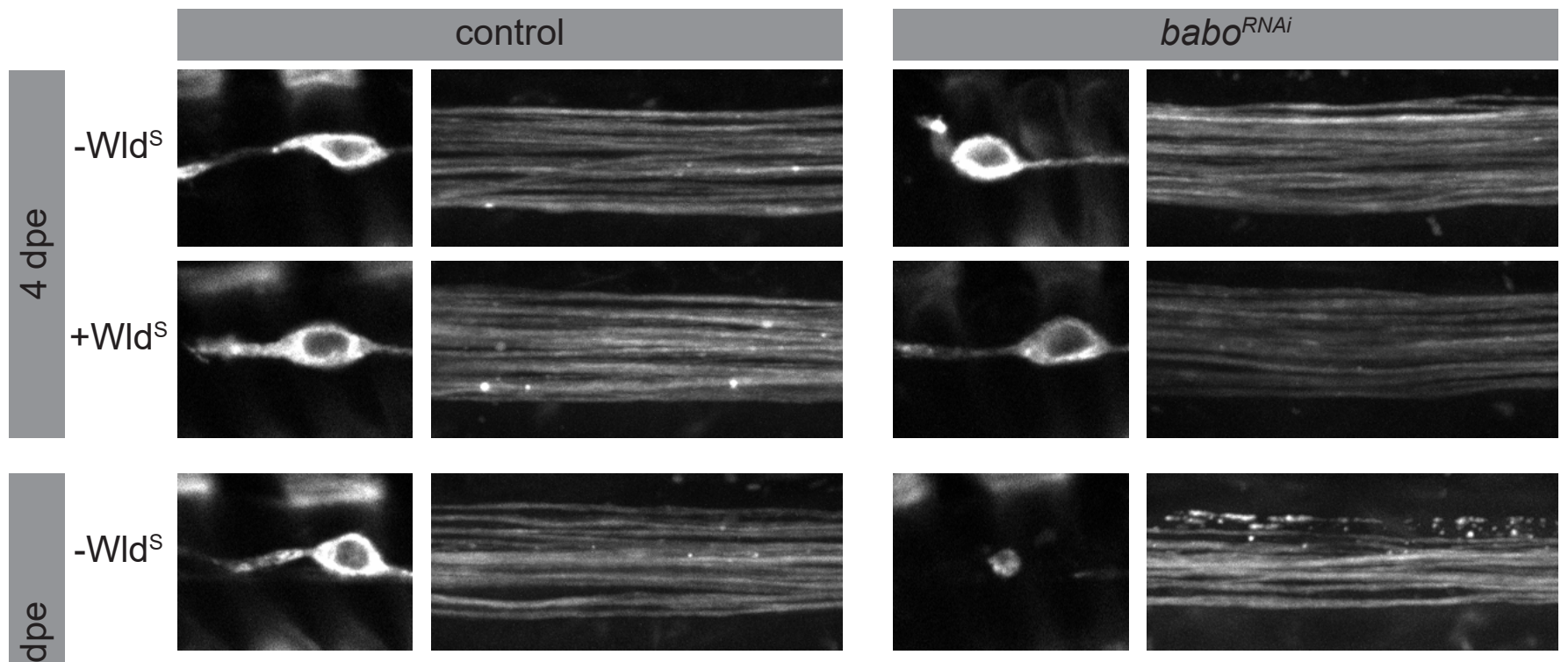

$\stackrel{\infty}{\sim}$

+ Wld ${ }^{\mathrm{s}}$
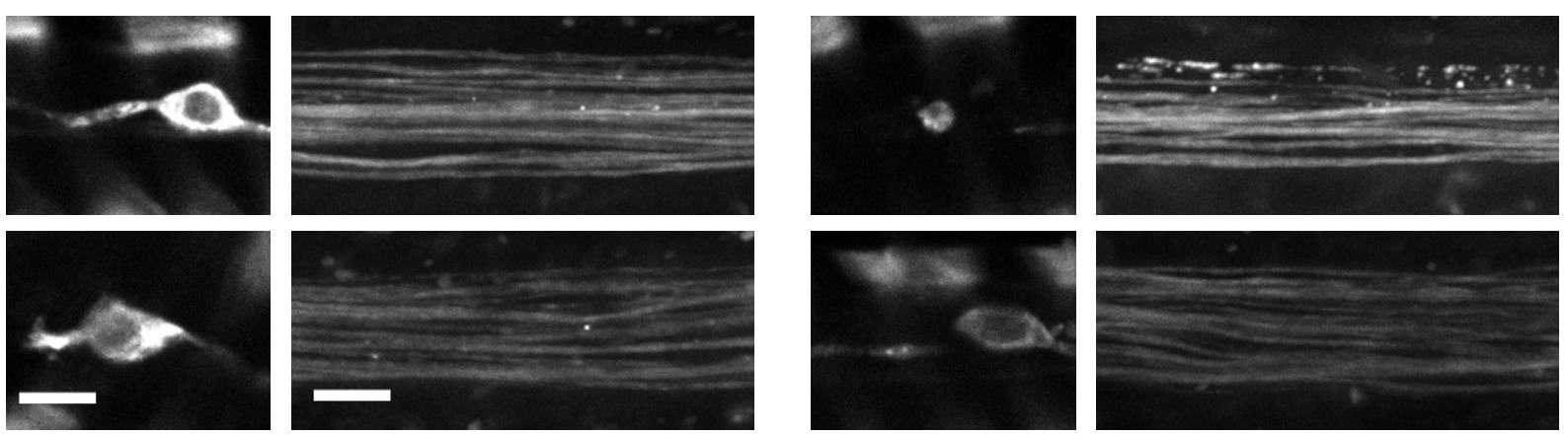

B

C

\section{Axon degeneration}

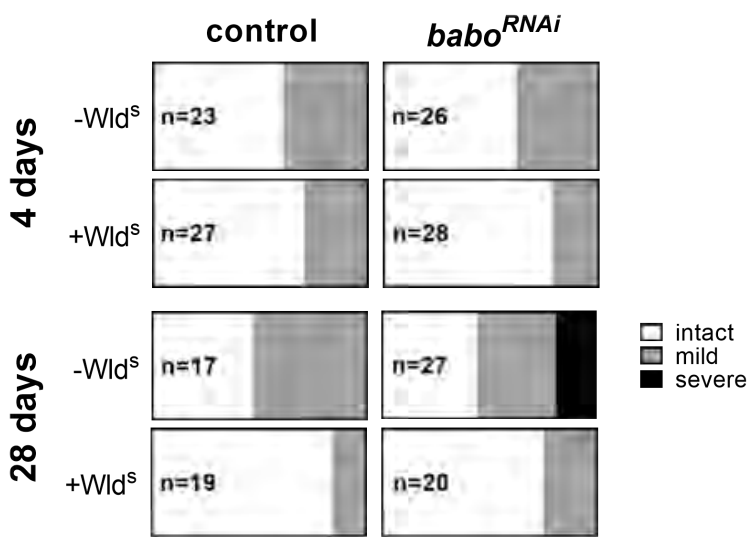

Neuron cell death

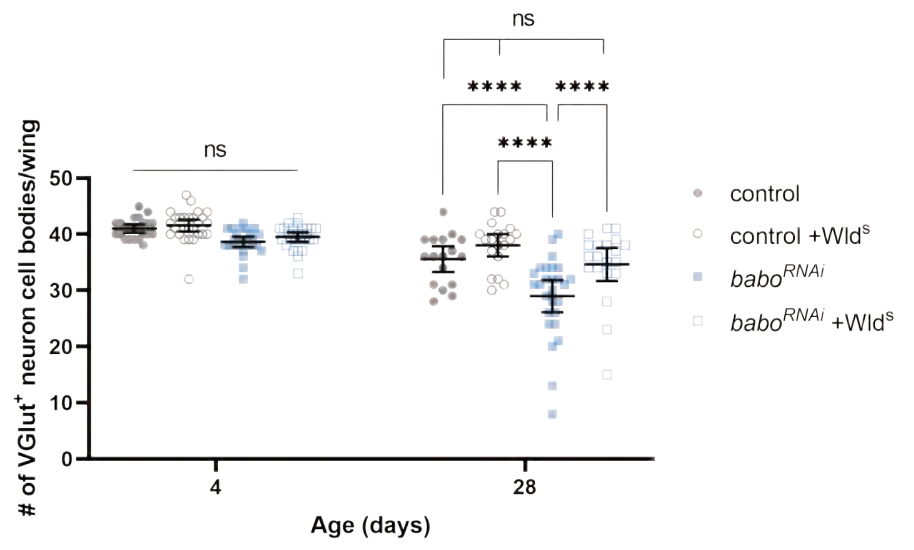


A
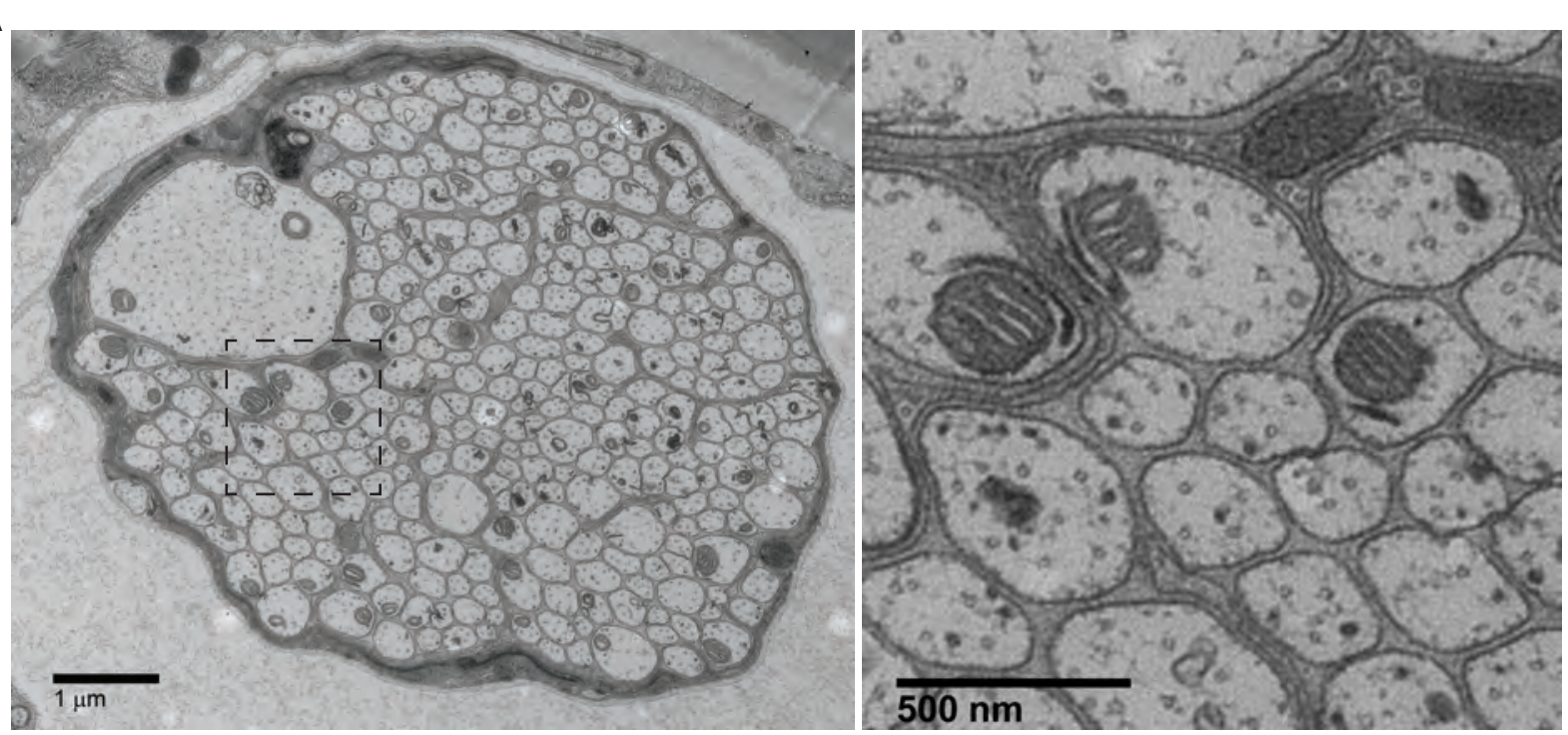

B

C
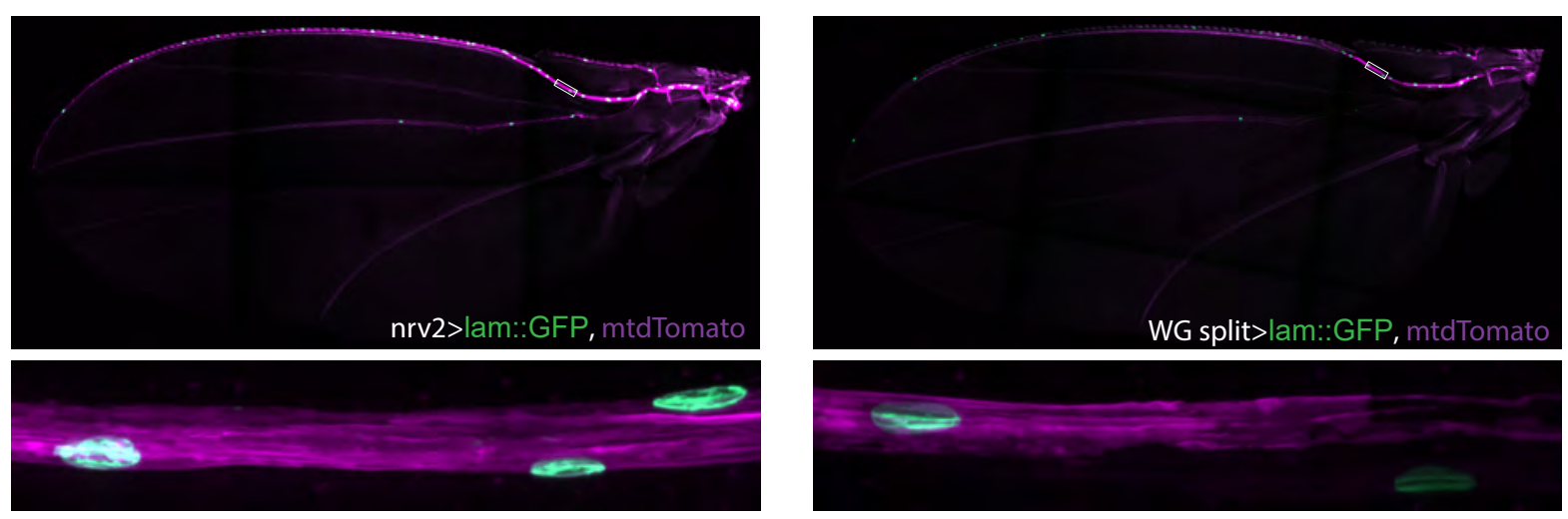

D

E

Wrapping glia nuclei
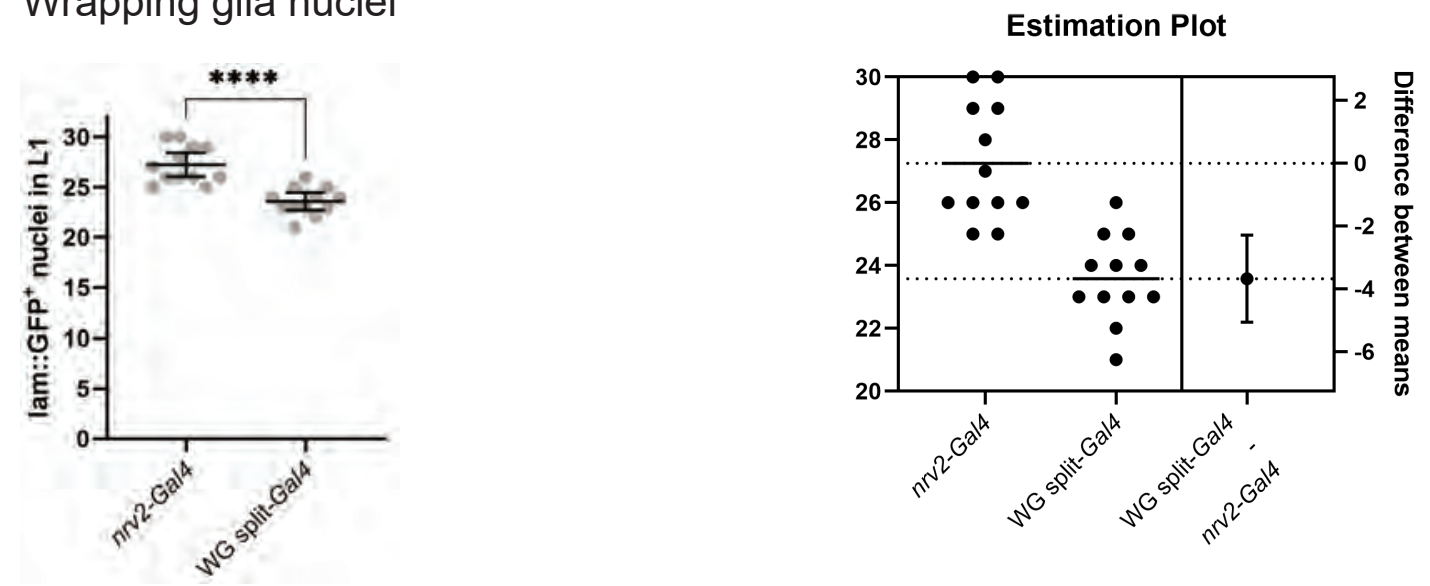

Supplemental Figure 1: A) Raw electron micrographs from Fig. 1. B) Expression pattern of $n r v 2$ in the adult wing. C) Expression pattern of the wrapping glia split-Gal4 in the adult wing. D) Quantification of the number of wrapping glia nuclei genetically labelled by nrv2 and the WG split-Gal4. E) Estimation plot of the difference in labelling efficiency of wrapping glia nuclei for each Gal4 construct within the wing. Statistics: Unpaired t test. ${ }^{* * * *}=p<0.0001$. 
A

intact
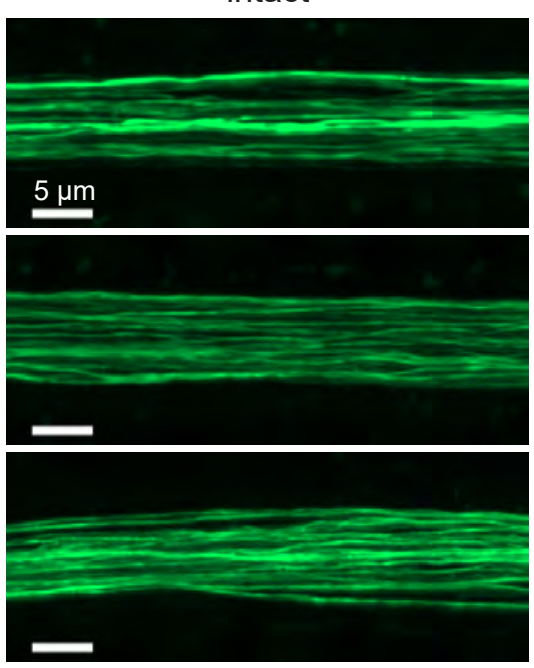

B

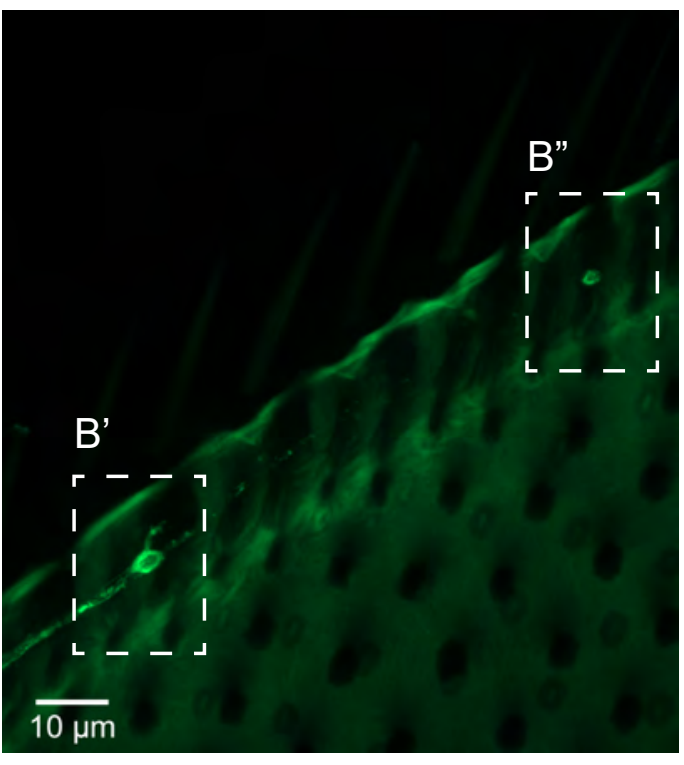

mild
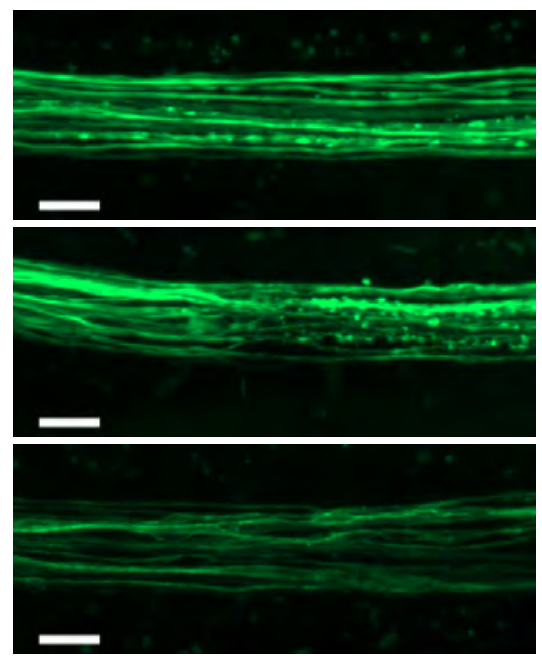

severe
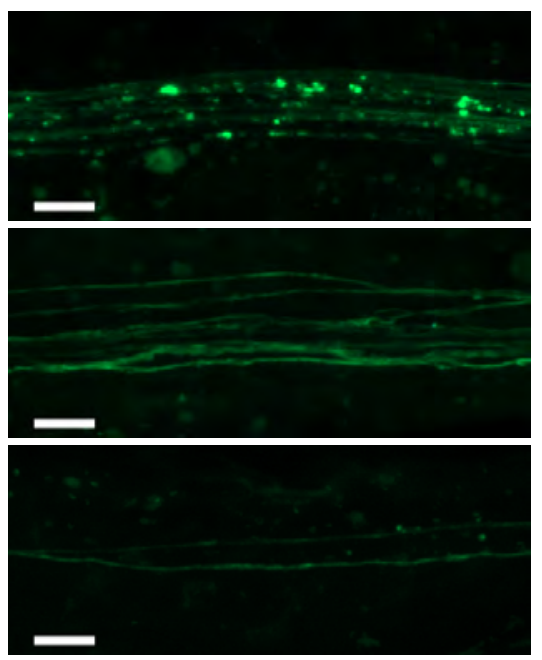
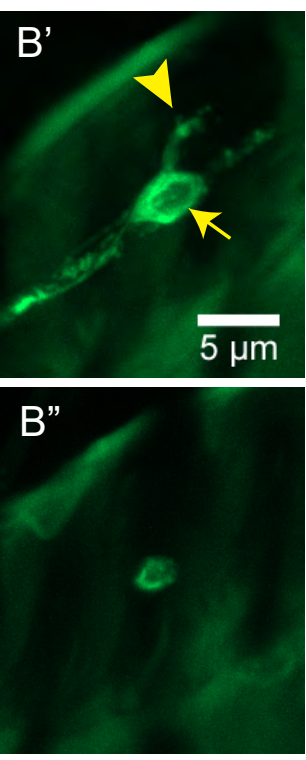

Supplemental Figure 2: A) Examples of orthogonal projections of axons classified as intact, mild, or severe degeneration phenotype. All examples are from wrapping glia-ablated nerves, only the GFP channel is shown. B) Examples of an intact ( $\left.B^{\prime}\right)$ and neuron corpse ( $\left.B^{\prime \prime}\right)$ within the same nerve. $\left.B^{\prime}\right)$ Arrow indicates the nucleus, arrowhead indicates dendrite. 

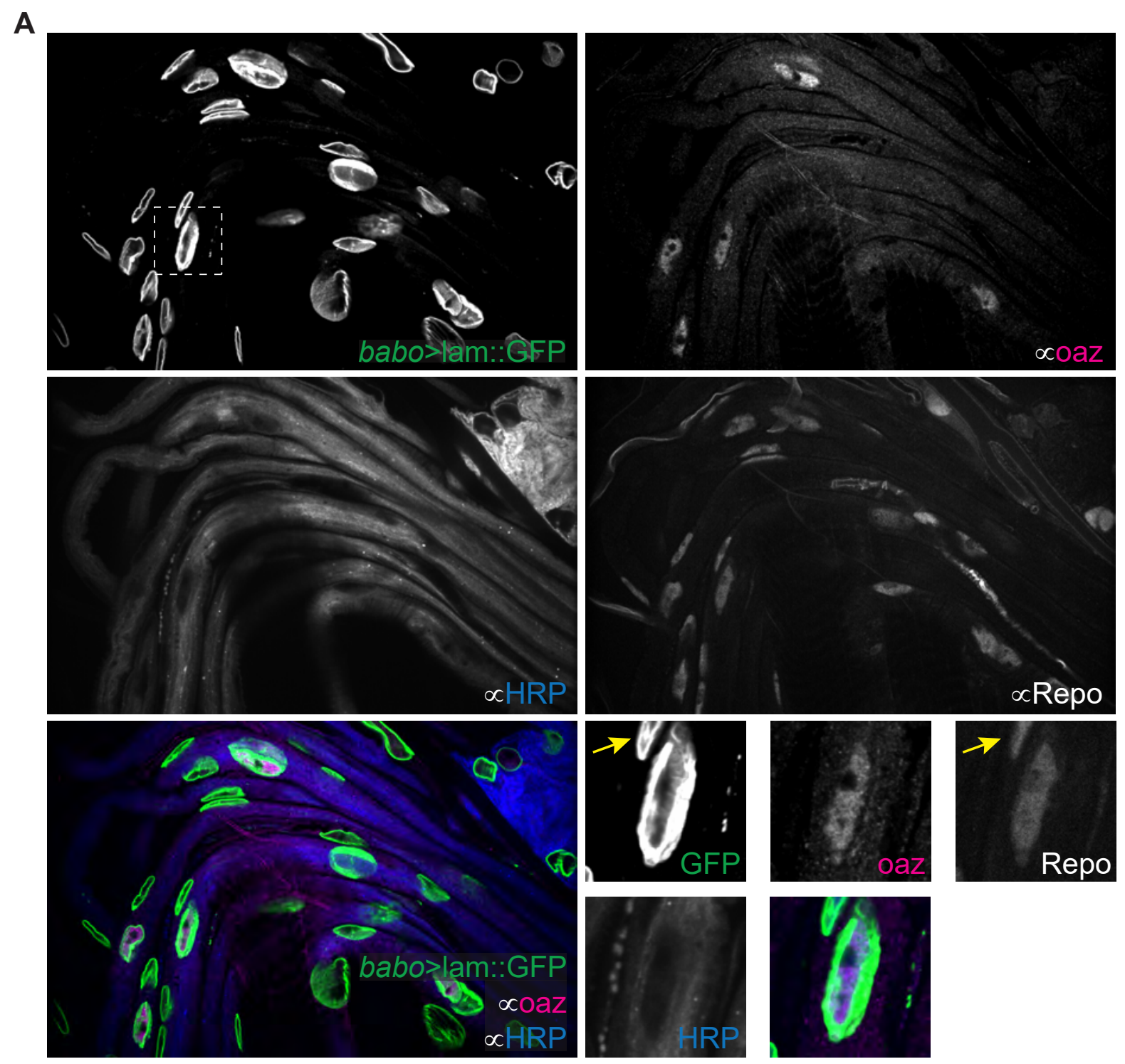

Supplemental figure 3: A) nerves from wandering $L 3$ animals expressing a nuclear membrane teathered GFP in babo+ cells. Nerves were co-stained for oaz (WG nuclei), HRP (neurons), and Repo (all glial nuclei). The region of interest indicated by the box is shown at higher magnification (bottom right panel). Yellow arrow indicates a GFP+/oaz/Repo+ nucleus. 


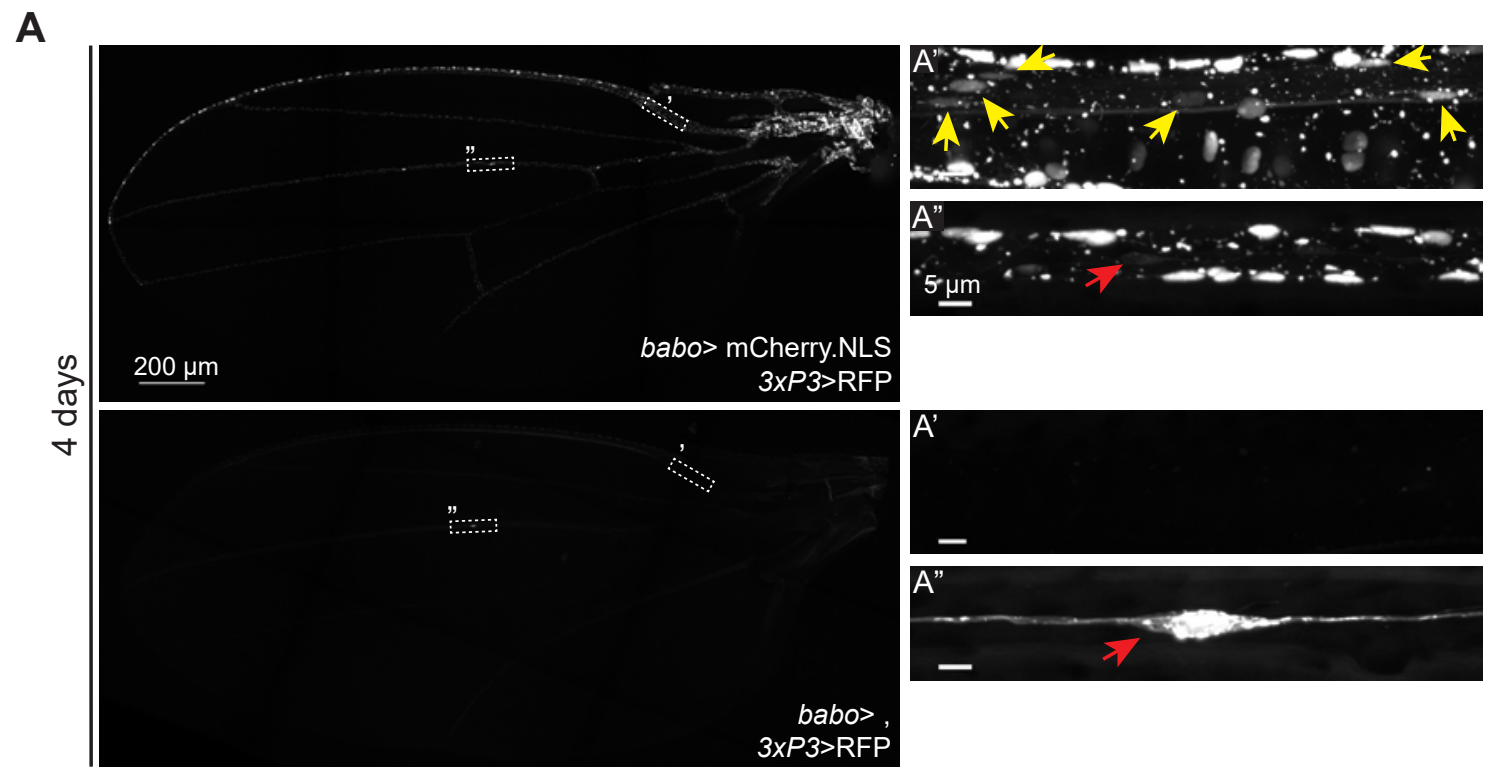

B

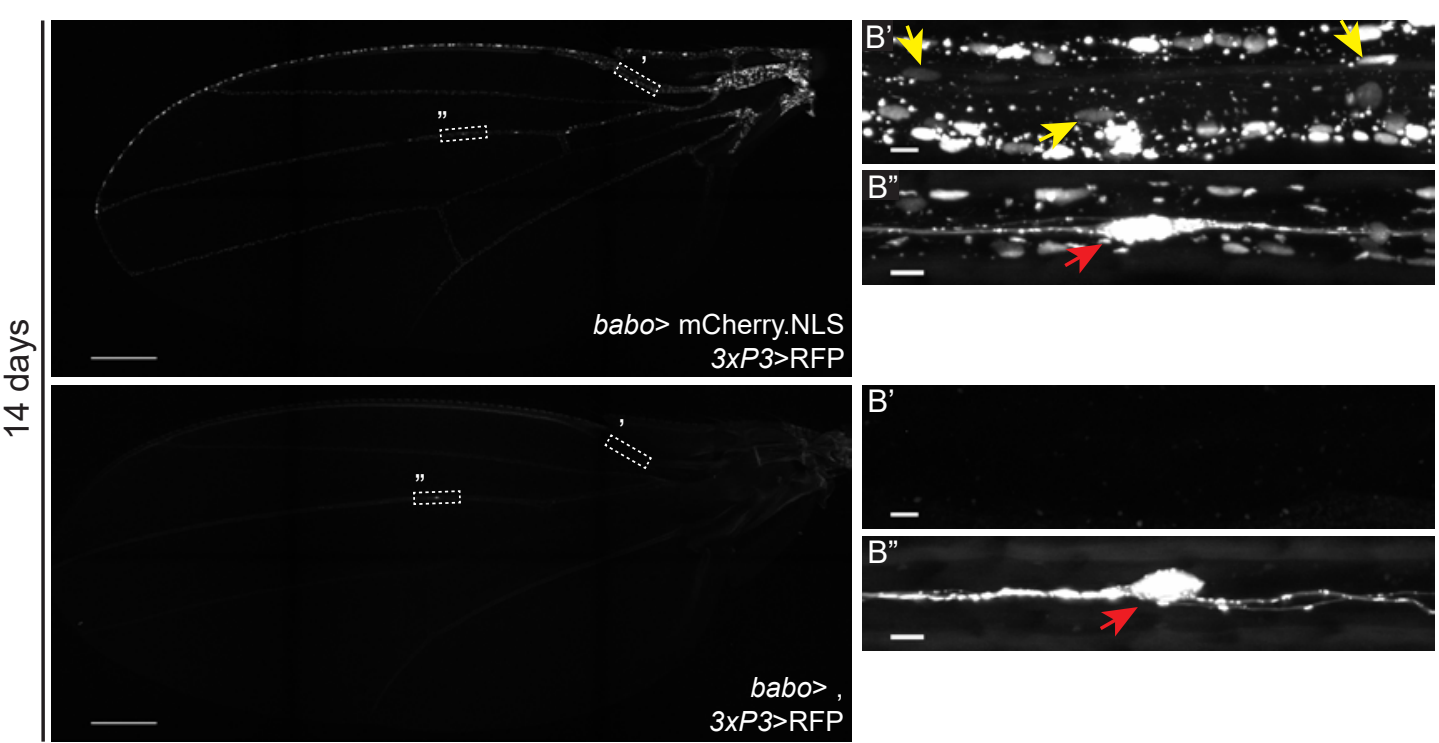

C

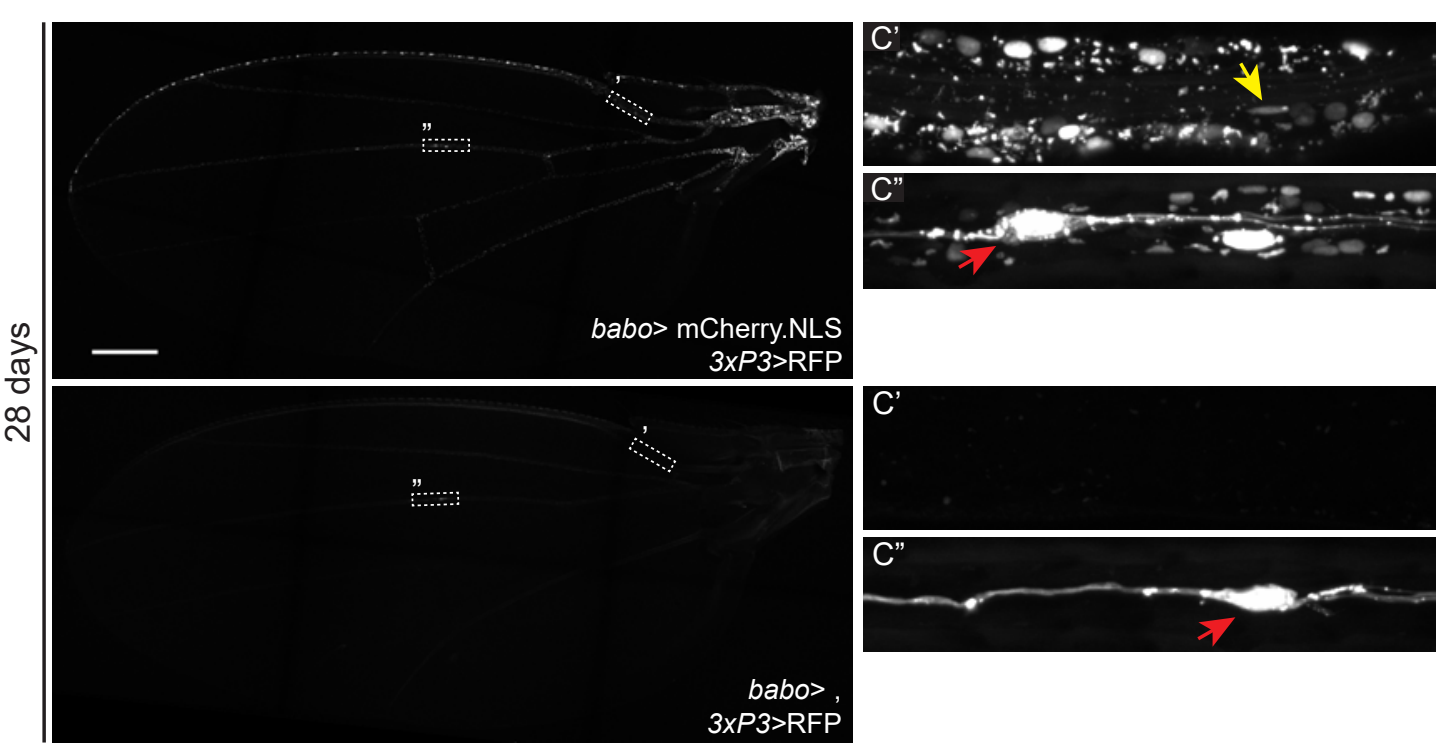

Supplemental Figure 4: babo-Gal4 expression is distinct from 3xP3>RFP expression. A-C) Expression patterns of babo-driven nuclear mCherry versus 3xP3-driven RFP within the wing at $4(\mathrm{~A}), 14(\mathrm{~B})$, and 28 (C) days. Nuclear mCherry is present throughout the wing (top) whereas RFP is expressed within one cell in the L3 vein (bottom). Corresponding ROls (' \& ") are shown to the right. At all timepoints mCherry ${ }^{+}$nuclei were present in the nerve region (yellow arrows) and was distinct from RFP ${ }^{+}$cells in the L3 vein (red arrows). 
A
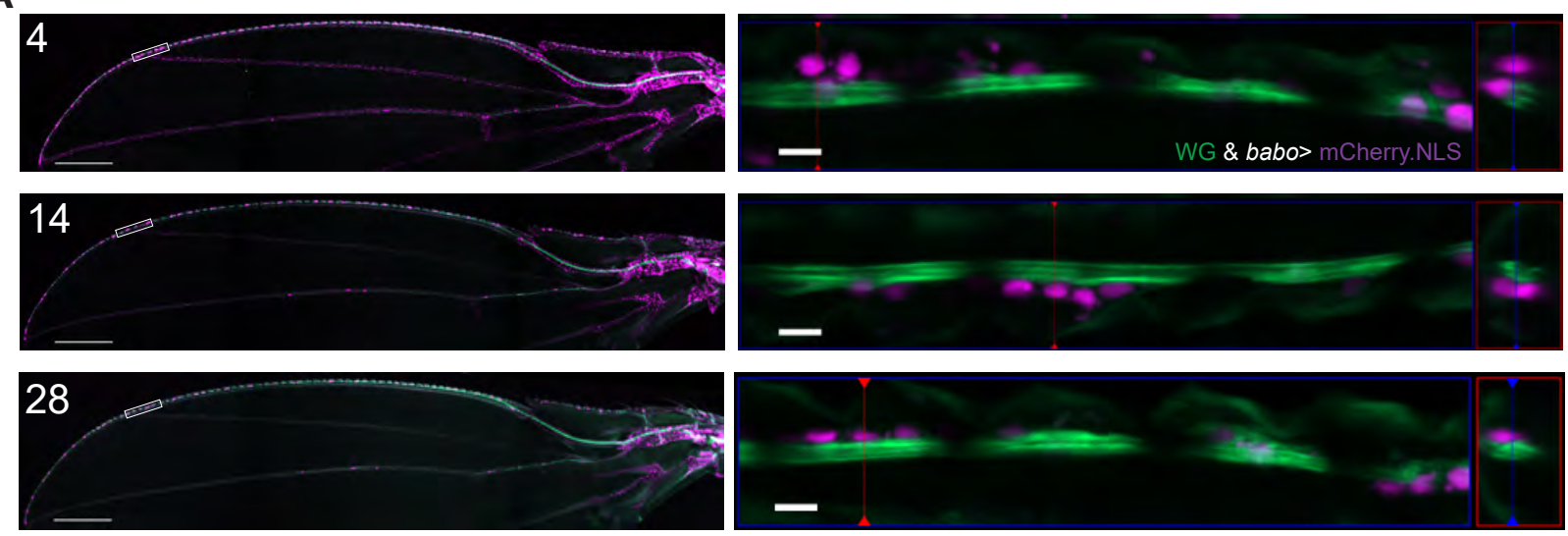

B
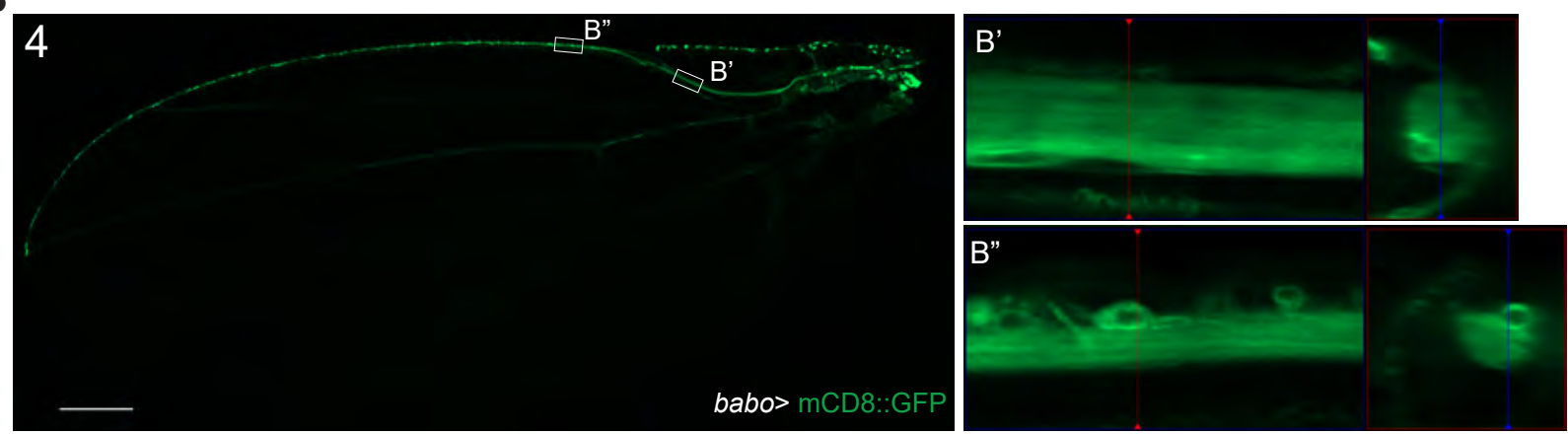

Supplemental Figure 5: A) babo nuclear reporter expression in the wing at 4 (top), 14 (middle), and 28 (bottom) days. ROls from boxes shown to the right. mCherry ${ }^{+}$ nuclei residing outside of WG GFP ${ }^{+}$membrane resemble neuronal nuclei. B) babo membrane reporter expression in the adult wing at 4 days. ROls from boxes shown to the right showing dense labeling throughout the nerve bundle (B') and GFP+ ${ }^{+}$cells that resemble neurons (B"). 
bioRxiv preprint doi: https://doi.org/10.1101/2021.09.02.458753; this version posted September 3, 2021. The copyright holder for this preprint (which was not certified by peer review) is the author/funder. All rights reserved. No reuse allowed without permission.

A

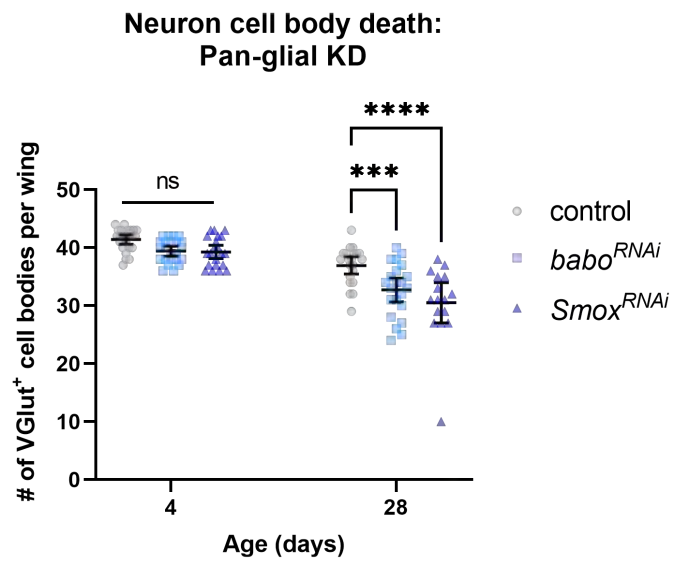

C

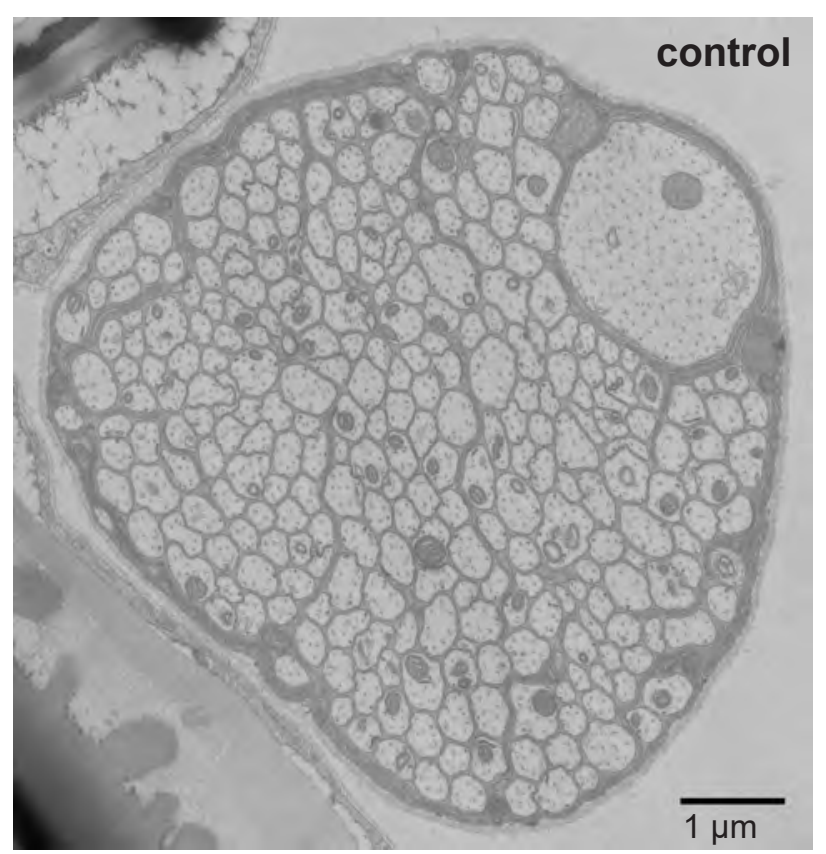

D

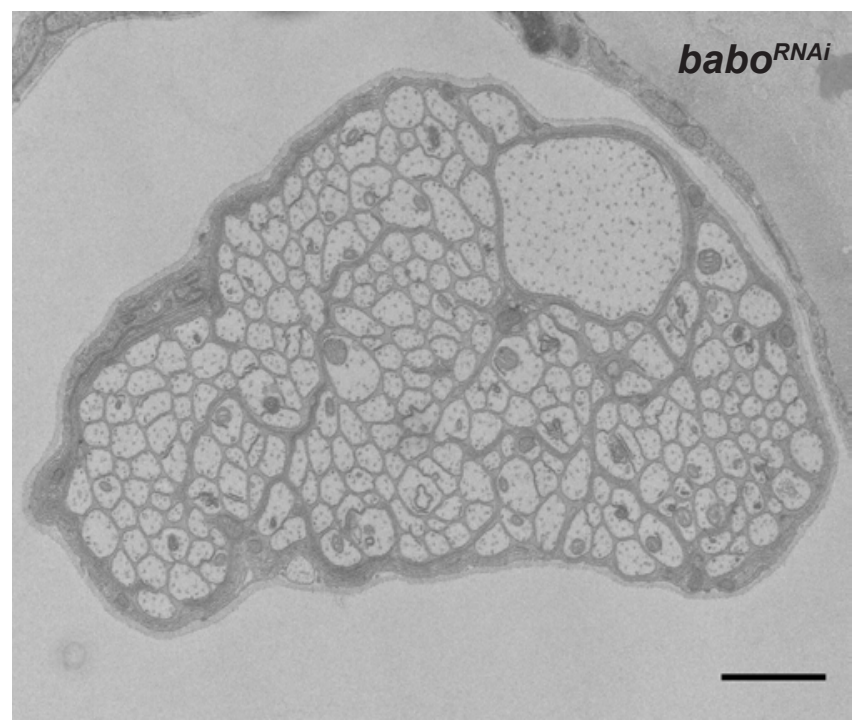

B

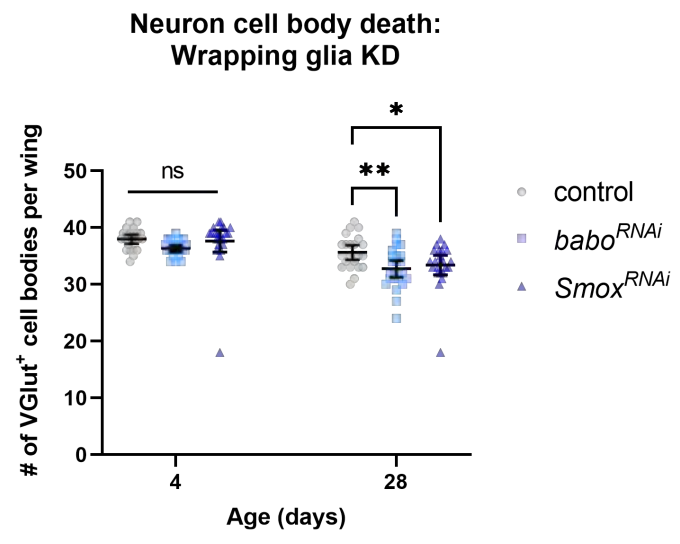

$\mathbf{E}$

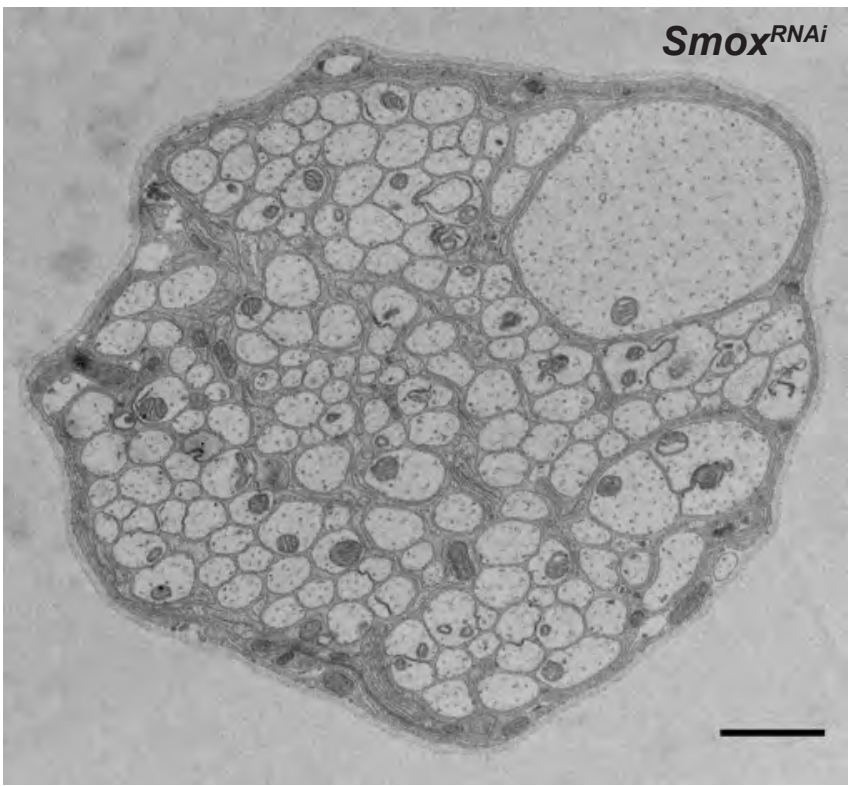

Supplemental Figure 6: Glial ensheathement is unchanged in TGF $\beta$ knockdown conditions. A) Quantification of the number of intact VGlut+ neuron cell bodies in the pan-glial (A) and wrapping glia (B) knockdown conditions. C-D) Raw electron microcgraphs corresponding to pseudo-colored micrographs in Figure 6. Control (C) babo ${ }^{R N A i}(\mathrm{D})$ $\operatorname{Smox}_{\text {RNAi }}(\mathrm{E})$ Scale bar $1 \mu \mathrm{m}$. 
A

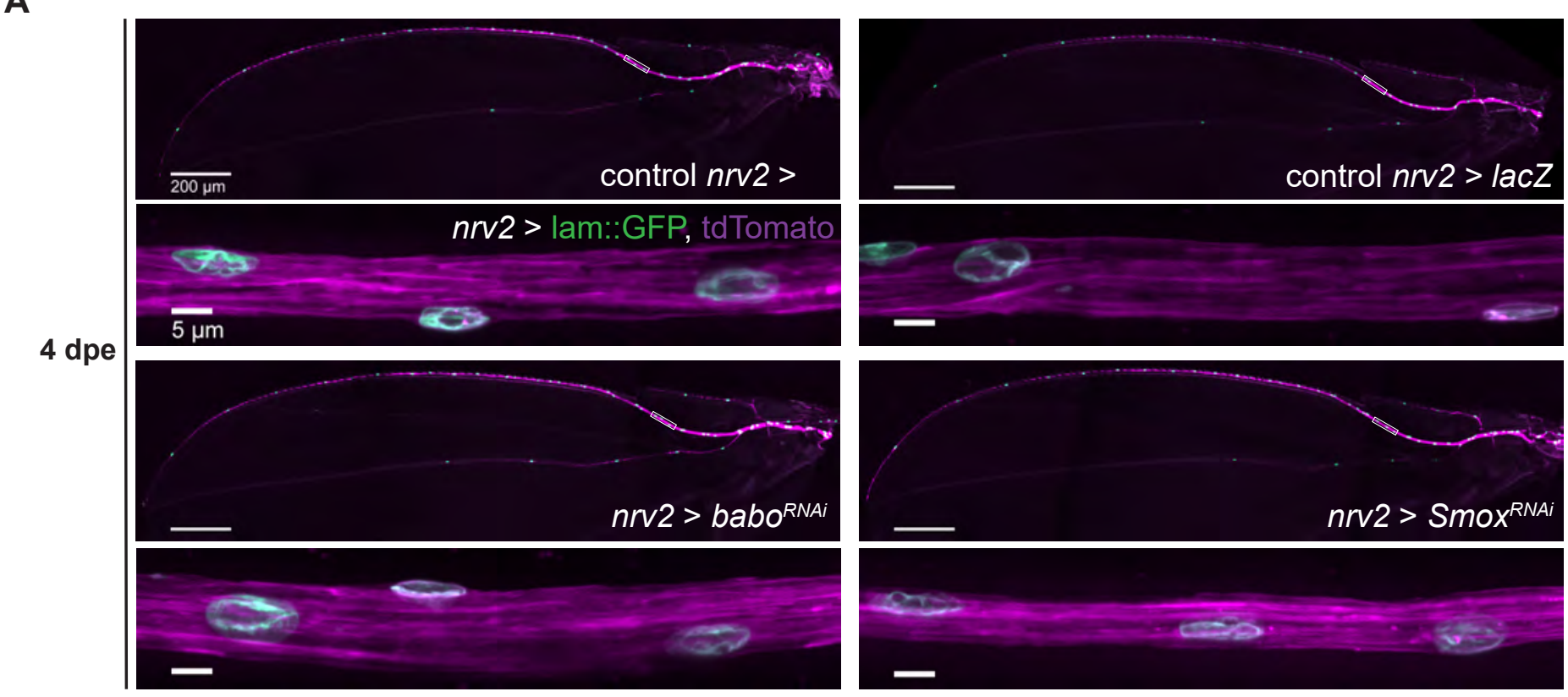

B
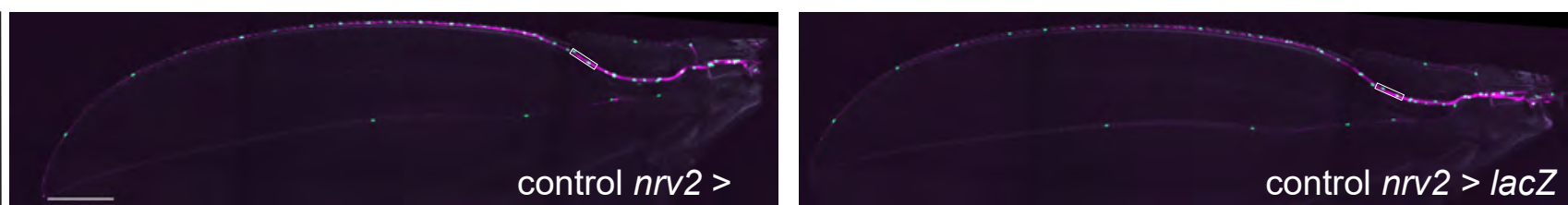

4 dpe
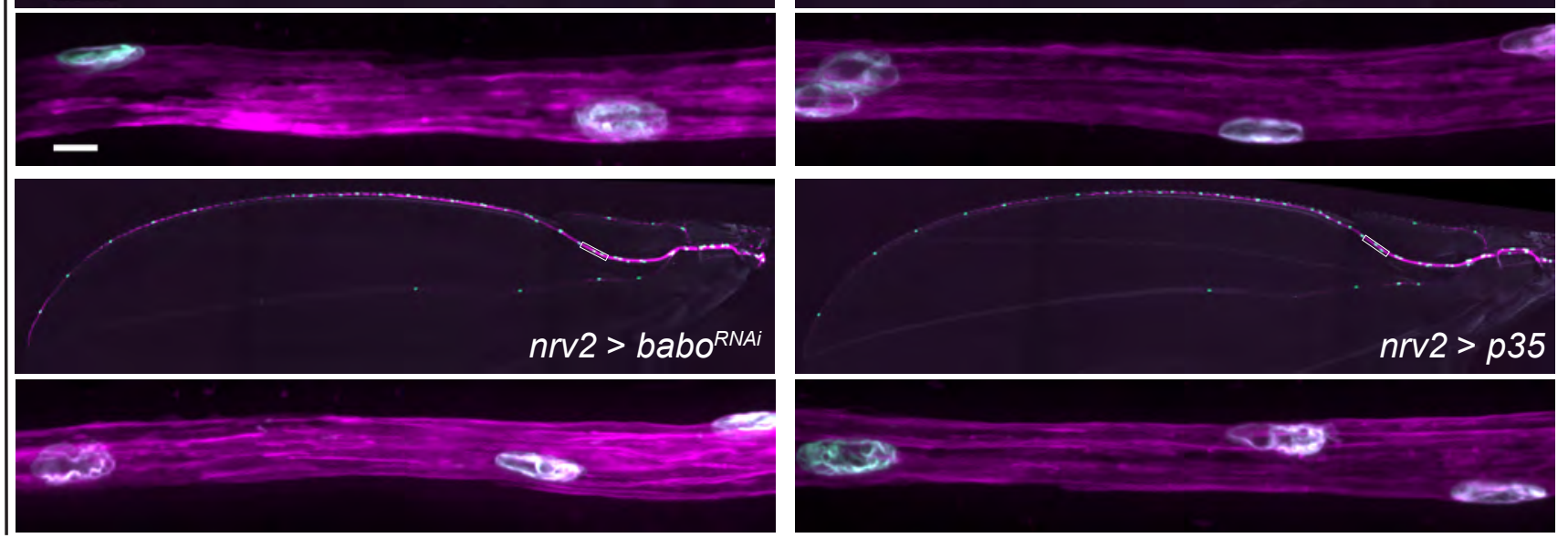

C

Wrapping glia nuclei

D
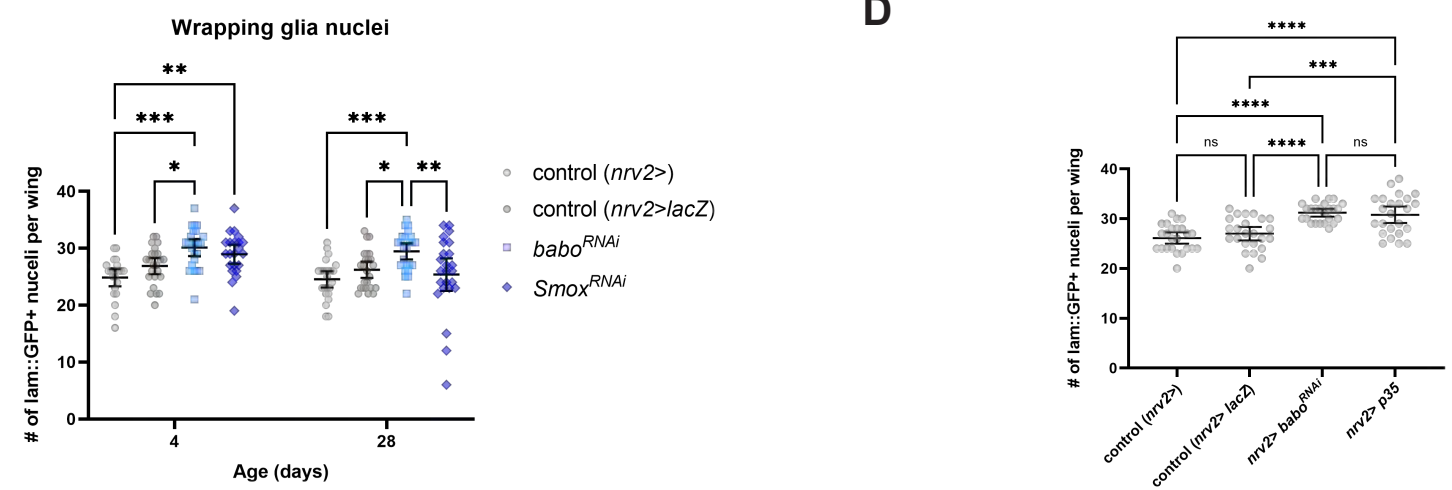

Supplemental Figure 7: Greater number of wrapping glia in TGF $\beta$ knockdown animals. A) Images from 4 dpe wings expressing nuclear GFP and membrane-tethered tdTomato in wrapping glia in control (n/a \& lacZ) and TGF $\beta$ knockdown animals. Higher magnification images from the boxed area are shown below each wing. B) Images from 4 dpe wings in control and $b a b o^{R N A i}$ or $p 35$ conditions. C) Quantification of the number of $\mathrm{GFP}^{+}$wrapping glia nuclei per wing. D) Quantification of the number of wrapping glia in control, babo ${ }^{R N A i}$, and $p 35$ conditions at 4 dpe. Graph: mean \pm 95\% Cl. Statistics: 2 -way ANOVA with Dunnett's (C) or Tukey's (D) multiple comparisons test. Significance: ${ }^{*}=p<0.05$, ${ }^{* *}=p<0.01,{ }^{* * *}=p<0.001,{ }^{* * * *}=p<0.0001$. 
A
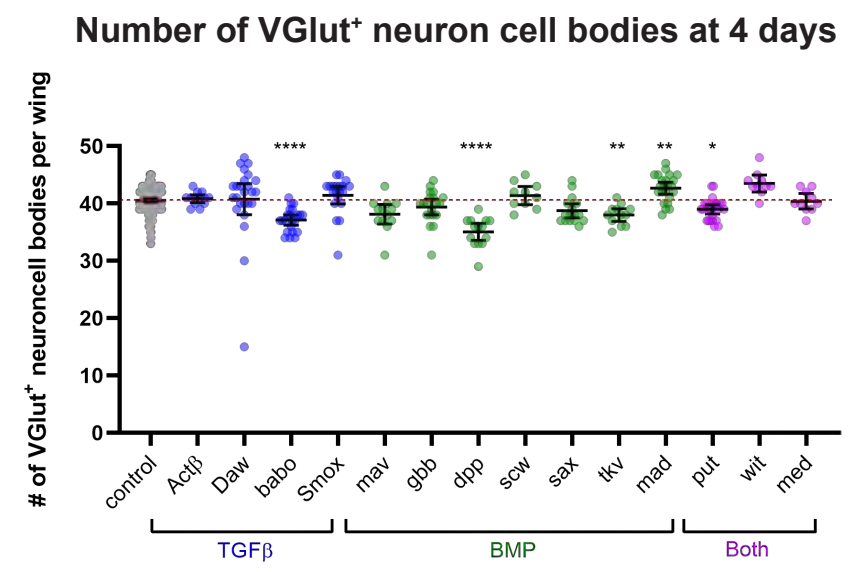

C

Animal death in TGF $\beta$ knockdown animals (28 days)

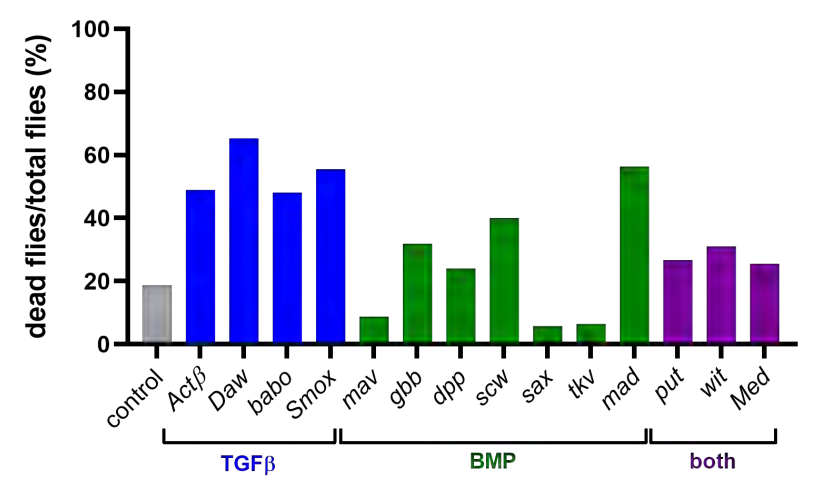

B

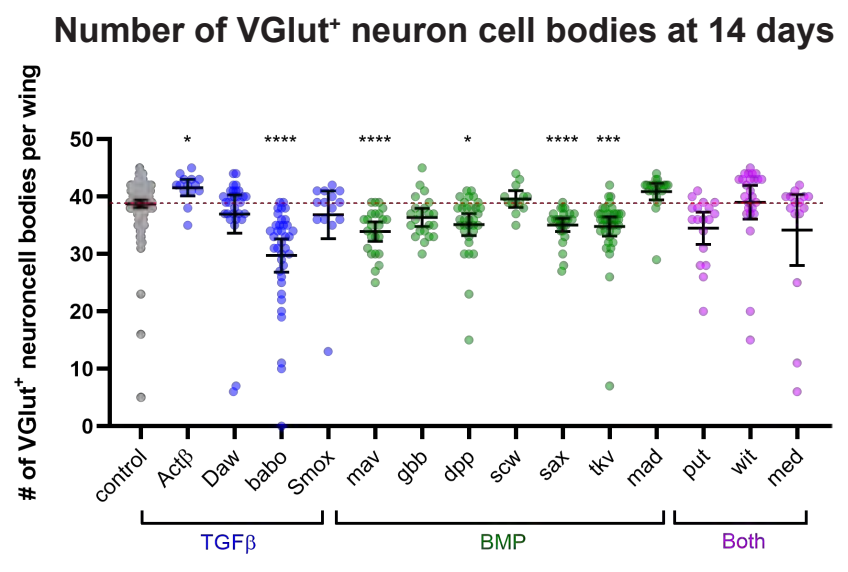

Supplemental Figure 8: A-B) Quantification of the number of intact VGlut neuron cell bodies present per wing of $4(\mathrm{~A})$ and $14(\mathrm{~B})$ dpe nerves in control and pan-glial RNAi conditions. Data are represented as mean \pm $95 \% \mathrm{Cl}$. C) The percent of flies that died by 28 days of age for each control and RNAi-mediated knockdown condition. 


\begin{tabular}{|c|c|c|}
\hline Gene & VDRC Stock \# & Name (blank = CG\# only) \\
\hline CG5847 & 3162 & zye \\
\hline CG8224 & 3825 & babo \\
\hline CG17941 & 4312 & ds \\
\hline CG10236 & 18873 & $\operatorname{Lan} A$ \\
\hline CG8745 & 23620 & CG8745 \\
\hline CG31058 & 25666 & CG31058 \\
\hline CG1724 & 30315 & CG1724 \\
\hline CG12832 & 30329 & Tsp42Eq \\
\hline CG13288 & 30363 & CG13288 \\
\hline CG6038 & 30379 & crim \\
\hline CG42698 & 30537 & pdm3 \\
\hline CG3764 & 34708 & CG3764 \\
\hline CG3389 & 36164 & Cad88C \\
\hline CG14226 & 36355 & dome \\
\hline CG10234 & 37123 & $\mathrm{Hs} 2 \mathrm{st}$ \\
\hline CG4698 & 38010 & Wnt4 \\
\hline CG8116 & 39218 & CG8116 \\
\hline CG42678 & 39474 & ReepA \\
\hline CG2813 & 44197 & cold \\
\hline CG3977 & 46757 & Ctr1A \\
\hline CG10617 & 47506 & Syt12 \\
\hline CG11010 & 47537 & Ent3 \\
\hline CG3936 & 100002 & $\mathrm{~N}$ \\
\hline CG3936 & 100002 & $\mathrm{~N}$ \\
\hline CG42674 & 100153 & CG42674 \\
\hline CG10952 & 100260 & eag \\
\hline CG34120 & 100384 & CG34120 \\
\hline CG10808 & 100789 & Syngr \\
\hline CG4608 & 101377 & $\mathrm{bnl}$ \\
\hline CG4356 & 101407 & mAChR-A \\
\hline CG8732 & 101504 & Acsl \\
\hline CG11147 & 101601 & CG11147 \\
\hline CG12844 & 102178 & Tsp42Eh \\
\hline CG33207 & 102240 & $p \times b$ \\
\hline CG30269 & 102266 & CG30269 \\
\hline CG11278 & 102432 & Syx13 \\
\hline CG18241 & 102642 & Toll-4 \\
\hline CG7075 & 102776 & $\mathrm{Ntl}$ \\
\hline CG14957 & 102784 & CG14957 \\
\hline CG10776 & 103808 & wit \\
\hline CG5550 & 103982 & CG5550 \\
\hline CG13948 & 104122 & Gr21a \\
\hline CG2310 & 104126 & CG2310 \\
\hline CG6927 & 104345 & CG6927 \\
\hline CG1148 & 104975 & Osi2 \\
\hline CG42248 & 105096 & CG43867 \\
\hline CG2467 & 105189 & pot \\
\hline
\end{tabular}




$\begin{array}{ll}\text { CG31695 } & 105303 \text { scw } \\ \text { CG42611 } & 105387 \text { mgl } \\ \text { CG30272 } & 105475 \text { CG30272 } \\ \text { CG6750 } & 105637 \text { CG6750 } \\ \text { CG13189 } & 105650 \text { CG13189 } \\ \text { CG5315 } & 106072 \text { CG5315 } \\ \text { CG4357 } & 106499 \text { Ncc69 } \\ \text { CG43225 } & 106616 \text { axo } \\ \text { CG33233 } & 106897 \text { CG33233 } \\ \text { CG16961 } & 107168 \text { Or33b } \\ \text { CG3074 } & 107301 \text { Swim } \\ \text { CG31284 } & 107423 \text { wtrw } \\ \text { CG11895 } & 107993 \text { stan } \\ \text { CG6293 } & 108619 \text { CG6293 } \\ \text { CG43128 } & 108861 \text { Shab } \\ \text { CG1448 } & 108913 \text { Inx3 } \\ \text { CG10978 } & 108991 \text { jagn } \\ \text { CG10781 } & 109143 \text { ng1 } \\ \text { CG11621 } & 109582 \text { Pi3K68D } \\ \text { CG7638 } & 109665 \text { CG7638 } \\ \text { CG11440 } & 109898 \text { laza } \\ \text { CG8583 } & 110331 \text { sec63 } \\ \text { CG43444 } & 110549 \text { Tet } \\ & \end{array}$




\begin{tabular}{|c|c|c|}
\hline Gene & VDRC Stock \# & Name (blank = CG\# only) \\
\hline CG2216 & 102406 & Fer1 $\mathrm{HCH}$ \\
\hline CG6906 & 108184 & $\mathrm{CAH} 2$ \\
\hline CG6827 & 108128 & Nrx-IV \\
\hline CG1560 & 103704 & mys \\
\hline CG10620 & 5236 & Tsf2 \\
\hline CG9637 & 9073 & Task6 \\
\hline CG9364 & 30730 & Treh \\
\hline CG4797 & 10598 & CG4797 \\
\hline CG9053 & 101312 & opm \\
\hline CG7708 & 101485 & CG7708 \\
\hline CG5484 & 101400 & CG5484 \\
\hline CG18000 & 101559 & sw \\
\hline CG1903 & 101404 & sno \\
\hline CG3500 & 101319 & CG3500 \\
\hline CG12525 & 100644 & $\operatorname{lr} 67 a$ \\
\hline CG14958 & 100844 & CG14958 \\
\hline CG12763 & 104287 & Dpt \\
\hline CG9664 & 42467 & CG9664 \\
\hline CG5802 & 103753 & CG5802 \\
\hline CG2893 & 40988 & CG2893 \\
\hline CG14779 & 50306 & pck \\
\hline CG1298 & 3962 & kune \\
\hline CG3161 & 104490 & Vha16-1 \\
\hline CG14026 & 105834 & tkv \\
\hline CG10789 & 104038 & ng4 \\
\hline CG13626 & 105113 & Syx18 \\
\hline CG10275 & 106680 & kon \\
\hline CG34412 & 105732 & tlk \\
\hline CG8121 & 105806 & CG8121 \\
\hline CG15658 & 102333 & Lapsyn \\
\hline CG4590 & 102194 & $\ln \times 2$ \\
\hline CG8795 & 100927 & CG8795 \\
\hline CG7713 & 102223 & CG7713 \\
\hline CG9128 & 37217 & Sac1 \\
\hline CG11395 & 16696 & CG11395 \\
\hline CG9702 & 6860 & CG9702 \\
\hline CG5803 & 26850 & Fas3 \\
\hline CG3702 & 7296 & CG3702 \\
\hline CG11098 & 21594 & Tango1 \\
\hline CG6668 & 6719 & atl \\
\hline CG9753 & 1385 & AdoR \\
\hline CG8422 & 110708 & Dh44-R1 \\
\hline CG6230 & 106920 & CG6230 \\
\hline CG4109 & 107014 & Syx8 \\
\hline CG10693 & 104421 & slo \\
\hline CG42321 & 107000 & CG42321 \\
\hline CG8222 & 105353 & Pvr \\
\hline
\end{tabular}




\begin{tabular}{|c|c|c|}
\hline CG12369 & 107450 & Lac \\
\hline CG7586 & 100197 & Mcr \\
\hline CG31201 & 49547 & GluRIIE \\
\hline CG7000 & 104210 & Snmp1 \\
\hline CG5876 & 103641 & heix \\
\hline CG14239 & 109855 & CG14239 \\
\hline CG3725 & 107446 & Сa-P60A \\
\hline CG13333 & 19555 & link \\
\hline CG13393 & 33166 & $\mathrm{I}(2) \mathrm{k} 12914$ \\
\hline CG6817 & 10102 & foi \\
\hline CG14181 & 42549 & Use1 \\
\hline CG4692 & 13324 & CG4692 \\
\hline CG4894 & 51491 & Ca-alpha1D \\
\hline CG13078 & 100234 & CG13078 \\
\hline CG10624 & 44929 & $\sin u$ \\
\hline CG9261 & 2660 & nrv2 \\
\hline CG13743 & 40975 & CG13743 \\
\hline CG5081 & 107264 & Syx7 \\
\hline CG10449 & 100095 & Catsup \\
\hline CG31116 & 110394 & ClC-a \\
\hline CG31004 & 108297 & CG31004 \\
\hline CG7398 & 105181 & Trn \\
\hline CG4775 & 108341 & Tango14 \\
\hline CG8034 & 106660 & CG8034 \\
\hline CG4214 & 108928 & Syx5 \\
\hline CG6901 & 104673 & CG6901 \\
\hline CG11325 & 109300 & GRHR \\
\hline CG3171 & 108952 & Tre1 \\
\hline CG8271 & 109464 & SIn \\
\hline CG4099 & 110014 & $\mathrm{Sr}-\mathrm{Cl}$ \\
\hline CG3954 & 108352 & csw \\
\hline CG7654 & 107186 & Tom 20 \\
\hline CG4166 & 45775 & not \\
\hline CG33162 & 110760 & SrpRbeta \\
\hline CG31634 & 109633 & Oatp26F \\
\hline CG17664 & 101847 & CG17664 \\
\hline CG4147 & 101766 & Hsc $70-3$ \\
\hline CG9539 & 109660 & Sec61alpha \\
\hline CG7223 & 27180 & htl \\
\hline CG15304 & 107937 & Neb-cGP \\
\hline CG1732 & 13359 & CG1732 \\
\hline CG18085 & 49925 & sev \\
\hline CG1560 & 103704 & CG1560 \\
\hline CG15658 & 102333 & lapsyn \\
\hline CG5802 & 103753 & CG5802 \\
\hline CG17117 & 12763 & CG17117 \\
\hline CG17117 & 100630 & $\mathrm{HTH}$ \\
\hline CG15658 & 3040 & CG15658 \\
\hline
\end{tabular}




\begin{tabular}{|c|c|c|}
\hline CG8725 & 103803 & CSN4 \\
\hline CG2845 & 20909 & Raf \\
\hline CG31317 & 21317 & stumps \\
\hline CG5838 & 22209 & Dref \\
\hline CG5838 & 22210 & Dref \\
\hline CG33110 & 29689 & CG33110 \\
\hline CG31366 & 41749 & Hsp70Aa \\
\hline CG6058 & 101339 & Ald1 \\
\hline CG4501 & 105635 & bgm \\
\hline CG9985 & 6229 & sktl \\
\hline CG2145 & 14874 & CG2145 \\
\hline CG31976 & 100198 & ovm \\
\hline CG33189 & 100386 & CG33189 \\
\hline CG1856 & 101980 & $\mathrm{ttk}$ \\
\hline CG4500 & 106260 & hll \\
\hline CG10374 & 106891 & Lsd-1 \\
\hline CG8628 & 110103 & Acbp3 \\
\hline CG1817 & 8010 & Ptp10D \\
\hline CG3246 & 15580 & CG3246 \\
\hline CG8745 & 23620 & CG8745 \\
\hline CG17838 & 33012 & Syp \\
\hline CG14224 & 47449 & Ubqn \\
\hline CG11901 & 100693 & eEF1gamma \\
\hline CG14792 & 101495 & sta \\
\hline CG44838 & 101978 & CG44838 \\
\hline CG3638 & 102444 & CG3638 \\
\hline CG4294 & 102636 & CG4294 \\
\hline CG15532 & 104322 & hdc \\
\hline CG18389 & 104390 & Eip93F \\
\hline CG8280 & 104502 & eEF1alpha1 \\
\hline CG31240 & 10424 & repo \\
\hline CG2893 & 40987 & zyd \\
\hline CG2979 & 50156 & Yp2 \\
\hline CG8367 & 102054 & $\mathrm{cg}$ \\
\hline CG2163 & 106466 & Pabp2 \\
\hline CG16884 & 108690 & Vajk3 \\
\hline CG45186 & 108962 & Svil \\
\hline CG5320 & 109499 & Gdh \\
\hline CG5651 & 109630 & pix \\
\hline CG5541 & 106909 & CG5541 \\
\hline CG5670 & 100619 & Atpalpha \\
\hline CG12210 & 102922 & Syb \\
\hline CG9138 & 1050 & uif \\
\hline CG1517 & 3306 & na \\
\hline CG31136 & 33112 & Syx1A \\
\hline CG5670 & 12330 & Atpalpha \\
\hline
\end{tabular}




\begin{tabular}{|c|c|c|c|}
\hline Gene & VDRC Stock \# & Name (blank = CG\# only) & Consensus $(0=0 k, 1=$ hit, $2=$ lethal $)$ \\
\hline CG8666 & 107776 & Tsp39D & 0 \\
\hline CG4096 & 108353 & CG4096 & 0 \\
\hline CG42543 & 38188 & $\mathrm{mp}$ & 0 \\
\hline CG10251 & 104763 & prt & 0 \\
\hline CG7727 & 108312 & Appl & 0 \\
\hline CG3790 & 108223 & CG3790 & 0 \\
\hline CG4626 & 102339 & $\mathrm{fz4}$ & 0 \\
\hline CG42275 & 107830 & alpha-Man-I & 0 \\
\hline CG3159 & 104371 & Eaat2 & 0 \\
\hline CG42248 & 102954 & CG42248 & 0 \\
\hline CG3665 & 36350 & Fas2 & 0 \\
\hline CG11140 & 107110 & Aldh-III & 0 \\
\hline CG42601 & 109690 & Cad86C & 0 \\
\hline CG2679 & 107822 & gol & 0 \\
\hline CG12251 & 109314 & $\mathrm{AQP}$ & 0 \\
\hline CG33116 & 107155 & CG33116 & 0 \\
\hline CG17943 & 110488 & comm & 0 \\
\hline CG14936 & 104079 & Tsp33B & 0 \\
\hline CG12443 & 102441 & ths & 0 \\
\hline CG7147 & 107036 & kuz & 0 \\
\hline CG4999 & 104430 & Tsp66E & 0 \\
\hline CG3747 & 109401 & Eaat1 & 0 \\
\hline CG6120 & 101411 & Tsp96F & 0 \\
\hline CG7100 & 101642 & CadN & 0 \\
\hline CG15138 & 109015 & beat-IIIc & 0 \\
\hline CG2216 & 102406 & Fer1HCH & 2 \\
\hline CG8250 & 107083 & Alk & 0 \\
\hline CG11210 & 7363 & CG11210 & 0 \\
\hline CG3305 & 7309 & Lamp1 & 0 \\
\hline CG8681 & 105870 & clumsy & 0 \\
\hline CG10776 & 103808 & wit & 1 \\
\hline CG15211 & 104929 & CG15211 & 0 \\
\hline CG4683 & 105877 & Teng|4 & 0 \\
\hline CG6936 & 102303 & mth & 0 \\
\hline CG10844 & 109631 & Rya-r44F & 0 \\
\hline CG1021 & 109620 & CG1021 & 0 \\
\hline CG8557 & 104397 & & 0 \\
\hline CG10152 & 110257 & beat-IV & 0 \\
\hline CG12843 & 101044 & Tsp42Ei & 0 \\
\hline CG2196 & 108782 & salt & 0 \\
\hline CG9614 & 102352 & pip & 0 \\
\hline CG17800 & 108835 & Dscam & 0 \\
\hline CG17245 & 8382 & plexB & 0 \\
\hline CG4135 & 104935 & beat-IIb & 0 \\
\hline CG12125 & 110737 & CG12125 & 0 \\
\hline CG43225 & 106616 & axo & 1 \\
\hline CG4471 & 108515 & Tsp42Ep & 0 \\
\hline
\end{tabular}




\begin{tabular}{|c|c|c|}
\hline CG12837 & $104950 \mathrm{Tsp} 42 \mathrm{Er}$ & 0 \\
\hline CG3903 & $107258 \mathrm{Gli}$ & 0 \\
\hline CG12844 & 102178 Tsp42Eh & 1 \\
\hline CG12841 & 102294 Tsp42Ek & 0 \\
\hline CG11415 & 101081 Tsp2A & 0 \\
\hline CG9550 & 100976 CG9550 & 0 \\
\hline CG11637 & $102359 \mathrm{NijB}$ & 0 \\
\hline CG8732 & $101504 \mathrm{Acsl}$ & 1 \\
\hline CG18405 & 104505 Sema-1a & 0 \\
\hline CG1511 & 110448 Eph & 0 \\
\hline CG3971 & 101557 Baldspot & 0 \\
\hline CG31743 & 105821 CG31743 & 0 \\
\hline CG9093 & 101473 Tsp26A & 0 \\
\hline CG6323 & 109600 Tsp97E & 0 \\
\hline CG31637 & 104472 CG31637 & 0 \\
\hline CG3576 & 109418 schlank & 0 \\
\hline CG1063 & 106982 Itp-r83A & 0 \\
\hline CG6515 & 13392 Takr86C & 0 \\
\hline CG1693 & 110431 tty & 0 \\
\hline CG11895 & 107993 stan & 1 \\
\hline CG4096 & 109025 CG4096 & 0 \\
\hline CG7740 & 102612 prominin-like & 0 \\
\hline CG42679 & $100113 \mathrm{Lmpt}$ & 0 \\
\hline CG4080 & 101426 CG4080 & 0 \\
\hline CG14049 & 102465 IIp6 & 0 \\
\hline CG10234 & $37123 \mathrm{Hs} 2 \mathrm{st}$ & 1 \\
\hline CG17839 & 100149 CG17839 & 0 \\
\hline CG14064 & 105798 beat-VI & 0 \\
\hline CG11081 & 107004 plexA & 0 \\
\hline CG42248 & 105096 & 1 \\
\hline CG17348 & $100039 \mathrm{drl}$ & 0 \\
\hline CG6205 & 100780 por & 0 \\
\hline CG13521 & 100624 robo & 0 \\
\hline CG7540 & 101757 M6 & 0 \\
\hline CG5014 & 100809 Vap-33-1 & 0 \\
\hline CG31298 & 106502 beat-Vb & 0 \\
\hline CG33950 & 110494 trol & 0 \\
\hline CG4893 & 110188 CG4893 & 0 \\
\hline CG6120 & 108375 Tsp96F & 0 \\
\hline CG42275 & 100654 alpha-Man-I & 0 \\
\hline CG42248 & 108508 & 0 \\
\hline CG7411 & 107363 ort & 0 \\
\hline CG33531 & $23316 \mathrm{Ddr}$ & 0 \\
\hline CG6906 & $108184 \mathrm{CAH} 2$ & 2 \\
\hline CG6827 & 108128 Nrx-IV & 2 \\
\hline CG6186 & 106479 Tsf1 & 0 \\
\hline CG42543 & 107319 mp & 0 \\
\hline CG6692 & 110619 Cp1 & 0 \\
\hline
\end{tabular}




\begin{tabular}{|c|c|c|}
\hline CG6982 & 9673 CG6982 & 0 \\
\hline CG12847 & 43534 Tsp42Ec & 0 \\
\hline CG42248 & 110590 & 0 \\
\hline CG14869 & 110157 CG14869 & 0 \\
\hline CG4357 & 106499 Ncc69 & 1 \\
\hline CG2040 & 109863 hig & 0 \\
\hline CG10742 & 10140 Tsp3A & 0 \\
\hline CG14734 & $103662 \mathrm{Tk}$ & 0 \\
\hline CG33179 & 107521 beat-IIIb & 0 \\
\hline CG7887 & 43329 Takr99D & 0 \\
\hline CG9033 & 44288 Tsp47F & 0 \\
\hline CG5315 & 106072 CG5315 & 0 \\
\hline CG14815 & 43473 Pex5 & 0 \\
\hline CG12840 & 107538 Tsp42El & 0 \\
\hline CG42256 & 107939 Dscam2 & 0 \\
\hline CG12846 & 105847 Tsp42Ed & 0 \\
\hline CG1311 & 103764 CG1311 & 0 \\
\hline CG6446 & 107233 Sema-1b & 0 \\
\hline CG30438 & 107604 CG30438 & 0 \\
\hline CG32136 & 101945 Tsp68C & 0 \\
\hline CG4846 & 4544 beat-la & 0 \\
\hline CG15013 & 102166 dyl & 0 \\
\hline CG10079 & 107130 Egfr & 0 \\
\hline CG6578 & $108359 \mathrm{phm}$ & 0 \\
\hline CG43225 & 107491 axo & 0 \\
\hline CG13095 & 15541 Bace & 0 \\
\hline CG11326 & 100721 Tsp & 0 \\
\hline CG3666 & 108470 Tsf3 & 0 \\
\hline CG4568 & 106072 fzo & 0 \\
\hline CG6331 & 6782 Orct & 0 \\
\hline CG9704 & $106080 \mathrm{Nrt}$ & 0 \\
\hline CG11144 & 103736 mGluRA & 0 \\
\hline CG8581 & 29910 fra & 0 \\
\hline CG17697 & $105493 \mathrm{fz}$ & 0 \\
\hline CG10106 & 7934 Tsp42Ee & 0 \\
\hline CG33531 & $29720 \mathrm{Ddr}$ & 0 \\
\hline CG5887 & 104350 desat1 & 0 \\
\hline CG5634 & 104368 dsd & 0 \\
\hline CG3798 & 108378 Nmda1 & 0 \\
\hline CG8075 & 100819 Vang & 0 \\
\hline CG10497 & $107320 \mathrm{Sdc}$ & 0 \\
\hline CG4591 & 102046 Tsp86D & 0 \\
\hline CG9494 & $105839 \mathrm{Tsp} 29 \mathrm{Fa}$ & 0 \\
\hline CG42242 & 102329 beat-VII & 0 \\
\hline CG4700 & 15810 Sema-2a & 0 \\
\hline CG5661 & 9429 Sema-5c & 0 \\
\hline CG10521 & 100840 NetB & 0 \\
\hline CG1560 & 103704 mys & 2 \\
\hline
\end{tabular}




\begin{tabular}{|c|c|c|}
\hline CG2310 & 104126 CG2310 & 0 \\
\hline CG10134 & 102698 beat-Va & 0 \\
\hline CG12845 & 8712 Tsp42Ef & 0 \\
\hline CG33531 & $51719 \mathrm{Ddr}$ & 0 \\
\hline CG1084 & 28294 Cont & 0 \\
\hline CG3665 & 8393 Fas2 & 0 \\
\hline CG3961 & 37305 CG3961 & 0 \\
\hline CG42679 & $42892 \mathrm{Lmpt}$ & 0 \\
\hline CG2913 & 104181 yin & 0 \\
\hline CG8804 & 51090 wun & 0 \\
\hline CG10620 & 5236 Tsf2 & 2 \\
\hline CG2930 & 7031 CG2930 & 0 \\
\hline CG12832 & 30329 Tsp42Eq & 1 \\
\hline CG1106 & 37865 Gel & 0 \\
\hline CG4926 & 29930 Ror & 0 \\
\hline CG11281 & 5247 snky & 0 \\
\hline CG43368 & $104168 \mathrm{cac}$ & 0 \\
\hline CG8331 & 105290 CG8331 & 0 \\
\hline CG12143 & 105191 Tsp42Ej & 0 \\
\hline CG17245 & 27220 plexB & 0 \\
\hline CG18816 & $49692 \mathrm{Tsp} 42 \mathrm{~Eb}$ & 0 \\
\hline CG18657 & 108577 NetA & 0 \\
\hline CG33166 & 7434 stet & 0 \\
\hline CG12142 & $108430 \mathrm{Tsp} 42 \mathrm{Eg}$ & 0 \\
\hline CG1634 & $27202 \mathrm{Nrg}$ & 0 \\
\hline CG9739 & 108998 fz2 & 0 \\
\hline CG10382 & 105314 wrapper & 0 \\
\hline CG8654 & 100112 CG8654 & 0 \\
\hline CG43225 & 106338 axo & 0 \\
\hline CG14468 & 109889 Tsp42A & 0 \\
\hline CG10277 & 109001 CG10277 & 0 \\
\hline CG30040 & 103047 jeb & 0 \\
\hline CG4630 & 101254 CG4630 & 0 \\
\hline CG7644 & 101662 beat-lb & 0 \\
\hline CG12919 & 108814 egr & 0 \\
\hline CG4920 & 102357 ea & 0 \\
\hline CG4690 & 45740 Tsp5D & 0 \\
\hline CG4608 & 101377 bnl & 1 \\
\hline CG12838 & 103222 Tsp42Eo & 0 \\
\hline CG4960 & 102701 CG4960 & 0 \\
\hline CG2781 & 102543 CG2781 & 0 \\
\hline CG6038 & 30379 crim & 1 \\
\hline CG7777 & 8124 CG7777 & 0 \\
\hline CG12900 & 11812 Ir47a & 0 \\
\hline CG5789 & 1204 CG5789 & 0 \\
\hline CG17928 & 103969 CG17928 & 0 \\
\hline CG9637 & 9073 Task6 & 2 \\
\hline CG3722 & 103962 shg & 0 \\
\hline
\end{tabular}




\begin{tabular}{|c|c|c|}
\hline CG17167 & 8677 CG17167 & 0 \\
\hline CG5550 & 103982 CG5550 & 1 \\
\hline CG32792 & 47047 CG32792 & \\
\hline CG33976 & 104050 Octbeta2R & \\
\hline CG1801 & 8655 CG1801 & \\
\hline CG15096 & 103956 CG15096 & \\
\hline CG9864 & 103970 CG9864 & \\
\hline CG7446 & 5329 Grd & \\
\hline CG6705 & 14429 tsl & \\
\hline CG9304 & 11142 CG9304 & \\
\hline CG6844 & 1194 nAcRalpha-96Ab & \\
\hline CG9035 & 8759 Tapdelta & U \\
\hline CG12825 & 103992 CG12825 & 0 \\
\hline CG12061 & 8681 CG12061 & 0 \\
\hline CG11655 & 9131 CG11655 & 0 \\
\hline CG4743 & 103950 CG4743 & 0 \\
\hline CG7596 & 30678 Sgs5 & 0 \\
\hline CG33253 & 6178 CG33253 & 0 \\
\hline CG12193 & 49835 Or22a & 0 \\
\hline CG9211 & 102602 ihog & 0 \\
\hline CG15113 & 9559 5-HT1B & 0 \\
\hline CG9972 & 102389 spz5 & 0 \\
\hline CG11537 & 103941 CG11537 & 0 \\
\hline CG9364 & 30730 Treh & 2 \\
\hline CG7115 & 103354 CG7115 & 0 \\
\hline CG2191 & 102662 Smvt & 0 \\
\hline CG6234 & 101649 CG6234 & 0 \\
\hline CG13317 & 105024 IIp7 & 0 \\
\hline CG9254 & 13407 CG9254 & 0 \\
\hline CG4545 & 11346 SerT & 0 \\
\hline CG5481 & 11823 lea & 0 \\
\hline CG42594 & 7042 CG42594 & 0 \\
\hline CG10359 & 102670 CG10359 & 0 \\
\hline CG3039 & 7136 ogre & 0 \\
\hline CG18281 & 8439 CG18281 & 0 \\
\hline CG12517 & 13463 CG12517 & 0 \\
\hline CG15095 & $11117 \mathrm{I}(2) 08717$ & 0 \\
\hline CG6134 & $105017 \mathrm{spz}$ & 0 \\
\hline CG33106 & 103411 mask & 0 \\
\hline CG11516 & 103931 Ptp99A & 0 \\
\hline CG2736 & 102672 CG2736 & 0 \\
\hline CG2003 & 6872 CG2003 & 0 \\
\hline CG13248 & 102635 CG13248 & 0 \\
\hline CG5805 & 104015 CG5805 & 0 \\
\hline CG4797 & 10598 CG4797 & 2 \\
\hline CG5811 & $103973 \mathrm{NepYr}$ & 0 \\
\hline CG42555 & 102639 tweek & 0 \\
\hline CG6531 & 9152 wgn & \\
\hline
\end{tabular}




\begin{tabular}{|c|c|c|}
\hline CG6530 & $104033 \mathrm{mthl} 3$ & 0 \\
\hline CG13288 & 30363 CG13288 & 1 \\
\hline CG14969 & 8913 CG14969 & 0 \\
\hline CG1907 & 103359 CG1907 & 0 \\
\hline CG15590 & 102392 Osi5 & 0 \\
\hline CG6812 & 103925 CG6812 & 0 \\
\hline CG15585 & 5738 Osi1 & 0 \\
\hline CG8594 & $103420 \mathrm{ClC}-\mathrm{b}$ & 0 \\
\hline CG10221 & $1162 \mathrm{Hrd3}$ & 0 \\
\hline CG7431 & 102643 TyrR & 0 \\
\hline CG31321 & 44940 CG31321 & 0 \\
\hline CG5803 & 939 Fas3 & 0 \\
\hline CG2855 & 16820 aph-1 & 0 \\
\hline CG9722 & 101679 CG9722 & 0 \\
\hline CG42584 & $101590 \operatorname{Ir} 76 a$ & 0 \\
\hline CG8602 & 101575 CG8602 & 0 \\
\hline CG8916 & 101633 CG8916 & 0 \\
\hline CG34366 & 102463 Shawl & 0 \\
\hline CG32183 & $101518 \mathrm{Ccn}$ & 0 \\
\hline CG43081 & 103427 vas & 0 \\
\hline CG18241 & 102642 Toll-4 & 1 \\
\hline CG9053 & 101312 opm & 2 \\
\hline CG7708 & 101485 CG7708 & 2 \\
\hline CG1214 & $101684 \mathrm{ru}$ & 0 \\
\hline CG7105 & 102488 Proct & 0 \\
\hline CG2715 & 102466 Syx4 & 0 \\
\hline CG4432 & 101636 PGRP-LC & 0 \\
\hline CG11589 & 101574 VhaM9.7-c & 0 \\
\hline CG13409 & 8628 CG13409 & 0 \\
\hline CG10353 & 101569 CG10353 & 0 \\
\hline CG13827 & 101466 CG13827 & 0 \\
\hline CG6965 & 101593 mthl5 & 0 \\
\hline CG11147 & 101601 CG11147 & 1 \\
\hline CG7499 & 101540 Rh50 & 0 \\
\hline CG11278 & 102432 Syx13 & 1 \\
\hline CG43155 & 101483 CG43155 & 0 \\
\hline CG33289 & 101664 CG33289 & 0 \\
\hline CG32183 & $101520 \mathrm{Ccn}$ & 0 \\
\hline CG1683 & 102533 Ant2 & 0 \\
\hline CG18788 & 101610 CG18788 & 0 \\
\hline CG42333 & 103345 Sytbeta & 0 \\
\hline CG5484 & 101400 CG5484 & 2 \\
\hline CG18000 & 101559 sw & 2 \\
\hline CG1903 & 101404 sno & 2 \\
\hline CG42269 & 101600 CG42269 & 0 \\
\hline CG4128 & 101571 nAcRalpha-30D & 0 \\
\hline CG32632 & 102476 Tango13 & 0 \\
\hline CG9681 & 101298 PGRP-SB1 & 0 \\
\hline
\end{tabular}




\begin{tabular}{|c|c|c|}
\hline CG17637 & 102424 CG17637 & 0 \\
\hline CG2977 & $103256 \ln \times 7$ & 0 \\
\hline CG42338 & 103298 Ten-a & 0 \\
\hline CG8111 & 101348 CG8111 & 0 \\
\hline CG13633 & 103215 Ast & 0 \\
\hline CG3500 & 101319 CG3500 & 2 \\
\hline CG8805 & 103452 wun2 & 0 \\
\hline CG18321 & 102644 miple2 & 0 \\
\hline CG42642 & $101682 \operatorname{Ir} 75 c$ & 0 \\
\hline CG1889 & 101573 CG1889 & 0 \\
\hline CG1358 & 101453 CG1358 & 0 \\
\hline CG12344 & 103271 CG12344 & 0 \\
\hline CG11516 & 103457 Ptp99A & 0 \\
\hline CG7589 & 102570 CG7589 & 0 \\
\hline CG3994 & 103263 ZnT35C & 0 \\
\hline CG14741 & 102648 CG14741 & 0 \\
\hline CG32206 & 102647 CG32206 & 0 \\
\hline CG42235 & 103285 CG42235 & 0 \\
\hline CG4722 & 103327 bib & 0 \\
\hline CG10303 & 102619 Osi4 & 0 \\
\hline CG13747 & 101982 CG13747 & 0 \\
\hline CG42301 & 100760 CCKLR-17D1 & 0 \\
\hline CG31689 & 102097 CG31689 & 0 \\
\hline CG42315 & $100837 \operatorname{Ir} 93 a$ & 0 \\
\hline CG16727 & 100852 CG16727 & 0 \\
\hline CG3218 & 102101 fs(1)K10 & 0 \\
\hline CG17218 & 102900 crok & 0 \\
\hline CG42677 & $102919 \mathrm{wb}$ & 0 \\
\hline CG1698 & 101947 CG1698 & 0 \\
\hline CG9880 & 100866 Or23a & 0 \\
\hline CG13687 & 102043 Ptth & 0 \\
\hline CG42318 & 100476 app & 0 \\
\hline CG8837 & 100670 CG8837 & 0 \\
\hline CG8784 & 103822 CG8784 & 0 \\
\hline CG15685 & $101920 \operatorname{Ir} 92 a$ & 0 \\
\hline CG1079 & 102047 Fie & 0 \\
\hline CG11155 & 100883 CG11155 & 0 \\
\hline CG8639 & $100749 \mathrm{Cirl}$ & 0 \\
\hline CG12525 & $100644 \operatorname{Ir} 67 a$ & 2 \\
\hline CG33203 & 102001 CG33203 & 0 \\
\hline CG9623 & 100770 if & 0 \\
\hline CG8546 & 100834 CG8546 & 0 \\
\hline CG34413 & 102018 NKAIN & 0 \\
\hline CG5002 & 100600 CG5002 & 0 \\
\hline CG32675 & 100745 Tango5 & 0 \\
\hline CG14958 & 100844 CG14958 & 2 \\
\hline CG13780 & 102072 Pvf2 & 0 \\
\hline CG17061 & $100829 \mathrm{mth} 10$ & 0 \\
\hline
\end{tabular}




\begin{tabular}{|c|c|c|}
\hline CG14214 & 100603 Sec61gamma & 0 \\
\hline CG32538 & 100756 gfA & 0 \\
\hline CG2675 & 100803 Csat & 0 \\
\hline CG15326 & $100498 \operatorname{lr} 7 b$ & 0 \\
\hline CG3212 & 100487 Sr-CIV & 0 \\
\hline CG16876 & 101915 nimC4 & 0 \\
\hline CG11328 & 100742 Nhe3 & 0 \\
\hline CG15555 & 102923 CG15555 & 0 \\
\hline CG6499 & 100416 CG6499 & 0 \\
\hline CG14376 & $100667 \operatorname{Ir} 87 a$ & 0 \\
\hline CG8399 & 100680 CG8399 & 0 \\
\hline CG9499 & 100643 ppk7 & 0 \\
\hline CG2969 & 100404 Atet & 0 \\
\hline CG11898 & 100660 CG11898 & 0 \\
\hline CG17382 & 100407 Ir94h & 0 \\
\hline CG7936 & 100456 mex1 & 0 \\
\hline CG8908 & 100472 CG8908 & 0 \\
\hline CG13225 & 100662 Or47a & 0 \\
\hline CG31911 & 100464 Ent2 & 0 \\
\hline CG17036 & 100656 CG17036 & 0 \\
\hline CG15732 & $100422 \operatorname{Ir} 11 a$ & 0 \\
\hline CG15325 & $100885 \mathrm{Ir} 7 \mathrm{~g}$ & 0 \\
\hline CG14808 & 102014 Scgdelta & 0 \\
\hline CG17922 & 100882 CG17922 & 0 \\
\hline CG11781 & 100613 CG11781 & 0 \\
\hline CG33270 & 109109 CG33270 & 0 \\
\hline CG10781 & 109143 ng1 & 1 \\
\hline CG31665 & 110588 wry & 0 \\
\hline CG5423 & 44702 robo3 & 0 \\
\hline CG31561 & 100479 Osi16 & 0 \\
\hline CG2822 & 110589 Shaw & 0 \\
\hline CG5250 & 46367 CG5250 & 0 \\
\hline CG31860 & 103398 CG31860 & 0 \\
\hline CG5076 & 45198 elk & 0 \\
\hline CG8428 & 105462 spin & 0 \\
\hline CG5621 & 47550 CG5621 & 0 \\
\hline CG11739 & 44562 CG11739 & 0 \\
\hline CG1780 & 14624 Idgf4 & 0 \\
\hline CG12420 & 48324 CG12420 & 0 \\
\hline CG1762 & 42235 betalnt-nu & 0 \\
\hline CG6788 & 42911 CG6788 & 0 \\
\hline CG1155 & 102979 Osi14 & 0 \\
\hline CG33344 & 102995 CcapR & 0 \\
\hline CG5772 & 104241 Sur & 0 \\
\hline CG3443 & 42391 pcx & 0 \\
\hline CG12484 & 104814 CG12484 & 0 \\
\hline CG10537 & 41103 Rdl & 0 \\
\hline CG4821 & 45232 Tequila & 0 \\
\hline
\end{tabular}




\begin{tabular}{|c|c|c|}
\hline CG7962 & $103415 \mathrm{CdsA}$ & 0 \\
\hline CG3047 & 21206 Sgs1 & 0 \\
\hline CG10413 & 103780 CG10413 & 0 \\
\hline CG14160 & 104744 CG14160 & 0 \\
\hline CG12676 & 104279 ed & 0 \\
\hline CG6417 & 42805 Oatp33Eb & 0 \\
\hline CG5372 & 100120 alphaPS5 & 0 \\
\hline CG31106 & 104301 CG31106 & 0 \\
\hline CG17063 & $46398 \ln \times 6$ & 0 \\
\hline CG12025 & 104336 CG12025 & 0 \\
\hline CG1916 & 104338 Wnt2 & 0 \\
\hline CG8178 & 45921 Nach & 0 \\
\hline CG8507 & 104321 CG8507 & 0 \\
\hline CG1268 & 104315 VhaM9.7-a & 0 \\
\hline CG43079 & $104295 \mathrm{nrm}$ & 0 \\
\hline CG3977 & $46757 \mathrm{Ctr} 1 \mathrm{~A}$ & 1 \\
\hline CG12763 & $104287 \mathrm{Dpt}$ & 2 \\
\hline CG12073 & 104804 5-HT7 & 0 \\
\hline CG7026 & 48830 VhaPPA1-2 & 0 \\
\hline CG9664 & 42467 CG9664 & 2 \\
\hline CG9887 & 104324 VGlut & 0 \\
\hline CG6210 & 103812 wls & 0 \\
\hline CG5802 & 103753 CG5802 & 2 \\
\hline CG10470 & 103707 CG10470 & 0 \\
\hline CG4928 & 103750 CG4928 & 0 \\
\hline CG9258 & 103702 nrv1 & 0 \\
\hline CG7514 & 103023 CG7514 & 0 \\
\hline CG42315 & $102983 \operatorname{lr} 93 a$ & 0 \\
\hline CG31832 & 104748 CG31832 & 0 \\
\hline CG32848 & 40918 VAChT & 0 \\
\hline CG14487 & $104752 \operatorname{Ir} 54 a$ & 0 \\
\hline CG14646 & 103770 CG14646 & 0 \\
\hline CG10326 & 104790 CG10326 & 0 \\
\hline CG31424 & $47552 \operatorname{Ir} 94 b$ & 0 \\
\hline CG7736 & 104795 Syx6 & 0 \\
\hline CG31678 & 103705 CG31678 & 0 \\
\hline CG10580 & 51977 fng & 0 \\
\hline CG2893 & 40988 CG2893 & 2 \\
\hline CG5959 & 43288 MCO3 & 0 \\
\hline CG3966 & 51855 ninaA & 0 \\
\hline CG8008 & 4158 CG8008 & 0 \\
\hline CG6928 & 5229 CG6928 & 0 \\
\hline CG33932 & 51043 CG33932 & 0 \\
\hline CG31253 & 25740 CG31253 & 0 \\
\hline CG12052 & 12573 lola & 0 \\
\hline CG14779 & 50306 pck & 2 \\
\hline CG12376 & 22879 CG12376 & 0 \\
\hline CG3979 & 9981 Indy & \\
\hline
\end{tabular}




\begin{tabular}{|c|c|c|}
\hline CG9428 & 107309 ZIP1 & 0 \\
\hline CG1298 & 3962 kune & 2 \\
\hline CG11760 & 11925 CG11760 & 0 \\
\hline CG14173 & 5198 IIp1 & 0 \\
\hline CG2723 & 16403 ImpE3 & 0 \\
\hline CG14723 & $6065 \mathrm{HisCl} 1$ & 0 \\
\hline CG10564 & 51979 Ac78C & 0 \\
\hline CG17795 & $26815 \mathrm{mth} / 2$ & 0 \\
\hline CG17244 & 6838 CG17244 & 0 \\
\hline CG2177 & 51083 CG2177 & 0 \\
\hline CG10236 & $18873 \operatorname{Lan} A$ & 1 \\
\hline CG4934 & 45457 brn & 0 \\
\hline CG9345 & 16643 Adgf-C & 0 \\
\hline CG10337 & 3912 CG10337 & 0 \\
\hline CG42575 & 49973 CG42575 & 0 \\
\hline CG10165 & 3909 CG10165 & 0 \\
\hline CG6869 & 5271 FucTA & 0 \\
\hline CG6383 & 39177 crb & 0 \\
\hline CG31783 & 3875 ninaD & 0 \\
\hline CG34127 & 18121 CG34127 & 0 \\
\hline CG17975 & 28206 sut2 & 0 \\
\hline CG5488 & 11570 B-H2 & 0 \\
\hline CG9126 & 47074 Stim & 0 \\
\hline CG2938 & 7035 CG2938 & 0 \\
\hline CG7549 & $28059 \mathrm{mtg}$ & 0 \\
\hline CG33543 & 17860 CG33543 & 0 \\
\hline CG30394 & 3470 CG30394 & 0 \\
\hline CG8776 & 40803 nemy & 0 \\
\hline CG4559 & 12423 Idgf3 & 0 \\
\hline CG8468 & 6452 CG8468 & 0 \\
\hline CG11051 & 15305 Nplp2 & 0 \\
\hline CG2019 & 10004 disp & 0 \\
\hline CG4531 & 47181 aos & 0 \\
\hline CG4604 & 15387 GLaz & 0 \\
\hline CG14585 & $37297 \operatorname{Ir} 75 a$ & 0 \\
\hline CG11775 & $5820 \operatorname{Ir} 85 a$ & 0 \\
\hline CG9778 & 11037 Syt14 & 0 \\
\hline CG9659 & 45160 egh & 0 \\
\hline CG6456 & 5294 Мip & 0 \\
\hline CG5992 & 50426 Adgf-A & 0 \\
\hline CG14226 & 36355 dome & 1 \\
\hline CG6508 & 28413 CG6508 & 0 \\
\hline CG13480 & 14091 Lk & 0 \\
\hline CG8389 & 8976 CG8389 & 0 \\
\hline CG11495 & 6459 rasp & 0 \\
\hline CG7816 & 1364 CG7816 & 0 \\
\hline CG8595 & 39176 Toll-7 & 0 \\
\hline CG6666 & 6031 SdhC & 0 \\
\hline
\end{tabular}




\begin{tabular}{|c|c|c|}
\hline CG33933 & 51048 Indy-2 & 0 \\
\hline CG4472 & 12416 Idgf1 & 0 \\
\hline CG1494 & 30320 CG1494 & 0 \\
\hline CG30272 & 105475 CG30272 & 1 \\
\hline CG6173 & 14704 Kal1 & \\
\hline CG10146 & 50319 AttA & $v$ \\
\hline CG1213 & 6487 CG1213 & \\
\hline CG33528 & 104072 Vmat & $u$ \\
\hline CG32632 & 105756 Tango13 & \\
\hline CG3074 & 107301 Swim & $\perp$ \\
\hline CG15553 & 104514 CG15553 & \\
\hline CG3161 & 104490 Vha16-1 & \\
\hline CG9224 & $105853 \mathrm{sog}$ & \\
\hline CG33976 & 104524 Octbeta2R & 0 \\
\hline CG7919 & 106149 fan & \\
\hline CG15624 & 106723 hoe2 & 0 \\
\hline CG11956 & 105785 SP1029 & \\
\hline CG14026 & $105834 \mathrm{tkv}$ & 2 \\
\hline CG3845 & 105121 NAT1 & $U$ \\
\hline CG9361 & 106135 Task7 & 0 \\
\hline CG9444 & 104529 CG9444 & 0 \\
\hline CG6981 & 105193 Ssk & 0 \\
\hline CG9723 & 105105 CG9723 & 0 \\
\hline CG6231 & 105194 CG6231 & 0 \\
\hline CG10789 & 104038 ng4 & 2 \\
\hline CG42340 & 104521 CG42340 & 0 \\
\hline CG2346 & 103981 Fmrf & 0 \\
\hline CG13920 & 105183 CG13920 & 0 \\
\hline CG17723 & 105145 ZnT63C & 0 \\
\hline CG13626 & 105113 Syx18 & 2 \\
\hline CG15094 & 106207 MFS15 & 0 \\
\hline CG3757 & 106068 y & 0 \\
\hline CG42825 & 5203 CG42825 & 0 \\
\hline CG8942 & 105799 nimC1 & 0 \\
\hline CG10176 & 104538 CG10176 & 0 \\
\hline CG32079 & 104454 CG32079 & 0 \\
\hline CG9431 & 105647 kek4 & 0 \\
\hline CG12531 & 105771 CG12531 & 0 \\
\hline CG10207 & $106729 \mathrm{NaPi}-\mathrm{T}$ & 0 \\
\hline CG42289 & $106225 \operatorname{Ir} 60 \mathrm{~b}$ & 0 \\
\hline CG16720 & 106094 5-HT1A & 0 \\
\hline CG4334 & 106785 CG4334 & 0 \\
\hline CG17752 & 106787 CG17752 & 0 \\
\hline CG17559 & $106056 \mathrm{dnt}$ & 0 \\
\hline CG10275 & 106680 kon & 2 \\
\hline CG8249 & 106077 CG8249 & 0 \\
\hline CG13610 & 106681 Orct2 & \\
\hline CG14909 & 106115 VhaM9.7-d & \\
\hline
\end{tabular}




\begin{tabular}{|c|c|c|}
\hline CG17662 & 104067 CG17662 & 0 \\
\hline CG7535 & 105754 GluClalpha & 0 \\
\hline CG9256 & 106053 Nhe2 & 0 \\
\hline CG3423 & 106046 SA & 0 \\
\hline CG34412 & $105732 \mathrm{tlk}$ & 2 \\
\hline CG15592 & 105724 Osi9 & 0 \\
\hline CG15627 & $106731 \operatorname{Ir} 25 a$ & 0 \\
\hline CG15596 & 105850 Osi11 & 0 \\
\hline CG32053 & 107225 CG32053 & 0 \\
\hline CG8434 & 106679 lbk & 0 \\
\hline CG14704 & 104557 PGRP-LB & 0 \\
\hline CG8121 & 105806 CG8121 & 2 \\
\hline CG10626 & $105155 \mathrm{Lkr}$ & 0 \\
\hline CG32042 & 102277 PGRP-LA & 0 \\
\hline CG2759 & 30033 w & 0 \\
\hline CG3206 & 101021 Or2a & 0 \\
\hline CG11303 & 102206 TM4SF & 0 \\
\hline CG8856 & 100928 Sr-CII & 0 \\
\hline CG7084 & 102270 CG7084 & 0 \\
\hline CG14709 & 101221 Mrp4 & 0 \\
\hline CG9559 & 101125 fog & 0 \\
\hline CG1389 & 101154 tor & 0 \\
\hline CG33273 & 105004 IIp5 & 0 \\
\hline CG12783 & 101110 CG12783 & 0 \\
\hline CG4231 & 105600 Or22b & 0 \\
\hline CG3592 & 100909 CG3592 & 0 \\
\hline CG14606 & 100903 CG14606 & 0 \\
\hline CG12866 & 101290 CG12866 & 0 \\
\hline CG13427 & 102132 CG13427 & 0 \\
\hline CG11069 & 101080 CG11069 & 0 \\
\hline CG14691 & 102107 CG14691 & 0 \\
\hline CG14690 & 100931 tomboy20 & 0 \\
\hline CG7234 & 105581 GluRIIB & 0 \\
\hline CG15551 & $102136 \mathrm{Ctr} 1 \mathrm{C}$ & 0 \\
\hline CG11209 & 101091 ppk6 & 0 \\
\hline CG15658 & 102333 Lapsyn & 2 \\
\hline CG16713 & 105067 CG16713 & 0 \\
\hline CG14575 & 105556 capaR & 0 \\
\hline CG9935 & 102351 CG9935 & 0 \\
\hline CG1171 & 105063 Akh & 0 \\
\hline CG1056 & $1021055-\mathrm{HT} 2$ & 0 \\
\hline CG3285 & 51060 CG3285 & 0 \\
\hline CG8167 & 102158 IIp2 & 0 \\
\hline CG12283 & 101166 kek1 & 0 \\
\hline CG31247 & 101175 tinc & 0 \\
\hline CG2611 & 102214 CG2611 & 0 \\
\hline CG4590 & $102194 \ln x 2$ & 2 \\
\hline CG11136 & 105555 Lrt & 0 \\
\hline
\end{tabular}




\begin{tabular}{|c|c|c|}
\hline CG9317 & 101145 CG9317 & 0 \\
\hline CG42611 & $105071 \mathrm{mgl}$ & 0 \\
\hline CG10788 & 102175 ng3 & 0 \\
\hline CG33181 & 103142 CG33181 & 0 \\
\hline CG1718 & 105608 CG1718 & 0 \\
\hline CG9918 & 101115 Pk1r & 0 \\
\hline CG5532 & 105693 CG5532 & 0 \\
\hline CG13061 & $105584 \mathrm{Nplp3}$ & 0 \\
\hline CG8925 & 101128 CG8925 & 0 \\
\hline CG7448 & 102236 CG7448 & 0 \\
\hline CG32227 & 43928 gogo & 0 \\
\hline CG7627 & 101084 CG7627 & 0 \\
\hline CG14375 & $102257 \mathrm{CCHa} 2$ & 0 \\
\hline CG5998 & 100933 Adgf-B & 0 \\
\hline CG14856 & 101004 CG14856 & 0 \\
\hline CG5855 & 102019 cni & 0 \\
\hline CG6627 & 100961 Dnz1 & 0 \\
\hline CG34366 & 100980 Shawl & 0 \\
\hline CG5154 & 100977 Idgf5 & 0 \\
\hline CG9196 & 100897 spz6 & 0 \\
\hline CG13592 & 101261 Ir60e & 0 \\
\hline CG8795 & 100927 CG8795 & 2 \\
\hline CG15538 & 101220 Osi23 & 0 \\
\hline CG13419 & 102204 burs & 0 \\
\hline CG7422 & 101136 Snmp2 & 0 \\
\hline CG31423 & 100967 Ir94c & 0 \\
\hline CG18734 & 101242 Fur2 & 0 \\
\hline CG10006 & 101031 CG10006 & 0 \\
\hline CG11064 & 100944 Rfabg & 0 \\
\hline CG8095 & $100949 \mathrm{scb}$ & 0 \\
\hline CG17797 & 100995 Aср29AB & 0 \\
\hline CG16960 & 101137 Or33a & 0 \\
\hline CG5404 & 100953 CG5404 & 0 \\
\hline CG7091 & 102183 CG7091 & 0 \\
\hline CG12594 & 101289 CG12594 & 0 \\
\hline CG15020 & 101086 CG15020 & 0 \\
\hline CG30035 & 103045 Tret1-1 & 0 \\
\hline CG10101 & $101238 \operatorname{Ir} 84 a$ & 0 \\
\hline CG7713 & 102223 CG7713 & 2 \\
\hline CG10369 & 101174 Irk3 & 0 \\
\hline CG33207 & 102240 pxb & 1 \\
\hline CG13253 & $101249 \mathrm{cmpy}$ & 0 \\
\hline CG8098 & 101082 Picot & 0 \\
\hline CG4805 & 100946 ppk28 & 0 \\
\hline CG10693 & 103193 slo & 0 \\
\hline CG15642 & 103040 CG15642 & 0 \\
\hline CG1318 & 102247 Hexo1 & 0 \\
\hline CG2507 & 100901 sas & 0 \\
\hline
\end{tabular}




\begin{tabular}{|c|c|c|}
\hline CG10772 & 22853 Fur1 & 0 \\
\hline CG32203 & 34444 Spn75F & 0 \\
\hline CG6070 & $1262 \mathrm{gb}$ & 0 \\
\hline CG6132 & 23526 Sgs8 & \\
\hline CG34380 & 39446 CG34380 & \\
\hline CG9128 & 37217 Sac1 & \\
\hline CG7255 & 8373 CG7255 & \\
\hline CG5427 & 105560 Oatp33Еа & \\
\hline CG11958 & 42397 Cnx99A & \\
\hline CG32853 & $105546 \mathrm{mthl} 12$ & \\
\hline CG8026 & 105681 CG8026 & \\
\hline CG11561 & 9542 smo & \\
\hline CG3413 & 37208 wdp & \\
\hline CG30265 & 106618 CG30265 & \\
\hline CG14194 & 6183 CG14194 & \\
\hline CG1154 & 105586 Osi12 & \\
\hline CG7888 & 37263 CG7888 & \\
\hline CG8714 & 104983 sut 1 & \\
\hline CG13077 & 105526 CG13077 & 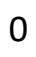 \\
\hline CG31693 & 105558 CG31693 & \\
\hline CG13094 & 50295 Dh31 & $u$ \\
\hline CG34369 & 104952 CG34369 & 0 \\
\hline CG3380 & 39470 Oatp58Dc & 0 \\
\hline CG9593 & 105528 CG9593 & 0 \\
\hline CG6750 & 105637 CG6750 & 1 \\
\hline CG7881 & 105576 CG7881 & 0 \\
\hline CG16700 & 45188 CG16700 & U \\
\hline CG3837 & 105549 CG3837 & 0 \\
\hline CG11395 & 16696 CG11395 & 2 \\
\hline CG3327 & 105055 E23 & 0 \\
\hline CG3156 & 105646 CG3156 & 0 \\
\hline CG1615 & 104883 Ork1 & 0 \\
\hline CG8663 & 104943 nrv3 & 0 \\
\hline CG13417 & 105595 Gr93a & 0 \\
\hline CG4435 & 105656 FucTB & 0 \\
\hline CG1607 & 105677 CG1607 & 0 \\
\hline CG41106 & 103171 CG41106 & 0 \\
\hline CG33124 & 105570 CG33124 & 0 \\
\hline CG33532 & 104892 lectin-37Da & 0 \\
\hline CG14871 & 105016 Trissin & 0 \\
\hline CG13189 & 105650 CG13189 & 1 \\
\hline CG4462 & 105566 CG4462 & 0 \\
\hline CG14624 & 105010 CG14624 & 0 \\
\hline CG42672 & 105645 CG42672 & 0 \\
\hline CG34378 & 105008 Pvf3 & 0 \\
\hline CG15406 & 105077 CG15406 & 0 \\
\hline CG1148 & 104975 Osi2 & 1 \\
\hline CG7459 & $5805 \mathrm{Ctr} 1 \mathrm{~B}$ & \\
\hline
\end{tabular}




\begin{tabular}{|c|c|c|}
\hline CG7485 & 26876 Oct-TyrR & 0 \\
\hline CG8234 & 49889 Tret1-2 & 0 \\
\hline CG6988 & $23358 \mathrm{Pdi}$ & 0 \\
\hline CG12490 & 1706 CG12490 & 0 \\
\hline CG9702 & 6860 CG9702 & \\
\hline CG1505 & $14892 \mathrm{gd}$ & 0 \\
\hline CG5803 & 26850 Fas3 & \\
\hline CG8116 & 39218 CG8116 & 1 \\
\hline CG11822 & 42742 nAcRbeta-21C & \\
\hline CG7577 & 36659 ppk20 & $u$ \\
\hline CG13195 & 45912 Ir $48 b$ & \\
\hline CG3702 & 7296 CG3702 & 2 \\
\hline CG6899 & 27232 Ptp4E & \\
\hline CG13648 & 42326 tnc & 0 \\
\hline CG12943 & 6762 CG12943 & \\
\hline CG34321 & 20874 inaF-C & 0 \\
\hline CG5304 & 6938 dmGlut & 0 \\
\hline CG15257 & 3837 Tim17b2 & 0 \\
\hline CG11282 & 27097 caps & 0 \\
\hline CG6006 & 106513 CG6006 & 0 \\
\hline CG7454 & 108042 Or85a & 0 \\
\hline CG10975 & 40631 Ptp69D & 0 \\
\hline CG7537 & $6950 \ln \times 5$ & 0 \\
\hline CG10019 & 7291 CG10019 & 0 \\
\hline CG32704 & $29917 \operatorname{Ir} 8 a$ & 0 \\
\hline CG2198 & 22944 Ama & 0 \\
\hline CG42333 & 106559 Sytbeta & 0 \\
\hline CG3690 & 28359 CG3690 & 0 \\
\hline CG42269 & 6205 CG42269 & 0 \\
\hline CG4178 & 35584 Lsp1beta & 0 \\
\hline CG5847 & 3162 zye & 1 \\
\hline CG33281 & 7274 CG33281 & 0 \\
\hline CG6890 & 27099 Tollo & 0 \\
\hline CG11098 & 21594 Tango1 & 2 \\
\hline \multirow[t]{2}{*}{ CG43128 } & 102218 Shab & 0 \\
\hline & 24189 & 0 \\
\hline CG4459 & 107022 CG4459 & 0 \\
\hline CG1688 & 30269 CG1688 & 0 \\
\hline CG3774 & $30240 \mathrm{Efr}$ & 0 \\
\hline CG7442 & 106555 CG7442 & 0 \\
\hline CG14039 & 17349 qtc & 0 \\
\hline CG2813 & 44197 cold & 1 \\
\hline CG4330 & 108045 MFS10 & 0 \\
\hline CG12366 & 44045 O-fut1 & 0 \\
\hline CG5912 & $6708 \mathrm{arr}$ & 0 \\
\hline CG9717 & 42669 CG9717 & 0 \\
\hline CG5803 & 42231 Fas3 & 0 \\
\hline CG15438 & 7303 MFS18 & \\
\hline
\end{tabular}




\begin{tabular}{|c|c|c|}
\hline CG14666 & 107739 Tim17a2 & 0 \\
\hline CG33298 & 42776 CG33298 & 0 \\
\hline CG31190 & 6685 Dscam3 & 0 \\
\hline CG18087 & 106575 sgs7 & 0 \\
\hline CG11703 & 8249 CG11703 & 0 \\
\hline CG6668 & 6719 atl & 2 \\
\hline CG30469 & $26817 \operatorname{Ir} 52 b$ & 0 \\
\hline CG11010 & 47537 Ent3 & 1 \\
\hline CG1149 & 108034 MstProx & 0 \\
\hline CG4445 & 42862 pgant3 & 0 \\
\hline CG4451 & 42658 Hs6st & 0 \\
\hline CG6845 & 107719 CG6845 & 0 \\
\hline CG12317 & 108509 Jhl-21 & 0 \\
\hline CG9964 & 2575 Сур309а1 & 0 \\
\hline CG10444 & 107008 CG10444 & 0 \\
\hline CG34358 & 24578 shakB & 0 \\
\hline CG10917 & $6774 \mathrm{fj}$ & 0 \\
\hline CG1090 & 26783 CG1090 & 0 \\
\hline CG9753 & 1385 AdoR & 2 \\
\hline CG14928 & 7679 spz4 & 0 \\
\hline CG42318 & 106488 app & 0 \\
\hline CG13194 & 36523 pyr & 0 \\
\hline CG32463 & 7254 Tengl2 & 0 \\
\hline CG9552 & 107752 rost & 0 \\
\hline CG6185 & $108047 \operatorname{Ir} 68 a$ & 0 \\
\hline CG8422 & 110708 Dh44-R1 & 2 \\
\hline CG32206 & 102647 CG32206 & 0 \\
\hline CG14767 & 105373 CG14767 & 0 \\
\hline CG7227 & 108059 CG7227 & 0 \\
\hline CG15221 & 105910 CG15221 & 0 \\
\hline CG4316 & $108455 \mathrm{Sb}$ & 0 \\
\hline CG31164 & $107734 \operatorname{Ir} 94 a$ & 0 \\
\hline CG42636 & 106525 Gyc76C & 0 \\
\hline CG11262 & 105920 CG11262 & 0 \\
\hline CG31547 & 105911 CG31547 & 0 \\
\hline CG11411 & $105859 \mathrm{fs}(1) \mathrm{N}$ & 0 \\
\hline CG1791 & 105446 CG1791 & 0 \\
\hline CG18110 & 105896 CG18110 & 0 \\
\hline CG9620 & 105410 nac & 0 \\
\hline CG7075 & $102776 \mathrm{Ntl}$ & 1 \\
\hline CG42611 & $105387 \mathrm{mgl}$ & 1 \\
\hline CG11348 & 106570 nAcRbeta-64B & 0 \\
\hline CG12286 & $105429 \mathrm{kar}$ & 0 \\
\hline CG13576 & $105895 \operatorname{Ir} 60 a$ & 0 \\
\hline CG9697 & 106538 PGRP-SB2 & 0 \\
\hline CG33350 & 105947 CheB42c & 0 \\
\hline CG6230 & 106920 CG6230 & 2 \\
\hline CG33131 & 106926 SCAP & 0 \\
\hline
\end{tabular}




\begin{tabular}{|c|c|c|}
\hline CG12414 & 12441 nAcRalpha-80B & 0 \\
\hline CG12092 & $108054 \mathrm{Npc1b}$ & 0 \\
\hline CG16992 & $108048 \mathrm{mthl} 6$ & 0 \\
\hline CG14167 & 106512 IIp3 & 0 \\
\hline CG6822 & 108445 ergic53 & 0 \\
\hline CG8116 & 106531 CG8116 & 0 \\
\hline CG4109 & 107014 Syx8 & 2 \\
\hline CG10698 & 108506 GRHRII & 0 \\
\hline CG42674 & 100153 CG42674 & 1 \\
\hline CG8458 & 107727 wntD & 0 \\
\hline CG32081 & 107023 CG32081 & 0 \\
\hline CG15593 & 105915 Osi10 & 0 \\
\hline CG4822 & 105922 CG4822 & 0 \\
\hline CG32000 & 105477 CG32000 & 0 \\
\hline CG3036 & 108500 CG3036 & 0 \\
\hline CG6736 & 105516 IIp4 & 0 \\
\hline CG6927 & 104345 CG6927 & 1 \\
\hline CG1275 & 105418 CG1275 & 0 \\
\hline CG10693 & 104421 slo & 2 \\
\hline CG7103 & 102699 Pvf1 & 0 \\
\hline CG4484 & 105439 Slc45-1 & 0 \\
\hline CG14621 & 106983 CG14621 & 0 \\
\hline CG42677 & $108020 \mathrm{wb}$ & 0 \\
\hline CG15121 & $105928 \operatorname{Ir} 56 b$ & 0 \\
\hline CG8348 & $108473 \mathrm{Dh} 44$ & 0 \\
\hline CG34413 & 105893 NKAIN & 0 \\
\hline CG42235 & 107662 CG42235 & 0 \\
\hline CG1824 & 106935 CG1824 & 0 \\
\hline CG17716 & 42236 fas & 0 \\
\hline CG5535 & 107030 CG5535 & 0 \\
\hline CG1744 & $108053 \mathrm{chp}$ & 0 \\
\hline CG16987 & 105309 daw & 0 \\
\hline CG14396 & 107648 Ret & 0 \\
\hline CG3649 & 104762 CG3649 & 0 \\
\hline CG15122 & $107633 \operatorname{lr} 56 c$ & 0 \\
\hline CG6398 & 107646 CG6398 & 0 \\
\hline CG9825 & 105868 CG9825 & 0 \\
\hline CG34058 & 107741 ppk11 & 0 \\
\hline CG4562 & 106975 CG4562 & 0 \\
\hline CG42321 & 107000 CG42321 & 2 \\
\hline CG8222 & $105353 \mathrm{Pvr}$ & 2 \\
\hline CG33533 & 107567 lectin-37Db & 0 \\
\hline CG33115 & 106392 nimB4 & 0 \\
\hline CG5507 & $100334 \mathrm{~T} 48$ & 0 \\
\hline CG8166 & 110155 unc-5 & 0 \\
\hline CG8062 & 108364 out & 0 \\
\hline CG1886 & 108373 ATP7 & \\
\hline CG15113 & 109929 5-HT1B & 0 \\
\hline
\end{tabular}




\begin{tabular}{|c|c|c|}
\hline CG11335 & 107435 lox & 0 \\
\hline CG15595 & 101778 Osi13 & 0 \\
\hline CG1004 & 107502 rho & 0 \\
\hline CG3382 & 100348 Oatp58Db & 0 \\
\hline CG9613 & 108373 Coq 2 & 0 \\
\hline CG3279 & 109819 Vti1 & 0 \\
\hline CG5700 & 100357 prc & 0 \\
\hline CG9024 & 107536 Acp26Ab & 0 \\
\hline CG42628 & $101811 \mathrm{rad}$ & 0 \\
\hline CG10226 & 108196 CG10226 & 0 \\
\hline CG14957 & 102784 CG14957 & 1 \\
\hline CG12369 & 107450 Lac & 2 \\
\hline CG8930 & 105360 rk & 0 \\
\hline CG42340 & 105046 CG42340 & 0 \\
\hline CG13568 & 106888 ppk29 & 0 \\
\hline CG4323 & 104152 Dic2 & 0 \\
\hline CG7586 & $100197 \mathrm{Mcr}$ & 2 \\
\hline CG31201 & 49547 GluRIIE & 2 \\
\hline CG6308 & 30273 CG6308 & 0 \\
\hline CG33717 & 5038 PGRP-LD & 0 \\
\hline CG6898 & 37358 Zip3 & 0 \\
\hline CG12199 & 47768 kek5 & 0 \\
\hline CG33513 & 12189 Nmdar2 & 0 \\
\hline CG8824 & $4637 \mathrm{fdl}$ & 0 \\
\hline CG31058 & 25666 CG31058 & 1 \\
\hline CG8224 & 3825 babo & 1 \\
\hline CG42292 & $8169 \operatorname{lr} 7 f$ & 0 \\
\hline CG42264 & 19603 CG42264 & 0 \\
\hline CG11709 & 5594 PGRP-SA & 0 \\
\hline CG15361 & 104662 Nplp4 & 0 \\
\hline CG13758 & 106381 Pdfr & 0 \\
\hline CG8394 & 103586 VGAT & 0 \\
\hline CG34120 & 100384 CG34120 & 1 \\
\hline CG31770 & $107469 \mathrm{He}$ & 0 \\
\hline CG31146 & 104209 Nlg1 & 0 \\
\hline CG7228 & 100391 pes & 0 \\
\hline CG7000 & 104210 Snmp1 & 2 \\
\hline CG3829 & 103492 CG3829 & 0 \\
\hline CG42611 & $103661 \mathrm{mgl}$ & 0 \\
\hline CG31105 & 106384 CG31105 & 0 \\
\hline CG18314 & 103494 DopEcR & 0 \\
\hline CG32475 & 100246 mthl8 & 0 \\
\hline CG5876 & 103641 heix & 2 \\
\hline CG33349 & 101808 ppk25 & 0 \\
\hline CG3302 & $106876 \mathrm{Crz}$ & 0 \\
\hline CG14745 & 104578 PGRP-SC2 & 0 \\
\hline CG4465 & 100202 CG4465 & 0 \\
\hline CG31718 & $100345 \operatorname{Ir} 31 a$ & \\
\hline
\end{tabular}




\begin{tabular}{|c|c|c|}
\hline CG2727 & $12233 \mathrm{emp}$ & 0 \\
\hline CG15002 & 32263 mas & 0 \\
\hline CG2657 & $2472 \operatorname{Ir} 21 a$ & 0 \\
\hline CG8785 & 4650 CG8785 & \\
\hline CG15598 & 37458 Osi17 & \\
\hline CG32635 & 19594 Neto & \\
\hline CG10211 & 12352 CG10211 & \\
\hline CG11937 & 5606 amn & \\
\hline CG5485 & 5341 Prestin & \\
\hline CG10633 & $9011 \operatorname{Ir} 64 a$ & \\
\hline CG5619 & 51240 trk & \\
\hline CG17646 & 100378 CG17646 & \\
\hline CG30345 & 103652 CG30345 & \\
\hline CG14239 & 109855 CG14239 & \\
\hline CG6788 & 101786 CG6788 & \\
\hline CG3725 & 107446 Са-P60A & \\
\hline CG8743 & 45989 trpml & \\
\hline CG7225 & $13864 \mathrm{wbl}$ & \\
\hline CG13333 & 19555 link & \\
\hline CG9095 & 23158 CG9095 & \\
\hline CG13393 & 33166 I(2)k12914 & $\angle$ \\
\hline CG5123 & 8269 W & U \\
\hline CG1847 & 43702 CG1847 & 4 \\
\hline CG8622 & 52435 Аср53Еа & 0 \\
\hline CG15549 & 37376 CG15549 & 0 \\
\hline CG5646 & 4402 CG5646 & 0 \\
\hline CG6496 & 50749 Pdf & 0 \\
\hline CG9703 & 6137 Axs & 0 \\
\hline CG6723 & 13769 CG6723 & 0 \\
\hline CG18802 & 5838 alpha-Man-II & 0 \\
\hline CG14605 & 5776 CG14605 & 0 \\
\hline CG11320 & 18054 CG11320 & 0 \\
\hline CG33934 & 50699 CG33934 & 0 \\
\hline CG10443 & 36269 Lar & 0 \\
\hline CG33670 & 51018 stg1 & 0 \\
\hline CG4288 & 104145 CG4288 & 0 \\
\hline CG7005 & 9795 Esp & 0 \\
\hline CG1232 & 4482 tipE & 0 \\
\hline CG3814 & 4671 CG3814 & 0 \\
\hline CG8323 & 4861 CG8323 & 0 \\
\hline CG9564 & 45718 Try29F & 0 \\
\hline CG18105 & 18825 ETH & 0 \\
\hline CG17131 & 5608 tyn & 0 \\
\hline CG10117 & 4871 ttv & 0 \\
\hline CG5474 & 12101 SsRbeta & 0 \\
\hline CG5853 & 2756 CG5853 & 0 \\
\hline CG10593 & 3324 Acer & 0 \\
\hline CG18243 & 3116 Ptp52F & \\
\hline
\end{tabular}




\begin{tabular}{|c|c|c|}
\hline CG14900 & 8405 Cad89D & 0 \\
\hline CG3615 & 10045 Atg9 & 0 \\
\hline CG6817 & 10102 foi & 2 \\
\hline CG7050 & $36328 \mathrm{Nrx}-1$ & 0 \\
\hline CG7571 & 37295 Oatp74D & 0 \\
\hline CG14181 & 42549 Use1 & 2 \\
\hline CG8577 & 51237 PGRP-SC1b & 0 \\
\hline CG3409 & 37141 CG3409 & 0 \\
\hline CG12960 & $37173 \operatorname{Ir} 52 a$ & 0 \\
\hline CG18146 & 3120 nimC2 & 0 \\
\hline CG10035 & 7524 CG10035 & 0 \\
\hline CG5803 & 3091 Fas3 & 0 \\
\hline CG1891 & 9434 sax & 0 \\
\hline CG5227 & 9437 sdk & 0 \\
\hline CG8791 & 7944 CG8791 & 0 \\
\hline CG9023 & 51939 Drip & 0 \\
\hline CG10702 & 100842 CG10702 & 0 \\
\hline CG7912 & 1378 CG7912 & 0 \\
\hline CG13983 & 38003 CG13983 & 0 \\
\hline CG31741 & 7930 CG31741 & 0 \\
\hline CG42330 & 25365 Dscam4 & 0 \\
\hline CG1151 & 44545 Osi6 & 0 \\
\hline CG31787 & 6372 CG31787 & 0 \\
\hline CG31668 & 2548 CG31668 & 0 \\
\hline CG4692 & 13324 CG4692 & 2 \\
\hline CG32146 & $100268 \mathrm{dlp}$ & 0 \\
\hline CG10345 & 100252 CG10345 & 0 \\
\hline CG4894 & 51491 Ca-alpha1D & 2 \\
\hline CG3424 & 44536 path & 0 \\
\hline CG10810 & 2703 Drs & 0 \\
\hline CG10960 & 8359 CG10960 & 0 \\
\hline CG5657 & 51526 Scgbeta & 0 \\
\hline CG7400 & 9406 Fatp & 0 \\
\hline CG30404 & 29385 Tango11 & 0 \\
\hline CG1153 & 100174 Osi7 & 0 \\
\hline CG13078 & 100234 CG13078 & 2 \\
\hline CG17715 & 43101 CG17715 & 0 \\
\hline CG15188 & 100210 Osi20 & 0 \\
\hline CG5610 & 48159 nAcRalpha-96Aa & 0 \\
\hline CG6440 & 12975 Dms & 0 \\
\hline CG7631 & 100141 CG7631 & 0 \\
\hline CG13796 & 102516 CG13796 & 0 \\
\hline CG42235 & 48562 CG42235 & 0 \\
\hline CG30081 & $29985 \operatorname{Ir} 51 b$ & 0 \\
\hline CG4370 & 4341 Irk2 & 0 \\
\hline CG7806 & 2804 CG7806 & 0 \\
\hline CG10624 & $44929 \sin u$ & 2 \\
\hline CG42253 & 107948 Ndae1 & 0 \\
\hline
\end{tabular}




\begin{tabular}{|c|c|c|}
\hline CG1380 & 44934 sut4 & 0 \\
\hline CG31793 & 8069 CG31793 & 0 \\
\hline CG12127 & $3295 \mathrm{amx}$ & 0 \\
\hline CG34368 & 44532 Fili & 0 \\
\hline CG11280 & $107883 \operatorname{trn}$ & \\
\hline CG13646 & 1571 CG13646 & 0 \\
\hline CG9261 & 2660 nrv2 & \\
\hline CG5549 & 8222 CG5549 & 0 \\
\hline CG43128 & 108861 Shab & 7 \\
\hline CG4550 & 44178 ninaE & $u$ \\
\hline CG11767 & 9340 or24a & \\
\hline CG5400 & 44967 Eh & 0 \\
\hline CG31103 & 2657 CG31103 & \\
\hline CG9369 & $8036 \mathrm{~m}$ & 0 \\
\hline CG7503 & 17898 Con & \\
\hline CG16827 & 109783 alphaPS4 & 0 \\
\hline CG4977 & 42450 kek2 & 0 \\
\hline CG42235 & 107896 CG42235 & 0 \\
\hline CG8896 & $96518 w$ & 0 \\
\hline CG13743 & 40975 CG13743 & 2 \\
\hline CG14855 & 40906 CG14855 & 0 \\
\hline CG12341 & 7391 CG12341 & 0 \\
\hline CG5993 & 3282 os & 0 \\
\hline CG8713 & 47977 CG8713 & 0 \\
\hline CG34059 & 22989 ppk16 & 0 \\
\hline CG8982 & 41194 Аср26Аа & 0 \\
\hline CG4145 & 104536 Cg25C & 0 \\
\hline CG43079 & 30072 nrm & 0 \\
\hline CG42701 & 101745 Cng & 0 \\
\hline CG10178 & 8064 CG10178 & 0 \\
\hline CG5183 & 9235 KdelR & 0 \\
\hline CG17751 & 50469 CG17751 & 0 \\
\hline CG14069 & 9517 CG14069 & 0 \\
\hline CG7309 & 100142 CG7309 & 0 \\
\hline CG6126 & 7326 CG6126 & 0 \\
\hline CG11853 & 100079 to & 0 \\
\hline CG32476 & 100173 mthl14 & 0 \\
\hline CG14925 & 100032 Osi21 & 0 \\
\hline CG17381 & 107901 Ir94g & 0 \\
\hline CG10671 & 109895 CG10671 & 0 \\
\hline CG11128 & 45590 slif & 0 \\
\hline CG10864 & 107858 CG10864 & 0 \\
\hline CG34345 & 110487 CG34345 & 0 \\
\hline CG6052 & 106738 CG6052 & 0 \\
\hline CG6125 & 107894 CG6125 & 0 \\
\hline CG14020 & 107355 CG14020 & 0 \\
\hline CG9520 & 110406 C1GalTA & 0 \\
\hline CG18617 & 109763 Vha100-2 & \\
\hline
\end{tabular}




\begin{tabular}{|c|c|c|}
\hline CG11163 & 107931 CG11163 & 0 \\
\hline CG31147 & 107371 mthl11 & 0 \\
\hline CG10505 & 107842 CG10505 & 0 \\
\hline CG11907 & 109885 Ent1 & 0 \\
\hline CG13907 & 107339 CG13907 & 0 \\
\hline CG7188 & 110358 BI-1 & 0 \\
\hline CG42514 & 45643 CG42514 & 0 \\
\hline CG15088 & 109791 List & 0 \\
\hline CG12787 & 110373 hoe1 & 0 \\
\hline CG9432 & $107350 \mid(2) 01289$ & 0 \\
\hline CG11527 & $100036 \mathrm{Tig}$ & 0 \\
\hline CG42314 & 109188 PMCA & 0 \\
\hline CG9820 & 108135 Or59a & 0 \\
\hline CG8046 & 7380 CG8046 & 0 \\
\hline CG32775 & 107840 GICAT-I & 0 \\
\hline CG5081 & 107264 Syx7 & 2 \\
\hline CG17853 & 109777 Or43b & 0 \\
\hline CG16857 & 109857 CG16857 & 0 \\
\hline CG10486 & 107903 CG10486 & 0 \\
\hline CG32058 & $107921 \operatorname{Ir} 67 c$ & 0 \\
\hline CG42576 & 110495 NT1 & 0 \\
\hline CG12048 & 107892 ppk21 & 0 \\
\hline CG6672 & 107388 CG6672 & 0 \\
\hline CG10449 & 100095 Catsup & 2 \\
\hline CG2857 & 107215 Трс2 & 0 \\
\hline CG8588 & 107243 pst & 0 \\
\hline CG5592 & 110489 CG5592 & 0 \\
\hline CG13384 & 106698 CG13384 & 0 \\
\hline CG32091 & 107236 CG32091 & 0 \\
\hline CG33492 & $109772 \operatorname{Ir} 41 \mathrm{a}$ & 0 \\
\hline CG17929 & 100093 CG17929 & 0 \\
\hline CG15753 & 107403 & 0 \\
\hline CG32054 & 107214 CG32054 & 0 \\
\hline CG14511 & 107875 CG14511 & 0 \\
\hline CG31116 & 110394 ClC-a & 2 \\
\hline CG5820 & 100134 Gp150 & 0 \\
\hline CG2316 & 107342 CG2316 & 0 \\
\hline CG9657 & 107361 CG9657 & 0 \\
\hline CG9655 & 110375 nes & 0 \\
\hline CG5490 & $100078 \mathrm{Tl}$ & 0 \\
\hline CG4607 & 107219 CG4607 & 0 \\
\hline CG33508 & 110084 ppk13 & 0 \\
\hline CG31121 & 100046 CG31121 & 0 \\
\hline CG9621 & 110490 Adgf-D & 0 \\
\hline CG12755 & $107911 \mathrm{I}(3) \mathrm{mbn}$ & 0 \\
\hline CG4790 & $100084 \mathrm{fs}(1) \mathrm{M} 3$ & 0 \\
\hline CG9270 & 109785 CG9270 & 0 \\
\hline CG7714 & 106781 CG7714 & 0 \\
\hline
\end{tabular}




\begin{tabular}{|c|c|c|}
\hline CG3168 & 48010 CG3168 & 0 \\
\hline CG31792 & 107237 CG31792 & 0 \\
\hline CG15151 & 107213 rdo & 0 \\
\hline CG9066 & 110480 MSBP & 0 \\
\hline CG3701 & 107370 CG3701 & 0 \\
\hline CG33207 & $106399 \mathrm{pxb}$ & 0 \\
\hline CG8451 & 104177 CG8451 & 0 \\
\hline CG5006 & 104198 Or33c & 0 \\
\hline CG34139 & 102676 CG34139 & 0 \\
\hline CG3054 & $103629 \mathrm{l}(2) \mathrm{k} 05819$ & 0 \\
\hline CG3770 & 103556 CG3770 & 0 \\
\hline CG33233 & 106897 CG33233 & 1 \\
\hline CG31720 & 102865 mthl15 & 0 \\
\hline CG1169 & 104590 Osi18 & 0 \\
\hline CG33970 & 101855 CG33970 & 0 \\
\hline CG7333 & 101790 CG7333 & 0 \\
\hline CG8642 & 101888 CG8642 & 0 \\
\hline CG8860 & 102745 CG8860 & 0 \\
\hline CG2374 & 102739 lbm & 0 \\
\hline CG5594 & $101742 \mathrm{kcc}$ & 0 \\
\hline CG31431 & 104697 CG31431 & 0 \\
\hline CG13948 & 104122 Gr21a & 1 \\
\hline CG33198 & 101752 pen-2 & 0 \\
\hline CG34405 & $101695 \mathrm{NaCP} 60 \mathrm{E}$ & 0 \\
\hline CG1157 & 101817 Osi15 & 0 \\
\hline CG31213 & 104215 CG31213 & 0 \\
\hline CG14076 & $106286 \operatorname{lr} 75 d$ & 0 \\
\hline CG6356 & 101866 CG6356 & 0 \\
\hline CG13801 & 104206 CG13801 & 0 \\
\hline CG6017 & 101736 Hip14 & 0 \\
\hline CG32975 & 101820 nAcRalpha-34E & 0 \\
\hline CG4672 & 8380 TMS1 & 0 \\
\hline CG18039 & 40929 GluRIID & 0 \\
\hline CG8226 & 102728 Tom7 & 0 \\
\hline CG14919 & 102735 Ast-C & 0 \\
\hline CG15520 & 101705 сара & 0 \\
\hline CG42314 & 101743 PMCA & 0 \\
\hline CG9089 & 110270 wus & 0 \\
\hline CG32055 & 108963 CG32055 & 0 \\
\hline CG8583 & $110331 \sec 63$ & 1 \\
\hline CG31004 & 108297 CG31004 & 2 \\
\hline CG7458 & 108770 CG7458 & 0 \\
\hline CG1500 & $106656 \mathrm{fw}$ & 0 \\
\hline CG6698 & $108234 \mathrm{NtR}$ & 0 \\
\hline CG32250 & 108323 CG32250 & 0 \\
\hline CG17660 & 110322 CG17660 & 0 \\
\hline CG10420 & 108354 CG10420 & 0 \\
\hline CG5977 & 108739 spas & 0 \\
\hline
\end{tabular}




\begin{tabular}{|c|c|c|}
\hline CG1599 & 108733 CG1599 & 0 \\
\hline CG11340 & 108337 CG11340 & 0 \\
\hline CG31358 & 108785 CG31358 & 0 \\
\hline CG14963 & 108714 CG14963 & 0 \\
\hline CG5528 & 109635 Toll-9 & 0 \\
\hline CG6371 & 107771 hug & 0 \\
\hline CG12370 & 102292 Dh44-R2 & 0 \\
\hline CG12773 & 108667 CG12773 & 0 \\
\hline CG17084 & 108967 mthl9 & 0 \\
\hline CG7398 & 105181 Trn & 2 \\
\hline CG15427 & 108746 tutl & 0 \\
\hline CG33348 & 106020 CheB42a & 0 \\
\hline CG1502 & $108750 \mathrm{tsg}$ & 0 \\
\hline CG31731 & 107135 CG31731 & 0 \\
\hline CG1804 & 109681 kek6 & 0 \\
\hline CG8632 & 108929 CG8632 & 0 \\
\hline CG6124 & 4301 eater & 0 \\
\hline CG33135 & $106655 \mathrm{KCNQ}$ & 0 \\
\hline CG1407 & 107080 CG1407 & 0 \\
\hline CG16961 & 107168 Or33b & 1 \\
\hline CG9194 & 108758 CG9194 & 0 \\
\hline CG6202 & 108944 Surf4 & 0 \\
\hline CG2187 & 101065 CG2187 & 0 \\
\hline CG12121 & 103605 CG12121 & 0 \\
\hline CG9652 & 107058 DopR & 0 \\
\hline CG4775 & 108341 Tango14 & 2 \\
\hline CG1471 & 110671 CDase & 0 \\
\hline CG7510 & 105969 CG7510 & 0 \\
\hline CG3252 & 106027 NAAT1 & 0 \\
\hline CG42576 & 108894 NT1 & 0 \\
\hline CG8028 & 102317 CG8028 & 0 \\
\hline CG1139 & 102363 CG1139 & 0 \\
\hline CG14430 & 107102 bou & 0 \\
\hline CG14040 & 110668 CG14040 & 0 \\
\hline CG16718 & 108953 CG16718 & 0 \\
\hline CG8034 & 106660 CG8034 & 2 \\
\hline CG4214 & 108928 Syx5 & 2 \\
\hline CG32701 & $110344 \mathrm{I}(1) \mathrm{G} 0320$ & 0 \\
\hline CG31729 & 105987 CG31729 & 0 \\
\hline CG15279 & 108759 CG15279 & 0 \\
\hline CG11516 & 27207 Ptp99A & 0 \\
\hline CG3953 & 16416 Invadolysin & 0 \\
\hline CG5888 & 12413 CG5888 & 0 \\
\hline CG7955 & 106039 АВСВ7 & 0 \\
\hline CG15917 & 108755 Gbp & 0 \\
\hline CG7121 & 109705 Tehao & 0 \\
\hline CG4402 & 108217 lox2 & 0 \\
\hline CG32134 & 110277 btl & 0 \\
\hline
\end{tabular}




\begin{tabular}{|c|c|c|}
\hline CG17923 & 106410 JYalpha & 0 \\
\hline CG4482 & $104668 \mathrm{~mol}$ & 0 \\
\hline CG11597 & 104729 CG11597 & 0 \\
\hline CG4605 & 102687 Aсp32CD & 0 \\
\hline CG4521 & $107488 \mathrm{mthl} 1$ & 0 \\
\hline CG17579 & 104703 sca & 0 \\
\hline CG30344 & 106870 CG30344 & 0 \\
\hline CG1221 & 104623 miple & 0 \\
\hline CG10373 & 6375 Jwa & 0 \\
\hline CG11592 & 104099 CG11592 & 0 \\
\hline CG7334 & 106397 Sug & 0 \\
\hline CG15284 & 102690 pburs & 0 \\
\hline CG30277 & 106377 Oatp58Da & 0 \\
\hline CG34120 & 101700 CG34120 & 0 \\
\hline CG3359 & $103621 \mathrm{mfas}$ & 0 \\
\hline CG14021 & 104112 fusl & 0 \\
\hline CG42352 & 101725 Ir40a & 0 \\
\hline CG3533 & 104208 uzip & 0 \\
\hline CG17610 & 101701 grk & 0 \\
\hline CG15189 & 102805 Osi19 & 0 \\
\hline CG3182 & 104698 sei & 0 \\
\hline CG7476 & $102811 \mathrm{mthl} 7$ & 0 \\
\hline CG42701 & 102783 Cng & 0 \\
\hline CG8527 & 106873 ppk23 & 0 \\
\hline CG11575 & $102826 \operatorname{Ir} 100 a$ & 0 \\
\hline CG10872 & 107437 CG31926 & 0 \\
\hline CG6901 & 104673 CG6901 & 2 \\
\hline CG42253 & 102707 Ndae1 & 0 \\
\hline CG12130 & 103604 Pal1 & 0 \\
\hline CG42260 & 38852 CG42260 & 0 \\
\hline CG31262 & 106408 CG31262 & 0 \\
\hline CG32632 & 102758 Tango13 & 0 \\
\hline CG2902 & 104773 Nmdar1 & 0 \\
\hline CG34405 & $40993 \mathrm{NaCP} 60 \mathrm{E}$ & 0 \\
\hline CG10037 & $110723 \mathrm{vvl}$ & 0 \\
\hline CG14238 & 2673 CG14238 & 0 \\
\hline CG3879 & 108327 Mdr49 & 0 \\
\hline CG6293 & 108619 CG6293 & 1 \\
\hline CG4019 & 107980 CG4019 & 0 \\
\hline CG8444 & 105281 VhaM8.9 & 0 \\
\hline CG7882 & 109918 CG7882 & 0 \\
\hline CG33134 & $106669 \mathrm{debcl}$ & 0 \\
\hline CG9518 & 8329 CG9518 & 0 \\
\hline CG11325 & 109300 GRHR & 2 \\
\hline CG14979 & 108203 Gr63a & 0 \\
\hline CG6281 & 109427 Timp & 0 \\
\hline CG7655 & 105286 CG7655 & 0 \\
\hline CG12303 & $109462 \operatorname{Ir} 67 \mathrm{~b}$ & 0 \\
\hline
\end{tabular}




\begin{tabular}{|c|c|c|}
\hline CG5284 & $106844 \mathrm{ClC}-\mathrm{C}$ & 0 \\
\hline CG15324 & 109485 Ir7c & 0 \\
\hline CG42352 & $100912 \operatorname{Ir} 40 \mathrm{a}$ & 0 \\
\hline CG10311 & 108426 CG10311 & 0 \\
\hline CG2915 & 107559 CG2915 & 0 \\
\hline CG4125 & 27225 rst & 0 \\
\hline CG33141 & 109442 sns & 0 \\
\hline CG12194 & 109287 CG12194 & 0 \\
\hline CG17673 & 109175 Aсp70A & 0 \\
\hline CG3171 & 108952 Tre1 & 2 \\
\hline CG15890 & 107962 CG15890 & 0 \\
\hline CG15904 & $6112 \operatorname{Ir} 56 \mathrm{~d}$ & 0 \\
\hline CG31795 & 110595 IA-2 & 0 \\
\hline CG14746 & 43201 PGRP-SC1a & 0 \\
\hline CG31695 & $105303 \mathrm{scw}$ & 1 \\
\hline CG30379 & 108179 CG30379 & 0 \\
\hline CG34123 & 110226 & 0 \\
\hline CG10491 & $109437 \mathrm{vn}$ & 0 \\
\hline CG4991 & 108419 CG4991 & 0 \\
\hline CG13999 & 107505 CG13999 & 0 \\
\hline CG6707 & 110291 CG6707 & 0 \\
\hline CG9947 & 105288 CG9947 & 0 \\
\hline CG42732 & 10268 CG42732 & 0 \\
\hline CG3135 & 14803 shf & 0 \\
\hline CG4324 & 109433 CG4324 & 0 \\
\hline CG8433 & 109949 Ext2 & 0 \\
\hline CG10197 & 109914 kn & 0 \\
\hline CG2448 & 109432 FucT6 & 0 \\
\hline CG5398 & 109717 CG5398 & 0 \\
\hline CG1467 & 109504 Syx16 & 0 \\
\hline CG4974 & 14136 dally & 0 \\
\hline CG30464 & $8963 \operatorname{Ir} 52 d$ & 0 \\
\hline CG8271 & 109464 SIn & 2 \\
\hline CG7449 & 105913 hbs & 0 \\
\hline CG2381 & 24988 Syt7 & 0 \\
\hline CG4099 & $110014 \mathrm{Sr}-\mathrm{Cl}$ & 2 \\
\hline CG4437 & 108313 PGRP-LF & 0 \\
\hline CG11897 & 105174 CG11897 & 0 \\
\hline CG12370 & 109558 Dh44-R2 & 0 \\
\hline CG13278 & 109927 CG13278 & 0 \\
\hline CG12908 & $109625 \mathrm{Ndg}$ & 0 \\
\hline CG9430 & 110047 CG9430 & 0 \\
\hline CG8380 & 106961 DAT & 0 \\
\hline CG3954 & 108352 csw & 2 \\
\hline CG5078 & 8442 CG5078 & 0 \\
\hline CG33688 & 48478 CG33688 & 0 \\
\hline CG3352 & $108863 \mathrm{ft}$ & 0 \\
\hline CG7638 & 109665 CG7638 & \\
\hline
\end{tabular}




\begin{tabular}{|c|c|c|}
\hline CG1150 & 42613 Osi3 & 0 \\
\hline CG11422 & 102252 Obp83b & 0 \\
\hline CG4476 & 109677 CG4476 & 0 \\
\hline CG7157 & 105453 Aсp36DE & 0 \\
\hline CG14981 & 109502 mge & \\
\hline CG1462 & 110043 Aph-4 & 0 \\
\hline CG6484 & 109481 CG6484 & \\
\hline CG7654 & 107186 Tom20 & 2 \\
\hline CG30125 & 109691 Ir56a & \\
\hline CG12664 & 110068 fend & 0 \\
\hline CG3671 & $109434 \mathrm{Mvl}$ & \\
\hline CG3777 & 109678 CG3777 & 0 \\
\hline CG10806 & 110016 Nha1 & 0 \\
\hline CG10069 & 108635 MFS16 & 0 \\
\hline CG3441 & 107116 Nplp1 & 0 \\
\hline CG4726 & 107656 MFS3 & 0 \\
\hline CG33321 & 47832 CheB38b & 0 \\
\hline CG14358 & $104974 \mathrm{CCHa} 1$ & 0 \\
\hline CG13439 & $33817 \mathrm{dpr}$ & 0 \\
\hline CG4166 & 45775 not & 2 \\
\hline CG13586 & 43848 itp & 0 \\
\hline CG34139 & 108713 CG34139 & 0 \\
\hline CG10342 & $108772 \mathrm{npf}$ & 0 \\
\hline CG33162 & 110760 SrpRbeta & 2 \\
\hline CG16944 & 52457 sesB & 0 \\
\hline CG6512 & 109629 CG6512 & 0 \\
\hline CG3874 & 107816 frc & 0 \\
\hline CG5760 & 110473 rtet & 0 \\
\hline CG42768 & $107183 \mathrm{Msp}-300$ & 0 \\
\hline CG31634 & 109633 Oatp26F & 2 \\
\hline CG4322 & 109601 moody & 0 \\
\hline CG9413 & 108867 CG9413 & 0 \\
\hline CG3297 & $110217 \mathrm{mnd}$ & 0 \\
\hline CG17664 & 101847 CG17664 & 2 \\
\hline CG4147 & $101766 \mathrm{Hsc} 70-3$ & 2 \\
\hline CG5581 & 105308 Ote & 0 \\
\hline CG3476 & 100372 CG3476 & 0 \\
\hline CG10978 & 108991 jagn & 1 \\
\hline CG33282 & 100325 CG33282 & 0 \\
\hline CG7452 & 108825 Syx17 & 0 \\
\hline CG12858 & 110674 CG12858 & 0 \\
\hline CG6798 & 109450 nAcRbeta-96A & 0 \\
\hline CG8850 & 104098 CG8850 & 0 \\
\hline CG1724 & 30315 CG1724 & 1 \\
\hline CG42338 & 105037 Ten-a & 0 \\
\hline CG8285 & 4365 boss & 0 \\
\hline CG9539 & 109660 Sec61alpha & 2 \\
\hline CG33114 & 108142 Gyc32E & \\
\hline
\end{tabular}




\begin{tabular}{|c|c|c|}
\hline CG3653 & 109585 kirre & 0 \\
\hline CG30281 & 108551 CG30281 & 0 \\
\hline CG42555 & 110686 tweek & 0 \\
\hline CG4314 & 109793 st & 0 \\
\hline CG4332 & 109624 CG4332 & 0 \\
\hline CG7250 & 108907 Toll-6 & 0 \\
\hline CG12201 & 109013 CG12201 & 0 \\
\hline CG34069 & $109278 \mathrm{mt}:$ Coll & 0 \\
\hline CG34127 & 100376 CG34127 & 0 \\
\hline CG4313 & 107434 CG4313 & 0 \\
\hline CG12178 & 110205 Nhe1 & 0 \\
\hline CG18090 & 14201 Dsk & 0 \\
\hline CG1771 & 109608 mew & 0 \\
\hline CG12444 & $45696 \operatorname{Ir} 48 c$ & 0 \\
\hline CG3853 & 100253 Glut3 & 0 \\
\hline CG1448 & $108913 \ln \times 3$ & 1 \\
\hline CG33542 & 106869 upd3 & 0 \\
\hline CG14584 & 109324 Ir20a & 0 \\
\hline CG1887 & 100219 CG1887 & 0 \\
\hline CG14266 & 109556 ng2 & 0 \\
\hline CG42768 & $109023 \mathrm{Msp}-300$ & 0 \\
\hline CG15444 & 8880 ine & 0 \\
\hline CG32796 & 108265 boi & 0 \\
\hline CG7223 & $27180 \mathrm{htl}$ & 2 \\
\hline CG8799 & $100105 \mathrm{I}(2) 03659$ & 0 \\
\hline CG12663 & $108171 \mathrm{Ir} 7 \mathrm{a}$ & 0 \\
\hline CG34396 & 6586 CG34396 & 0 \\
\hline CG34123 & 107537 TrpM & 0 \\
\hline CG15304 & 107937 Neb-cGP & 2 \\
\hline CG8596 & 109291 CG8596 & 0 \\
\hline CG42829 & 101659 CadN2 & 0 \\
\hline CG40263 & 109570 MFS17 & 0 \\
\hline CG17336 & 109606 Lcch3 & 0 \\
\hline CG17370 & $110663 \mathrm{SppL}$ & 0 \\
\hline CG1732 & 13359 CG1732 & 2 \\
\hline CG3822 & 110201 CG3822 & 0 \\
\hline CG12703 & 110698 Pmp70 & 0 \\
\hline CG9990 & 107544 CG9990 & 0 \\
\hline CG9903 & 42689 CG9903 & 0 \\
\hline CG1158 & 9455 Tim17b1 & 0 \\
\hline CG10125 & 33277 zpg & 0 \\
\hline CG4225 & 108877 Hmt-1 & 0 \\
\hline CG34378 & 110248 Pvf3 & 0 \\
\hline CG3811 & 110237 Oatp30B & 0 \\
\hline CG7285 & 110739 star1 & 0 \\
\hline CG33478 & 4848 Or46a & 0 \\
\hline CG18085 & 49925 sev & 0 \\
\hline CG43066 & 101768 CG43066 & 0 \\
\hline
\end{tabular}




\begin{tabular}{|c|c|c|}
\hline CG9981 & 100351 CG9981 & 0 \\
\hline CG34143 & $100181 \operatorname{Ir} 10 a$ & 0 \\
\hline CG3615 & 10045 Atg9 & 0 \\
\hline CG7734 & 3226 shn & 0 \\
\hline CG15591 & 100240 Osi 8 & 0 \\
\hline CG32669 & 102859 CG32669 & 0 \\
\hline CG17119 & 107195 CG17119 & 0 \\
\hline CG8585 & $110274 \mathrm{Ih}$ & 0 \\
\hline CG34369 & 109685 CG34369 & 0 \\
\hline CG15110 & 108262 botv & 0 \\
\hline CG1697 & 100200 rho-4 & 0 \\
\hline CG17930 & 108912 CG17930 & 0 \\
\hline CG5085 & 103790 CG5085 & 0 \\
\hline CG7139 & 35177 CG3139 & 0 \\
\hline CG42242 & 102329 CG42242 & 0 \\
\hline CG4700 & 15810 CG4700 & 0 \\
\hline CG10521 & 100840 CG10521 & 0 \\
\hline CG7127 & 103717 CG7127 & 0 \\
\hline CG1560 & 103704 CG1560 & 2 \\
\hline CG2310 & 104126 CG2310 & 1 \\
\hline CG1200 & 109501 CG1200 & 0 \\
\hline CG11347 & 105330 DOR & 0 \\
\hline CG11347 & 41186 CG11347 & 0 \\
\hline CG2679 & 107822 CG2679 & 0 \\
\hline CG2679 & 37435 CG2679 & 0 \\
\hline CG42679 & 100716 CG42679 & 0 \\
\hline CG42679 & 100113 LIMPET & 0 \\
\hline CG42679 & 34082 CG42679 & 0 \\
\hline CG6998 & 109084 CTP & 0 \\
\hline CG12846 & 105847 TSP42ED & 0 \\
\hline CG11637 & 102359 CG11637 & 0 \\
\hline CG11637 & 48786 CG11637 & 0 \\
\hline CG18361 & 101525 DISHEVELLED & 0 \\
\hline CG6205 & 100780 CG6205 & 0 \\
\hline CG4096 & 108353 CG4096 & 0 \\
\hline CG1063 & $10698217 p-r 83 A$ & 0 \\
\hline CG7954 & 100582 CG7954 & 0 \\
\hline CG9366 & 102461 CG9366 & 0 \\
\hline CG3143 & 106097 CG3143 & 0 \\
\hline CG4080 & 101426 CG4080 & 0 \\
\hline CG43368 & 48092 CG43368 & 0 \\
\hline CG43368 & 104168 Саc \#321 & 0 \\
\hline CG15658 & 102333 lapsyn & 2 \\
\hline CG43368 & 5551 CG43368 & 0 \\
\hline CG5802 & 103753 CG5802 & 2 \\
\hline CG4096 & 109025 CG4096 & 0 \\
\hline CG43368 & 48093 CG43368 & 0 \\
\hline CG8725 & 28941 CG8725 & 0 \\
\hline
\end{tabular}




\begin{tabular}{|c|c|c|}
\hline CG5802 & 6800 CG5802 & 0 \\
\hline CG17117 & 12763 CG17117 & 2 \\
\hline CG17117 & $100630 \mathrm{HTH}$ & 2 \\
\hline CG43368 & 43368 CG43368 & 0 \\
\hline CG8725 & 28942 CG8725 & 0 \\
\hline CG15658 & 3040 CG15658 & 2 \\
\hline CG17117 & 12764 CG17117 & 0 \\
\hline CG3936 & $1112 \mathrm{~N}$ & 0 \\
\hline CG5508 & 1316 mino & 0 \\
\hline CG11144 & 1793 mGluR & 0 \\
\hline CG11144 & 1794 mGluR & 0 \\
\hline CG4717 & 2980 kni & 0 \\
\hline CG4717 & 2981 kni & 0 \\
\hline CG11614 & $3005 \mathrm{nkd}$ & 0 \\
\hline CG3394 & 3621 Fatp3 & 0 \\
\hline CG11387 & $4138 \mathrm{ct}$ & 0 \\
\hline CG18507 & 7705 CG18507 & 0 \\
\hline CG6906 & $8357 \mathrm{CAH} 2$ & 0 \\
\hline CG3940 & 13807 САH7 & 0 \\
\hline CG7047 & 15204 Vdup1 & 0 \\
\hline CG33956 & 19512 kay & 0 \\
\hline CG2845 & 20909 Raf & 2 \\
\hline CG42678 & 21114 ReepA & 0 \\
\hline CG31317 & 21317 stumps & 2 \\
\hline CG5344 & 22082 wkd & 0 \\
\hline CG5838 & 22209 Dref & 2 \\
\hline CG5838 & 22210 Dref & 2 \\
\hline CG6148 & 22254 Past1 & 0 \\
\hline CG3936 & $27229 \mathrm{~N}$ & 0 \\
\hline CG9559 & 28667 fog & 0 \\
\hline CG33110 & 29689 CG33110 & 2 \\
\hline CG8721 & 30038 Odc1 & 0 \\
\hline CG10627 & 31298 nst & 0 \\
\hline CG31211 & 33787 CG31211 & 0 \\
\hline CG4394 & 34836 Traf-like & 0 \\
\hline CG42678 & 39474 ReepA & 1 \\
\hline CG31366 & 41749 Hsp70Aa & 2 \\
\hline CG3297 & $42485 \mathrm{mnd}$ & 0 \\
\hline CG1322 & 42856 zfh 1 & 0 \\
\hline CG1322 & 42857 zfh1 & 0 \\
\hline CG4527 & 43784 Slik & 0 \\
\hline CG10076 & 44092 spir & 0 \\
\hline CG31523 & 45226 CG31523 & 0 \\
\hline CG9485 & 45809 CG9485 & 0 \\
\hline CG9127 & 47972 Pfas & 0 \\
\hline CG5493 & 50637 CG5493 & 0 \\
\hline CG12070 & 51129 Sap-r & 0 \\
\hline CG12070 & 51130 Sap-r & 0 \\
\hline
\end{tabular}




\begin{tabular}{|c|c|c|}
\hline CG2125 & $51479 \mathrm{ci}$ & 0 \\
\hline CG3936 & $100002 \mathrm{~N}$ & 1 \\
\hline CG4389 & 100021 Mtpalpha & 0 \\
\hline CG9009 & 100411 pdgy & 0 \\
\hline CG7409 & 100517 CG7409 & \\
\hline CG6378 & 100566 SPARC & 0 \\
\hline CG5403 & 100579 retn & \\
\hline CG9238 & 100593 Gbs-70E & 0 \\
\hline CG32717 & $100685 \mathrm{sdt}$ & \\
\hline CG13124 & 100966 CG13124 & 0 \\
\hline CG6058 & 101339 Ald1 & \\
\hline CG42311 & 101428 grh & 0 \\
\hline CG17228 & 101477 pros & 0 \\
\hline CG4859 & $101505 \mathrm{Mmp} 1$ & 0 \\
\hline CG6509 & 101596 Dlg5 & 0 \\
\hline CG4070 & 101765 Tis11 & 0 \\
\hline CG4250 & 101949 CG4250 & 0 \\
\hline CG13503 & $102253 \operatorname{Vrp} 1$ & 0 \\
\hline CG30269 & 102266 CG30269 & 1 \\
\hline CG8630 & 102299 CG8630 & 0 \\
\hline CG31694 & 103565 CG31694 & 0 \\
\hline CG17657 & 103611 frtz & 0 \\
\hline CG33174 & 103713 inaE & 0 \\
\hline CG1664 & $103715 \mathrm{sbr}$ & 0 \\
\hline CG3331 & $104174 \mathrm{e}$ & 0 \\
\hline CG14032 & 104515 Сур4ас1 & 0 \\
\hline CG4005 & 104523 yki & 0 \\
\hline CG11405 & 105036 Atf3 & 0 \\
\hline CG32180 & 105301 Eip74EF & 0 \\
\hline CG10627 & 105398 nst & 0 \\
\hline CG6214 & $105419 \mathrm{MRP}$ & 0 \\
\hline CG4501 & 105635 bgm & 2 \\
\hline CG42665 & 105885 Exn & 0 \\
\hline CG31999 & 106122 CG31999 & 0 \\
\hline CG10842 & 106354 Сур4p1 & 0 \\
\hline CG33967 & 106507 kibra & 0 \\
\hline CG5326 & 106540 CG5326 & 0 \\
\hline CG43443 & 106577 hts & 0 \\
\hline CG9485 & 106668 CG9485 & 0 \\
\hline CG5588 & $108427 \mathrm{Mtl}$ & 0 \\
\hline CG15629 & 108604 CG15629 & 0 \\
\hline CG8085 & 108670 RN-tre & 0 \\
\hline CG11100 & 109111 Mes2 & 0 \\
\hline CG12559 & $109193 \mathrm{rl}$ & 0 \\
\hline CG12559 & $109200 \mathrm{rl}$ & 0 \\
\hline CG10939 & 109289 CG10939 & 0 \\
\hline CG12559 & $109573 \mathrm{rl}$ & 0 \\
\hline CG11621 & $109582 \mathrm{Pi3K68D}$ & \\
\hline
\end{tabular}




\begin{tabular}{|c|c|c|}
\hline CG33087 & 109605 LRP1 & 0 \\
\hline CG33080 & 109888 CG33080 & 0 \\
\hline CG31163 & 109892 SKIP & 0 \\
\hline CG11440 & 109898 laza & 1 \\
\hline CG1673 & 110229 CG1673 & 0 \\
\hline CG6706 & 110268 GABA-B-R2 & 0 \\
\hline CG6016 & 110371 bbc & 0 \\
\hline CG1817 & 110443 Ptp10D & 0 \\
\hline CG43444 & 110549 Tet & 1 \\
\hline CG1167 & 110574 Ras64B & 0 \\
\hline CG9635 & 110577 RhoGEF2 & 0 \\
\hline CG16833 & 110676 TTLL4A & 0 \\
\hline CG6638 & 110684 CG6638 & 0 \\
\hline CG10037 & $110723 \mathrm{vvl}$ & 0 \\
\hline CG3048 & 110766 Traf4 & 0 \\
\hline CG5803 & 940 Fas3 & 0 \\
\hline CG6178 & 1172 CG6178 & 0 \\
\hline CG10021 & 3775 bowl & 0 \\
\hline CG9985 & 6229 sktl & 2 \\
\hline CG2930 & 7031 CG2930 & 0 \\
\hline CG33166 & 7434 stet & 0 \\
\hline CG11437 & 9452 CG11437 & 0 \\
\hline CG9310 & $12692 \mathrm{Hnf} 4$ & 0 \\
\hline CG2145 & 14874 CG2145 & 2 \\
\hline CG32209 & 15466 serp & 0 \\
\hline CG10970 & 16136 CG10970 & 0 \\
\hline CG14489 & 17657 olf186-M & 0 \\
\hline CG11153 & 19022 Sox102F & 0 \\
\hline CG2867 & 20926 Prat & 0 \\
\hline CG9665 & $23720 \mathrm{Cpr} 73 \mathrm{D}$ & 0 \\
\hline CG12449 & 24540 Gfat1 & 0 \\
\hline CG10680 & 26758 CG10680 & 0 \\
\hline CG1634 & $27202 \mathrm{Nrg}$ & 0 \\
\hline CG10618 & 27290 CHKov1 & 0 \\
\hline CG5687 & 33262 CG5687 & 0 \\
\hline CG9019 & 33909 dsf & 0 \\
\hline CG6701 & 36557 CG6701 & 0 \\
\hline CG2841 & 36665 CG2841 & 0 \\
\hline CG1106 & 37865 Gel & 0 \\
\hline CG8808 & 37968 Pdk & 0 \\
\hline CG42369 & 38008 CG42369 & 0 \\
\hline CG5867 & 38020 CG5867 & 0 \\
\hline CG42679 & $42892 \mathrm{Lmpt}$ & 0 \\
\hline CG1124 & 43210 CG1124 & 0 \\
\hline CG4690 & 45739 Tsp5D & 0 \\
\hline CG32019 & $46253 \mathrm{bt}$ & 0 \\
\hline CG17292 & 46538 CG17292 & 0 \\
\hline CG3874 & $47543 \mathrm{frc}$ & 0 \\
\hline
\end{tabular}




\begin{tabular}{|c|c|c|}
\hline CG17029 & 49565 CG17029 & 0 \\
\hline CG33720 & 49782 Pif1B & 0 \\
\hline CG31447 & 50586 MESK4 & 0 \\
\hline CG7595 & 100010 ck & 0 \\
\hline CG2380 & $100018 \mathrm{Nfl}$ & 0 \\
\hline CG5958 & 100038 CG5958 & 0 \\
\hline CG11910 & $100085 \mathrm{alrm}$ & 0 \\
\hline CG17028 & 100100 CG17028 & 0 \\
\hline CG9512 & 100193 CG9512 & 0 \\
\hline CG9649 & 100194 CG9649 & 0 \\
\hline CG31976 & 100198 ovm & 2 \\
\hline CG33522 & 100199 scaf6 & 0 \\
\hline CG9390 & 100281 AcCoAS & 0 \\
\hline CG15661 & 100321 Ugt49C1 & 0 \\
\hline CG4409 & 100354 CG4409 & 0 \\
\hline CG33189 & 100386 CG33189 & 2 \\
\hline CG5643 & $101406 \mathrm{wdb}$ & 0 \\
\hline CG43657 & 101729 Муо10A & 0 \\
\hline CG10851 & 101740 B52 & 0 \\
\hline CG17364 & 101844 CG17364 & 0 \\
\hline CG34100 & $101867 \mathrm{mld}$ & 0 \\
\hline CG1856 & $101980 \mathrm{ttk}$ & 2 \\
\hline CG32695 & 102678 CG32695 & 0 \\
\hline CG33177 & 102679 CG33177 & 0 \\
\hline CG44325 & 102684 CG44325 & 0 \\
\hline CG8740 & 102750 CG8740 & 0 \\
\hline CG16743 & 102762 CG16743 & 0 \\
\hline CG45017 & 102772 IP3K2 & 0 \\
\hline CG42613 & 102823 CG42613 & 0 \\
\hline CG9902 & 102850 CG9902 & 0 \\
\hline CG15293 & 102861 CG15293 & 0 \\
\hline CG11801 & 103506 Elo68beta & 0 \\
\hline CG11909 & 103544 tobi & 0 \\
\hline CG30421 & 103553 Usp15-31 & 0 \\
\hline CG11194 & 103570 Hey & 0 \\
\hline CG30483 & 103592 Prosap & 0 \\
\hline CG7980 & 103630 RabX5 & 0 \\
\hline CG10743 & 103645 Liprin-beta & 0 \\
\hline CG3328 & 103651 CG3328 & 0 \\
\hline CG5455 & 104118 CG5455 & 0 \\
\hline CG33991 & 104172 nuf & 0 \\
\hline CG6816 & 104180 Сур18a1 & 0 \\
\hline CG3095 & $104214 \mathrm{hfw}$ & 0 \\
\hline CG7206 & 104572 CG7206 & 0 \\
\hline CG42274 & 104589 RhoGAP18B & 0 \\
\hline CG32356 & 104613 ImpE1 & 0 \\
\hline CG9347 & 104683 ninaB & 0 \\
\hline CG33484 & 104689 zormin & 0 \\
\hline
\end{tabular}




\begin{tabular}{|c|c|c|}
\hline CG3019 & $104716 \mathrm{su}(\mathrm{w}[\mathrm{a}])$ & 0 \\
\hline CG32513 & 104719 bves & 0 \\
\hline CG7486 & 104726 Dredd & 0 \\
\hline CG32239 & 105252 RhoGEF64C & 0 \\
\hline CG30460 & 105307 CG30460 & 0 \\
\hline CG15546 & 105784 CG15546 & 0 \\
\hline CG7125 & 106255 PKD & 0 \\
\hline CG4500 & $106260 \mathrm{hll}$ & 2 \\
\hline CG1092 & 106284 CG1092 & 0 \\
\hline CG31769 & 106293 CG31769 & 0 \\
\hline CG43078 & 106298 CG43078 & 0 \\
\hline CG3488 & 106307 Hydr2 & 0 \\
\hline CG17273 & 106314 AdSS & 0 \\
\hline CG8086 & 106334 CG8086 & 0 \\
\hline CG5023 & 106355 CG5023 & 0 \\
\hline CG31352 & 106405 Unc-115a & 0 \\
\hline CG33261 & $106433 \mathrm{Trl}$ & 0 \\
\hline CG2272 & $106449 \mathrm{slpr}$ & 0 \\
\hline CG2789 & 106470 Tspo & 0 \\
\hline CG15112 & 106484 ena & 0 \\
\hline CG9220 & 106839 CG9220 & 0 \\
\hline CG11525 & 106846 CycG & 0 \\
\hline CG10374 & 106891 Lsd-1 & 2 \\
\hline CG6945 & 106907 sstn & 0 \\
\hline CG5541 & 106909 CG5541 & 0 \\
\hline CG9023 & 106911 Drip & 0 \\
\hline CG31706 & 107174 CG31706 & 0 \\
\hline CG18445 & 107418 oys & 0 \\
\hline CG3937 & 107451 cher & 0 \\
\hline CG10026 & 107452 CG10026 & 0 \\
\hline CG1136 & 107455 CG1136 & 0 \\
\hline CG4680 & 107457 Gagr & 0 \\
\hline CG31762 & 107459 bru1 & 0 \\
\hline CG14629 & 107496 CG14629 & 0 \\
\hline CG12038 & 107527 CG12038 & 0 \\
\hline CG3541 & 107534 pio & 0 \\
\hline CG11407 & 107610 CG11407 & 0 \\
\hline CG10645 & 107629 lama & 0 \\
\hline CG3050 & 107641 Сyp6d5 & 0 \\
\hline CG7414 & 107955 CG7414 & 0 \\
\hline CG6649 & 108160 Ugt35B1 & 0 \\
\hline CG4962 & 108198 CG4962 & 0 \\
\hline CG5249 & 108374 Blimp-1 & 0 \\
\hline CG42265 & 108591 OtopLc & 0 \\
\hline CG34404 & 108594 CG34404 & 0 \\
\hline CG8909 & $108629 \operatorname{Lrp} 4$ & 0 \\
\hline CG31326 & 108815 CG31326 & 0 \\
\hline CG44244 & 109071 Gyg & 0 \\
\hline
\end{tabular}




\begin{tabular}{|c|c|c|}
\hline CG12505 & 109141 Arc1 & 0 \\
\hline CG40005 & 109148 CR40005 & 0 \\
\hline CG11765 & $109152 \operatorname{Pr} \times 2540-2$ & 0 \\
\hline CG33105 & 109179 p24-2 & 0 \\
\hline CG12896 & 109180 CG12896 & 0 \\
\hline CG4385 & $109838 \mathrm{~S}$ & 0 \\
\hline CG42599 & 109849 Pif1A & 0 \\
\hline CG12581 & 109871 CG12581 & 0 \\
\hline CG31176 & 109897 CG31176 & 0 \\
\hline CG43897 & 109901 CG43897 & 0 \\
\hline CG5840 & 109908 P5cr-2 & 0 \\
\hline CG1220 & 109970 Kaz1-ORFB & 0 \\
\hline CG4104 & 110050 Tps1 & 0 \\
\hline CG8628 & 110103 Acbp3 & 2 \\
\hline CG7217 & $110117 \operatorname{Prx5}$ & 0 \\
\hline CG43770 & $110137 \mathrm{SxI}$ & 0 \\
\hline CG11659 & 110139 CG11659 & 0 \\
\hline CG7766 & 110184 CG7766 & 0 \\
\hline CG44533 & 110603 Nna1 & 0 \\
\hline CG1830 & 110638 PhKgamma & 0 \\
\hline CG43394 & 2793 CG43394 & 0 \\
\hline CG12116 & 6498 CG12116 & 0 \\
\hline CG1817 & 8010 Ptp10D & 2 \\
\hline CG11715 & 8034 Сур4g15 & 0 \\
\hline CG11066 & 13249 scaf & 0 \\
\hline CG2985 & 13343 Yp1 & 0 \\
\hline CG14153 & 14109 CG14153 & 0 \\
\hline CG3246 & 15580 CG3246 & 2 \\
\hline CG42230 & 15975 bbg & 0 \\
\hline CG10365 & 16037 CG10365 & 0 \\
\hline CG10514 & 16063 CG10514 & 0 \\
\hline CG32372 & $18977 \mathrm{lt} \mid$ & 0 \\
\hline CG15105 & 19291 tn & 0 \\
\hline CG18445 & 20099 oys & 0 \\
\hline CG1691 & $20321 \mathrm{Imp}$ & 0 \\
\hline CG31712 & 21401 CG31712 & 0 \\
\hline CG8010 & 22667 CG8010 & 0 \\
\hline CG8745 & 23620 CG8745 & 2 \\
\hline CG30092 & 28471 jbug & 0 \\
\hline CG13707 & 29257 CG13707 & 0 \\
\hline CG11172 & 30567 NFAT & 0 \\
\hline CG10837 & 31364 elF4B & 0 \\
\hline CG16901 & 32395 sqd & 0 \\
\hline CG17523 & 32945 GstE2 & 0 \\
\hline CG17838 & 33012 Syp & 2 \\
\hline CG34383 & 38787 kmr & 0 \\
\hline CG1483 & 39690 Map205 & 0 \\
\hline CG10433 & 41162 CG10433 & 0 \\
\hline
\end{tabular}




\begin{tabular}{|c|c|c|}
\hline CG1212 & 41479 p130CAS & 0 \\
\hline CG8978 & 42172 Arpc1 & 0 \\
\hline CG31158 & 42321 Efa6 & 0 \\
\hline CG31100 & 42630 CG31100 & \\
\hline CG3829 & 42872 CG3829 & \\
\hline CG14141 & 43018 nkt & \\
\hline CG9528 & 44687 retm & \\
\hline CG5099 & 44895 msi & \\
\hline CG9467 & 45807 CG9467 & \\
\hline CG33494 & 47112 CG33494 & \\
\hline CG17514 & $47269 \mathrm{I}(3) 80 \mathrm{Fj}$ & \\
\hline CG14224 & 47449 Ubqn & \\
\hline CG4404 & 48184 CG4404 & \\
\hline CG33052 & 48410 Gorab & \\
\hline CG17026 & 49200 CG17026 & \\
\hline CG33229 & 49217 CG33229 & \\
\hline CG1742 & 49320 Mgstl & \\
\hline CG33178 & 49464 CG33178 & \\
\hline CG18853 & 50099 CG18853 & \\
\hline CG43067 & 50200 FoxP & \\
\hline CG11889 & 50352 CG11889 & 0 \\
\hline CG7509 & 51584 CG7509 & $U$ \\
\hline CG8091 & 100424 Dronc & 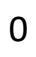 \\
\hline CG2194 & $100560 \mathrm{su}(\mathrm{r})$ & 0 \\
\hline CG9507 & $100641 \mathrm{Nepl5}$ & 0 \\
\hline CG5803 & 100642 Fas3 & 0 \\
\hline CG31676 & 100658 CG31676 & 0 \\
\hline CG11901 & 100693 eEF1gamma & 2 \\
\hline CG3926 & 100698 Spat & 0 \\
\hline CG8846 & 100739 Thor & 0 \\
\hline CG32687 & 100795 CG32687 & 0 \\
\hline CG18177 & 101408 Naa60 & 0 \\
\hline CG1417 & 101449 slgA & 0 \\
\hline CG7470 & 101476 CG7470 & 0 \\
\hline CG14792 & 101495 sta & 2 \\
\hline CG13116 & 101563 CG13116 & 0 \\
\hline CG31673 & 101618 CG31673 & 0 \\
\hline CG10175 & 101643 CG10175 & 0 \\
\hline CG33957 & 101645 Plp & 0 \\
\hline CG42345 & 101687 stw & 0 \\
\hline CG8012 & 101924 CG8012 & 0 \\
\hline CG6096 & 101948 E(spl)m5-HLH & 0 \\
\hline CG44838 & 101978 CG44838 & 2 \\
\hline CG1128 & 102058 alpha-Est9 & 0 \\
\hline CG4716 & 102087 CG4716 & 0 \\
\hline CG42234 & $102396 \mathrm{Dbx}$ & 0 \\
\hline CG15717 & 102398 CG15717 & 0 \\
\hline CG43395 & $102411 \mathrm{Cngl}$ & \\
\hline
\end{tabular}




\begin{tabular}{|c|c|c|}
\hline CG2082 & 102438 CG2082 & 0 \\
\hline CG5955 & 102443 CG5955 & 0 \\
\hline CG3638 & 102444 CG3638 & 2 \\
\hline CG16886 & 102445 Vajk1 & 0 \\
\hline CG31778 & 102505 CG31778 & 0 \\
\hline CG10287 & 102518 Gasp & 0 \\
\hline CG31764 & 102534 vir-1 & 0 \\
\hline CG7478 & 102588 Act79B & 0 \\
\hline CG10675 & 102615 CHKov2 & 0 \\
\hline CG31974 & 102631 CG31974 & 0 \\
\hline CG4294 & 102636 CG4294 & 2 \\
\hline CG9812 & 102880 CG9812 & 0 \\
\hline CG16756 & 102908 CG16756 & 0 \\
\hline CG45049 & 102985 CG45049 & 0 \\
\hline CG32694 & 103234 CG32694 & 0 \\
\hline CG17027 & 103270 CG17027 & 0 \\
\hline CG44015 & $103382 \mathrm{Hph}$ & 0 \\
\hline CG3665 & 103807 Fas2 & 0 \\
\hline CG4677 & 103821 Imd & 0 \\
\hline CG5791 & 103825 BomBc3 & 0 \\
\hline CG9780 & 103966 Nepl11 & 0 \\
\hline CG10560 & 104272 CG10560 & 0 \\
\hline CG9394 & 104278 CG9394 & 0 \\
\hline CG15532 & $104322 \mathrm{hdc}$ & 2 \\
\hline CG9904 & 104326 Seipin & 0 \\
\hline CG18389 & 104390 Eip93F & 2 \\
\hline CG10157 & 104414 GILT2 & 0 \\
\hline CG10225 & 104432 RanBP3 & 0 \\
\hline CG44193 & 104438 Cdep & 0 \\
\hline CG1869 & 104445 Cht7 & 0 \\
\hline CG8280 & 104502 eEF1alpha1 & 2 \\
\hline CG6659 & 104503 CG6659 & 0 \\
\hline CG42351 & 104543 Jabba & 0 \\
\hline CG2397 & 104735 Сур6а13 & 0 \\
\hline CG31619 & 104736 nolo & 0 \\
\hline CG31973 & $104771 \mathrm{Cda} 5$ & 0 \\
\hline CG9450 & 105108 tud & 0 \\
\hline CG9098 & 105144 CG9098 & 0 \\
\hline CG2467 & 105189 pot & 1 \\
\hline CG40494 & 105202 RhoGAP1A & 0 \\
\hline CG8907 & 105372 CG8907 & 0 \\
\hline CG12891 & 105400 whd & 0 \\
\hline CG43398 & 105412 scrib & 0 \\
\hline CG32982 & 105472 CG32982 & 0 \\
\hline CG33197 & $105486 \mathrm{mbl}$ & 0 \\
\hline CG7437 & 105495 mub & 0 \\
\hline CG1803 & 105509 regucalcin & 0 \\
\hline CG1443 & 105518 wat & 0 \\
\hline
\end{tabular}




\begin{tabular}{|c|c|c|}
\hline CG2520 & 105767 lap & 0 \\
\hline CG6034 & 105780 CG6034 & 0 \\
\hline CG18330 & 105794 Pcyt2 & 0 \\
\hline CG43729 & 105848 Stacl & 0 \\
\hline CG8815 & $105852 \operatorname{Sin} 3 A$ & 0 \\
\hline CG1987 & 105883 Rbp1-like & 0 \\
\hline CG10550 & 106064 CG10550 & 0 \\
\hline CG3593 & $106090 \mathrm{r}-\mathrm{I}$ & 0 \\
\hline CG8224 & 106092 babo & 0 \\
\hline CG8817 & 106142 lilli & 0 \\
\hline CG4615 & 106673 CG4615 & 0 \\
\hline CG2179 & $106690 \mathrm{Xe7}$ & 0 \\
\hline CG10553 & 106737 CG10553 & 0 \\
\hline CG9977 & 106749 AhcyL1 & 0 \\
\hline CG1545 & 106790 CG1545 & 0 \\
\hline CG5893 & $107194 \mathrm{D}$ & 0 \\
\hline CG31753 & 107275 ham & 0 \\
\hline CG5583 & 107292 Ets98B & 0 \\
\hline CG34126 & 107307 CG34126 & 0 \\
\hline CG1753 & $107325 \mathrm{Cbs}$ & 0 \\
\hline CG11049 & 107343 sv & 0 \\
\hline CG7021 & 107366 Elal & 0 \\
\hline CG3308 & 107374 CG3308 & 0 \\
\hline CG12023 & 107768 GV1 & 0 \\
\hline CG13003 & 107843 CG13003 & 0 \\
\hline CG9932 & 107846 CG9932 & 0 \\
\hline CG1146 & 107857 CG1146 & 0 \\
\hline CG10237 & 108388 CG10237 & 0 \\
\hline CG42671 & 109186 CG42671 & 0 \\
\hline CG8629 & 109198 Acbp4 & 0 \\
\hline CG14995 & 109283 CG14995 & 0 \\
\hline CG3767 & 109317 Jhl-26 & 0 \\
\hline CG42329 & 110085 CG42329 & 0 \\
\hline CG32555 & 110213 RhoGAPp190 & 0 \\
\hline CG10185 & 110223 CG10185 & 0 \\
\hline CG12132 & 110241 c11.1 & 0 \\
\hline CG43693 & 110246 CG43693 & 0 \\
\hline CG18599 & 110312 CG18599 & 0 \\
\hline CG11186 & 110353 toy & 0 \\
\hline CG32082 & 110374 IRSp53 & 0 \\
\hline CG13458 & 110492 CG13458 & 0 \\
\hline CG32062 & 110518 Rbfox1 & 0 \\
\hline CG8547 & 110523 CG8547 & 0 \\
\hline CG7450 & 110650 CrebA & 0 \\
\hline CG1449 & 110784 zfh2 & 0 \\
\hline CG9930 & 110804 E5 & 0 \\
\hline CG10823 & $1783 \mathrm{SIFaR}$ & 0 \\
\hline CG2789 & 2507 Tspo & 0 \\
\hline
\end{tabular}




\begin{tabular}{|c|c|c|}
\hline CG3131 & 2593 Duox & 0 \\
\hline CG4847 & 3231 CG4847 & 0 \\
\hline CG10697 & $3329 \mathrm{Ddc}$ & 0 \\
\hline CG15162 & 3339 MESR3 & 0 \\
\hline CG7442 & 8450 SLC22A & 0 \\
\hline CG32072 & 9206 Elo68alpha & 0 \\
\hline CG2988 & 9417 ems & 0 \\
\hline CG14777 & 9737 CG14777 & 0 \\
\hline CG31240 & 10424 repo & 2 \\
\hline CG5966 & 13164 CG5966 & 0 \\
\hline CG13676 & 14063 CG13676 & 0 \\
\hline CG11842 & 14853 CG11842 & 0 \\
\hline CG12090 & $16390 \mathrm{Iml}$ & 0 \\
\hline CG31332 & 16813 Unc-115b & 0 \\
\hline CG5321 & 22061 CG5321 & 0 \\
\hline CG34413 & 23153 NKAIN & 0 \\
\hline CG13873 & 23206 Obp56g & 0 \\
\hline CG5804 & 23587 Acbp5 & 0 \\
\hline CG9391 & 23725 CG9391 & 0 \\
\hline CG8464 & $24106 \mathrm{HtrA2}$ & 0 \\
\hline CG5973 & 24998 CG5973 & 0 \\
\hline CG3083 & $25020 \operatorname{Prx} 6005$ & 0 \\
\hline CG30159 & 25586 CG30159 & 0 \\
\hline CG5803 & 26852 Fas3 & 0 \\
\hline CG32169 & $29799 \mathrm{Rbp} 6$ & 0 \\
\hline CG32138 & $34412 \mathrm{Frl}$ & 0 \\
\hline CG3764 & 34708 CG3764 & 1 \\
\hline CG11205 & $35499 \mathrm{phr}$ & 0 \\
\hline CG30084 & 36563 Zasp52 & 0 \\
\hline CG12344 & 37165 CG12344 & 0 \\
\hline CG3413 & 37209 wdp & 0 \\
\hline CG7888 & 37264 CG7888 & 0 \\
\hline CG31522 & 37329 CG31522 & 0 \\
\hline CG31274 & 40223 CG31274 & 0 \\
\hline CG5072 & 40577 Cdk4 & 0 \\
\hline CG17691 & 40686 CG17691 & 0 \\
\hline CG2893 & 40987 zyd & 2 \\
\hline CG31605 & 43307 Bsg & 0 \\
\hline CG1412 & 43955 RhoGAP19D & 0 \\
\hline CG11967 & 44117 CAHbeta & 0 \\
\hline CG11891 & 44271 CG11891 & 0 \\
\hline CG9389 & 44663 CG9389 & 0 \\
\hline CG6199 & 45486 Plod & 0 \\
\hline CG3168 & 48011 CG3168 & 0 \\
\hline CG1552 & 48551 CG1552 & 0 \\
\hline CG2979 & 50156 Yp2 & 2 \\
\hline CG12405 & $50772 \operatorname{Prx} 2540-1$ & 0 \\
\hline CG1629 & 100481 yellow-h & 0 \\
\hline
\end{tabular}




\begin{tabular}{|c|c|c|}
\hline CG31445 & 100932 CG31445 & 0 \\
\hline CG12945 & 100936 CG12945 & 0 \\
\hline CG6067 & 100950 CG6067 & 0 \\
\hline CG13360 & 100997 CG13360 & 0 \\
\hline CG14153 & 101041 CG14153 & 0 \\
\hline CG3897 & 101083 blot & 0 \\
\hline CG43901 & 101093 CG43901 & 0 \\
\hline CG3234 & $101100 \mathrm{tim}$ & 0 \\
\hline CG14630 & 101204 CG14630 & 0 \\
\hline CG32220 & 101396 Csas & 0 \\
\hline CG8367 & $102054 \mathrm{cg}$ & 2 \\
\hline CG13252 & 102110 CG13252 & 0 \\
\hline CG13432 & 102182 qsm & 0 \\
\hline CG14935 & $102201 \mathrm{Mal}-\mathrm{B} 2$ & 0 \\
\hline CG5835 & 102220 CG5835 & 0 \\
\hline CG9057 & 102269 Lsd-2 & 0 \\
\hline CG4710 & 102281 Pino & 0 \\
\hline CG12175 & $102295 \mathrm{tth}$ & 0 \\
\hline CG12781 & 102319 nahoda & 0 \\
\hline CG8788 & 102344 CG8788 & 0 \\
\hline CG33968 & 103032 drd & 0 \\
\hline CG11425 & 103037 CG11425 & 0 \\
\hline CG12045 & 103041 Cpr100A & 0 \\
\hline CG9619 & 103044 Gbs-76A & 0 \\
\hline CG17271 & 103101 CG17271 & 0 \\
\hline CG6910 & 103766 CG6910 & 0 \\
\hline CG34398 & 103861 CG34398 & 0 \\
\hline CG17754 & 104337 CG17754 & 0 \\
\hline CG6321 & 104408 CG6321 & 0 \\
\hline CG34394 & 104874 GramD1B & 0 \\
\hline CG7345 & 104888 Sox21a & 0 \\
\hline CG16705 & 104906 SPE & 0 \\
\hline CG16844 & 104908 BomS3 & 0 \\
\hline CG16704 & 104956 CG16704 & 0 \\
\hline CG8956 & 104964 AhcyL2 & 0 \\
\hline CG9336 & 104986 CG9336 & 0 \\
\hline CG7068 & 105530 Тер3 & 0 \\
\hline CG3244 & 105562 slf & 0 \\
\hline CG4335 & 105611 CG4335 & 0 \\
\hline CG31732 & 105697 yuri & 0 \\
\hline CG30069 & 105841 CG30069 & 0 \\
\hline CG3597 & 106006 CG3597 & 0 \\
\hline CG14996 & 106455 Chd64 & 0 \\
\hline CG2163 & 106466 Pabp2 & 2 \\
\hline CG8865 & $106468 \mathrm{Rgl}$ & 0 \\
\hline CG4678 & 106490 CG4678 & 0 \\
\hline CG45051 & 106504 sima & 0 \\
\hline CG31509 & 106548 TotA & 0 \\
\hline
\end{tabular}




\begin{tabular}{|c|c|c|}
\hline CG6040 & 106606 CG6040 & 0 \\
\hline CG43313 & 106610 CG43313 & 0 \\
\hline CG1464 & 106628 ey & 0 \\
\hline CG33526 & 106862 PNUTS & 0 \\
\hline CG14616 & 106973 I(1)G0196 & 0 \\
\hline CG30147 & $106992 \mathrm{Hil}$ & 0 \\
\hline CG17896 & 107006 CG17896 & 0 \\
\hline CG8811 & 107043 muskelin & 0 \\
\hline CG30011 & 107051 gem & 0 \\
\hline CG42702 & 107061 Oaz & 0 \\
\hline CG42273 & $107066 \mathrm{mnb}$ & 0 \\
\hline CG6042 & 107088 Сур12a4 & 0 \\
\hline CG34417 & 107122 CG34417 & 0 \\
\hline CG9628 & 107136 CG9628 & 0 \\
\hline CG3090 & 107146 Sox14 & 0 \\
\hline CG10514 & 107169 CG10514 & 0 \\
\hline CG9850 & 107199 sona & 0 \\
\hline CG2155 & 107798 v & 0 \\
\hline CG33103 & 108005 Ppn & 0 \\
\hline CG10348 & 108049 CG10348 & 0 \\
\hline CG11804 & 108101 ced-6 & 0 \\
\hline CG16947 & 108103 Rchy1 & 0 \\
\hline CG43286 & 108127 cnc & 0 \\
\hline CG4434 & 108274 bb8 & 0 \\
\hline CG7860 & 108281 CG7860 & 0 \\
\hline CG9134 & 108295 tfc & 0 \\
\hline CG43340 & 108330 CG43340 & 0 \\
\hline CG42610 & 108347 Fhos & 0 \\
\hline CG8032 & 108652 CG8032 & 0 \\
\hline CG16884 & 108690 Vajk3 & 2 \\
\hline CG8864 & 108709 Сур28а5 & 0 \\
\hline CG9438 & 108766 Сур6а2 & 0 \\
\hline CG45186 & 108962 Svil & 2 \\
\hline CG33111 & 108980 CG33111 & 0 \\
\hline CG42748 & 108990 CG42748 & 0 \\
\hline CG12730 & 109016 CG12730 & 0 \\
\hline CG5381 & 109022 CG5381 & 0 \\
\hline CG42390 & 109325 CG42390 & 0 \\
\hline CG5320 & 109499 Gdh & 2 \\
\hline CG40160 & 109559 CG40160 & 0 \\
\hline CG12926 & 109580 CG12926 & 0 \\
\hline CG31719 & 109586 RluA-1 & 0 \\
\hline CG8177 & 109594 Ae2 & 0 \\
\hline CG5651 & 109630 pix & 2 \\
\hline CG17342 & 109663 Lk6 & 0 \\
\hline CG44162 & 109937 Strn-Mlck & 0 \\
\hline CG13606 & 109997 CG13606 & 0 \\
\hline CG17136 & 110008 Rbp1 & 0 \\
\hline
\end{tabular}




\begin{tabular}{|c|c|c|}
\hline CG1702 & 110018 GstT3 & 0 \\
\hline CG31751 & 110319 CG31751 & 0 \\
\hline CG7749 & 110390 kug & 0 \\
\hline CG12582 & 110464 beta-Man & 0 \\
\hline CG3705 & 110661 aay & 0 \\
\hline CG8442 & 108019 GluRIA & 0 \\
\hline CG9280 & 101918 Glt & 0 \\
\hline CG32498 & 107967 dnc & 0 \\
\hline CG10047 & 33317 Syt4 & 0 \\
\hline CG10609 & 13386 Orco & 0 \\
\hline CG31999 & 29155 CG31999 & 0 \\
\hline CG1058 & $105463 \mathrm{rpk}$ & 0 \\
\hline CG14743 & 105880 CG14743 & 0 \\
\hline CG7875 & $1366 \operatorname{trp}$ & 0 \\
\hline CG10334 & $103817 \mathrm{spi}$ & 0 \\
\hline CG3389 & 8408 Cad88C & 0 \\
\hline CG10808 & 100789 Syngr & 1 \\
\hline CG5670 & 100619 Atpalpha & 2 \\
\hline CG6977 & 105901 Cad87A & 0 \\
\hline CG7447 & 106464 slow & 0 \\
\hline CG10609 & 100825 Orco & 0 \\
\hline CG12210 & 102922 Syb & 2 \\
\hline CG3139 & 100608 Syt 1 & 0 \\
\hline CG5685 & 104789 Calx & 0 \\
\hline CG7526 & 104254 frac & 0 \\
\hline CG3856 & 106511 Oamb & 0 \\
\hline CG12295 & $108569 \mathrm{stj}$ & 0 \\
\hline CG6378 & 100566 SPARC & 0 \\
\hline CG18250 & $107029 \mathrm{Dg}$ & 0 \\
\hline CG1634 & $107991 \mathrm{Nrg}$ & 0 \\
\hline CG9907 & 104775 para & 0 \\
\hline CG9976 & 100935 Lectin-galC1 & 0 \\
\hline CG17632 & 101584 bw & 0 \\
\hline CG10706 & 103985 SK & 0 \\
\hline CG6378 & 16677 SPARC & 0 \\
\hline CG6992 & 101686 GluRIIA & 0 \\
\hline CG5559 & 100957 Sytalpha & 0 \\
\hline CG13664 & $103296 \mathrm{Cad} 96 \mathrm{Cb}$ & 0 \\
\hline CG15899 & 48008 Ca-alpha1T & 0 \\
\hline CG7904 & 848 put & 0 \\
\hline CG4859 & $101505 \mathrm{Mmp} 1$ & 0 \\
\hline CG18803 & 101379 Psn & 0 \\
\hline CG4969 & 104020 Wnt6 & 0 \\
\hline CG4356 & 101407 mAChR-A & 1 \\
\hline CG3139 & 8875 Syt1 & 0 \\
\hline CG9138 & 1050 uif & 2 \\
\hline CG6407 & 101621 Wnt5 & 0 \\
\hline CG31009 & 27215 Cad99C & 0 \\
\hline
\end{tabular}




\begin{tabular}{|c|c|c|}
\hline CG7100 & 1092 CadN & 0 \\
\hline CG6445 & 36320 Cad74A & 0 \\
\hline CG31092 & 107597 LpR2 & 0 \\
\hline CG9355 & 102255 dy & 0 \\
\hline CG14744 & 108697 CG14744 & 0 \\
\hline CG7851 & 108612 Scgalpha & 0 \\
\hline CG4280 & $45883 \mathrm{crq}$ & 0 \\
\hline CG6151 & 104993 fwe & 0 \\
\hline CG5348 & 1698 CG5348 & 0 \\
\hline CG33196 & 44029 dpy & 0 \\
\hline CG18345 & $104450 \mathrm{trpl}$ & 0 \\
\hline CG5751 & $37249 \operatorname{TrpA} 1$ & 0 \\
\hline CG12348 & $104474 \mathrm{Sh}$ & 0 \\
\hline CG3478 & 108683 ppk & 0 \\
\hline CG6863 & 2656 tok & 0 \\
\hline CG9429 & 51272 Calr & 0 \\
\hline CG6127 & 108348 Ser & 0 \\
\hline CG6868 & 100930 tld & 0 \\
\hline CG6151 & 39596 fwe & 0 \\
\hline CG5348 & 101003 CG5348 & 0 \\
\hline CG5842 & 100090 & 0 \\
\hline CG9668 & 101708 Rh4 & 0 \\
\hline CG5410 & 106683 Miro & 0 \\
\hline CG4587 & 108150 CG4587 & 0 \\
\hline CG9533 & 101759 rut & 0 \\
\hline CG6588 & 101779 Fas1 & 0 \\
\hline CG10244 & 1089 Cad96Ca & 0 \\
\hline CG13206 & 9354 Or47b & 0 \\
\hline CG8967 & 42566 otk & 0 \\
\hline CG2264 & 106494 magu & 0 \\
\hline CG4356 & 33123 mAChR-A & 0 \\
\hline CG6919 & 47896 Octbeta1R & 0 \\
\hline CG4698 & 104671 Wnt4 & 0 \\
\hline CG3389 & 36164 Cad88C & 1 \\
\hline CG10706 & 28155 SK & 0 \\
\hline CG7749 & 3749 kug & 0 \\
\hline CG9280 & $15428 \mathrm{Glt}$ & 0 \\
\hline CG4698 & 38010 Wnt4 & 1 \\
\hline CG31284 & 42620 wtrw & 0 \\
\hline CG1517 & 103754 na & 0 \\
\hline CG10701 & 37917 Moe & 0 \\
\hline CG9472 & 8424 brv1 & 0 \\
\hline CG9148 & 105422 scf & 0 \\
\hline CG4889 & 13352 wg & 0 \\
\hline CG10952 & 100260 eag & 1 \\
\hline CG6407 & 32257 Wnt5 & 0 \\
\hline CG8442 & 44438 GluRIA & 0 \\
\hline CG1517 & 3306 na & 2 \\
\hline
\end{tabular}




\begin{tabular}{|c|c|c|}
\hline CG31999 & 106122 CG31999 & 0 \\
\hline CG3619 & $37288 \mathrm{DI}$ & 0 \\
\hline CG17941 & 36219 ds & 0 \\
\hline CG11101 & 101282 pwn & 0 \\
\hline CG5996 & 105280 Trpgamma & 0 \\
\hline CG1058 & 8549 rpk & 0 \\
\hline CG9262 & 103363 Shal & 0 \\
\hline CG13762 & 101019 brv3 & 0 \\
\hline CG3936 & $100002 \mathrm{~N}$ & 1 \\
\hline CG18741 & 3392 Dop1R2 & 0 \\
\hline CG7904 & 107071 put & 0 \\
\hline CG1506 & 33217 Ac3 & 0 \\
\hline CG6453 & 106254 GCS2beta & 0 \\
\hline CG9138 & 101153 uif & 0 \\
\hline CG32451 & 22975 SPoCk & 0 \\
\hline CG31136 & 33112 Syx1A & 2 \\
\hline CG5670 & 12330 Atpalpha & 2 \\
\hline CG15860 & 39478 pain & 0 \\
\hline CG14743 & 4142 CG14743 & 0 \\
\hline CG3619 & $3720 \mathrm{DI}$ & 0 \\
\hline CG4226 & 101180 GluRIIC & 0 \\
\hline CG4536 & 7126 iav & 0 \\
\hline CG17142 & 107870 рух & 0 \\
\hline CG11059 & 36348 Cals & 0 \\
\hline CG9668 & 46920 Rh4 & 0 \\
\hline CG17941 & 4312 ds & 1 \\
\hline CG13223 & 1684 CG13223 & 0 \\
\hline CG6453 & 37988 GCS2beta & 0 \\
\hline CG2328 & 9285 eve & 0 \\
\hline CG18660 & 51459 Nckx30C & 0 \\
\hline CG32179 & 1038 Krn & 0 \\
\hline CG4226 & 51438 GluRIIC & 0 \\
\hline CG10617 & 47506 Syt12 & 1 \\
\hline CG7447 & 30935 slow & 0 \\
\hline CG11020 & 105579 nompC & 0 \\
\hline CG31284 & 107423 wtrw & 1 \\
\hline cg3936 & $27229 \mathrm{~N}$ & 0 \\
\hline
\end{tabular}

